\title{
Aux prémices du Gravettien dans le Nord-Ouest européen Étude de la production des pointes lithiques à Maisières-Canal (province de Hainaut, Belgique)
}

\author{
Olivier Touzé
}

\begin{abstract}
Résumé : Entre environ 29000 et 21000 BP, l'Europe fut occupée par des communautés humaines dont les traces sont rassemblées au sein de l'entité gravettienne. L'unité de cette entité est aujourd'hui de plus en plus discutée, et l'un des points clés du débat paraît résider dans la période de formation supposée du Gravettien, c'est-à-dire celle voyant la disparition et le remplacement progressifs des traditions rapportées à l'Aurignacien vers 29000-28000 BP. Datée d'environ 28000 BP, l'occupation principale du site de Maisières-Canal (Belgique) s'inscrit dans cette période. Considéré comme éponyme de la «tradition », ou de la « culture » du Maisièrien, l'industrie lithique de ce site est reconnue de longue date pour ses particularités. Cependant, malgré les nombreuses études qui lui ont été consacrées, les schémas opératoires mis en œuvre restent encore peu documentés. Le réexamen approfondi du matériel permet de reconstituer un système technique lithique articulé autour d'un débitage laminaire original, induisant l'exploitation des plus larges surfaces disponibles sur les nucléus. Ces surfaces sont investies à l'issue d'une phase d'initialisation impliquant une progression dissymétrique depuis une face étroite. Les supports laminaires recherchés sont préférentiellement larges, d'épaisseur modérée, et de profil subrectiligne ou peu courbe, et sont extraits par percussion directe minérale à partir de deux plans de frappe opposés. Ces supports servent à la confection d'une gamme étendue d'outils retouchés, dont les pointes se révèlent être les plus singuliers. Comprenant plusieurs catégories morphologiques (pointes de Maisières, pointes pédonculées, pointes à cran), ces outils sont préparés selon une méthode de façonnage procédant par enlèvements rasants directs détachés au percuteur organique. Ces différents éléments viennent étayer la place très particulière occupée par Maisières-Canal dans le paysage des premières industries gravettiennes.
\end{abstract}

Mots-clés : Gravettien ancien, Maisièrien, Belgique, pointes de Maisières, pointes pédonculées, débitage laminaire.

Abstract: Between around 29.000 and 21.000 BP, Europe was occupied by human societies whose archaeological traces are gathered within the Gravettian entity. However, several authors are now openly questioning the unity of the Gravettian, and one of the key aspects of these debates is the supposed formation period of the Gravettian, that is to say the period covering the disappearance and replacement of the traditions related to the Aurignacian around 29.00028.000 BP. Dated to around 28.000 BP (De Heinzelin, 1973a, p. 45; Haesaerts and Damblon, 2004; Jacobi et al., 2010), the main occupation of Maisières-Canal (Belgium) is clearly relevant to the period. For a long time, the site's lithic industry has been recognized for its peculiarities, most notably numerous points with flat retouch and tanged tools. The industry was therefore the key factor in the definition of the Maisierian, which is sometimes seen as a "tradition" (Campbell, 1980) or a "culture" (Dewez, 1989) that has no link with the Gravettian itself. On the other hand, some have postulated that the Maisierian simply represents a northern variation of Early Gravettian industries, possibly as the origin of the industries with Font-Robert points from South-West France (former Perigordian Va; De Heinzelin, 1973a, p. 54; Otte, 1976 and 1979b, p. 632; Desbrosse and Kozłowski, 1988, p. 47). The difficulties in the classification of Maisières-Canal illustrate its importance for understanding the period covering the development of the Gravettian. However, although previous research on Maisières-Canal's lithic industry has focused on typological, technological and functional aspects, as well as raw materials provisioning, little has been done to characterize the lithic technical system and the chaines opératoires followed to produce lithic tools.

Maisières-Canal was discovered in 1966 during enlargement work of the "canal du Centre" near the village of Maisières and the city of Mons, and was excavated between 1966 and 1967. Two distinct areas were identified. The most important in terms of the quantity of remains is known as the "Champ de fouille", while the other is much more limited and was interpreted as a knapping area. This article presents study of the lithic material coming from the Champ de fouille, with specific focus on both the production of points and the laminar reduction sequence.

The industry includes 945 retouched tools, mostly made on large blades. Retouched tools on bladelets are extremely rare. The retouched assemblage is dominated by several types of burins and points. The point category comprises 
several morphological groups. Among these, Maisières points and tanged points are the most important, but a limited number of shouldered points are also present, as well as several distal fragments that cannot be associated with any of these groups. Despite their morphological differences, these point type display a similar shaping method, using direct flat retouch prepared with an organic hammer. A specific succession of actions is identified that ultimately allows detachment of removals overshooting ridges of the blank's dorsal face. These so-called "ridge-overshot" removals offer the possibility to reduce the blank's thickness. This characteristic of the shaping method can potentially lead to a complete modification of both the morphological and volumetric properties of the blank. However, the extent to which the method was applied was determined by characteristics of the chosen blank and their proximity to the functional parameters of the desired tool. Consequently, only some points display a completely invasive flat retouch, while most are retouched in a more limited way. This observation illustrates the flexibility of the method which allows various degrees of investment for the knapper, ranging from a very limited correction of the blank's initial properties to its complete shaping.

Blade production is made on several flint types all coming from the Mons region (Miller, 2001; Moreau et al., 2013; Moreau et al., 2016). The maximum distance between the site and exploited flint sources is therefore around $10 \mathrm{~km}$. Blades are generally produced on regular blocks that have both narrow and wide surfaces. Initialization of the reduction sequence is made on one of the narrow sides after a limited configuration of the volume that usually includes preparation of a two- or one-sided crest. The reduction sequence then becomes dissymmetrical (Valentin et al., 2014) as it progresses gradually toward one of the adjacent wide sides of the core. The bipolar exploitation of this wide débitage surface leads to production of straight, large and moderately thick blades. Maintenance of the convexities needed is made with the detachment of blades at the limit between the débitage surface and its flanks, as well as by the alternate use of both striking platforms. Percussion techniques include soft and hard stone, which clearly demonstrate a change of hammers between the laminar production and the transformation of blades into points.

Outside the few, and often isolated discoveries of Maisierian elements across North-Western Europe, these two components of the lithic technical system appear unique with regards to the Early Gravettian. No similarity is evident with industries uncovered at other sub-contemporaneous sites in France (Digan, 2008; Pesesse, 2008a; Floss and Taller, 2011), Belgium (Touzé, Flas et al., 2016) and Central Europe (Moreau, 2010 and 2012b). The characterization of blade and point productions at Maisières-Canal thus questions the history of lithic technical systems between the end of the Aurignacian and the (presumably) full development of the Gravettian. It seems that this history is complex and followed different trajectories across Europe.

Keywords: Early Gravettian, Maisierian, Belgium, Maisières points, tanged points, laminar production.

$\mathrm{L}$ A PÉRIODE couvrant le passage de l'Aurignacien au Gravettien - autour de 29000 - $28000 \mathrm{BP}$ - constitue un sujet très investi ces dernières années. La révision de plusieurs séries de référence du Gravettien ancien en France a permis de reconnaître l'apparition de systèmes techniques lithiques singuliers durant cette période. Ces observations atténuent ainsi l'impression de rupture qui pouvait se dégager d'une perception globalisante de l'Aurignacien et du Gravettien, et permettent d'envisager par suite la possibilité d'un transfert technique du premier vers le second (Pesesse, 2008a, 2008b et 2010). Un changement culturel continu est par ailleurs proposé (Moreau, 2011) à partir des données lithiques de l'Aurignacien récent et du Gravettien ancien d'Europe centrale (Moreau, 2010, 2011, 2012a et 2012b). L'industrie sur matières dures animales suggère également certains rapprochements entre les deux entités (Goutas et Tejero, 2016), de même que l'art pariétal qui, de l'Aurignacien au Gravettien, voit la perduration de codes stylistiques et de thèmes iconographiques particuliers qui se raréfient ou disparaissent avec le Magdalénien (Petrognani, 2013). Le renouvellement pluridisciplinaire des données ouvre ainsi la voie à une révision plus anthropologique de l'apparition des traditions rapportées au Gravettien, ainsi que des principaux modèles avancés quant au développement de ce dernier (Kozłowski, 2015). Une telle démarche paraît devoir constituer aujourd'hui le socle nécessaire de toute tentative de modélisation à grande échelle.
Contrairement à d'autres territoires, le Nord-Ouest européen est longtemps resté en marge des débats sur l'apparition du Gravettien par manque de données - situation qui devrait néanmoins évoluer grâce aux recherches en cours sur plusieurs gisements récemment découverts (Bodu et al., 2011 ; Goval et Hérisson, 2012 ; Paris et al., 2013 ; Antoine et al., 2014 ; Lacarrière et al., 2015 ; Paris et al., sous presse). Parmi les rares sites connus de longue date et attribuables aux débuts du Gravettien, celui de Maisières-Canal en Belgique réuni néanmoins toutes les conditions requises pour un examen détaillé des comportements techno-culturels. Sur ce point, l'industrie lithique représente évidemment une source d'information privilégiée, même si ceci ne doit aucunement éclipser les autres sphères techniques (industrie sur matières dures animales), ou celles renvoyant vers d'autres registres (activités de subsistance, comportements à connotation symbolique), dont des témoins ont été également retrouvés sur le site (De Heinzelin, 1973a et 1973b ; Gautier et al., 1973).

De nombreux travaux ont été consacrés à l'industrie lithique de Maisières-Canal. Ceux-ci se sont tout d'abord attachés à caractériser typologiquement l'outillage retouché (De Heinzelin, 1973a ; Otte, 1976, 1979a et 1979b), avant d'explorer par la suite l'ensemble de la chaîne opératoire, depuis l'acquisition des matières premières (Miller, 2001 ; Moreau et al., 2013 ; Moreau et al., 2016) jusqu'à la sphère techno-fonctionnelle (Otte 


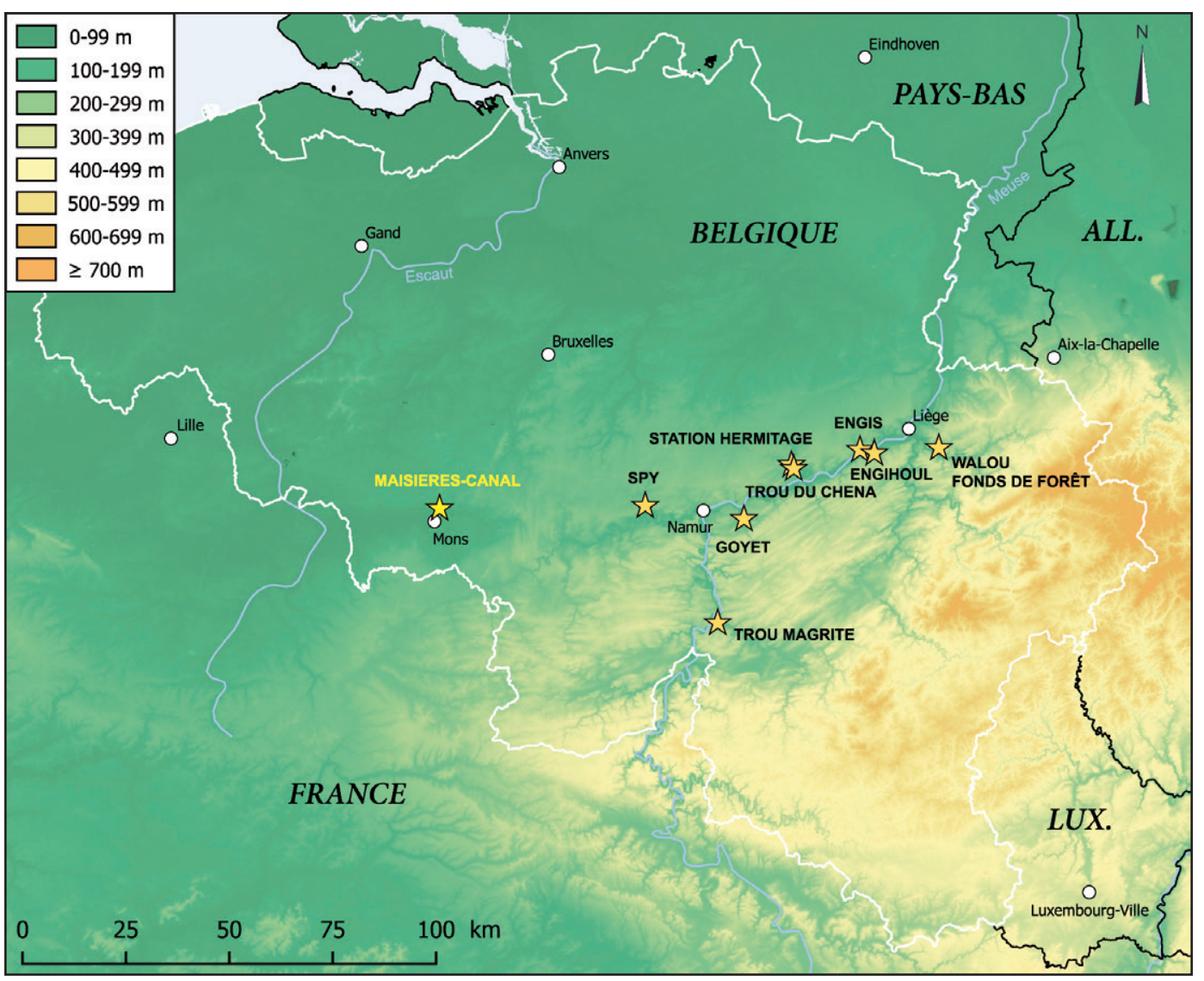

Fig. 1 - Localisation de Maisières-Canal et des sites gravettiens de Belgique.

Fig. 1 - Location of Maisières-Canal and Gravettian sites in Belgium.

et Caspar, 1987 ; Le Mené, 1999 ; Rots, 2002a et 2002b ; Milks, 2010 ; Pesesse et Flas, 2012 ; Milks et al., 2016). En dépit de la diversité des données ainsi collectées, la reconstitution du système de production lithique, et des différents schémas opératoires afférents, est restée délaissée. De fait, cet aspect n'a que très récemment suscité un intérêt (Pesesse et Flas, 2012). L'industrie lithique de Maisières-Canal est pourtant réputée pour son caractère singulier au regard des premiers ensembles gravettiens, en raison notamment de la présence de nombreuses pointes à retouches rasantes et d'outils pédonculés, mais aussi du fait de la rareté des pièces à dos. Cette singularité a d'ailleurs conduit à la création du « Maisièrien » (Campbell, 1980 et 1986) interprété par certains auteurs comme une " tradition » (Campbell, 1980), ou une « culture » (Dewez, 1989) distincte du Gravettien proprement dit. Pour d'autres, à l'inverse, le Maisièrien ne représente qu'une simple variation septentrionale du Gravettien ancien liée aux industries à pointes de la FontRobert du Sud-Ouest français (ex-Périgordien Va), dont le Maisièrien pourrait représenter un stade plus ancien (De Heinzelin, 1973a, p. 54 ; Otte, 1976 et 1979b, p. 632 ; Desbrosse et Kozłowski, 1988, p. 47). La question de l'origine du Maisièrien a été tout aussi discutée, mais celle-ci se trouve actuellement dans une impasse. Si une filiation avec le Lincombien-Ranisien-Jerzmanowicien (LRJ) fut un temps postulée (Kozłowski et Kozłowski, 1981 ; Otte, 1990 ; Flas, 2000-2001 et 2008, p. 134), cette piste est désormais abandonnée (Jacobi, 2007 ; Pesesse et Flas, 2012). L'Aurignacien récent, mal connu dans le Nord-Ouest de l'Europe jusqu'il y a peu (Dinnis, 2009 et 2013 ; Flas, 2015), notamment en raison de l'absence de site important et bien contextualisé (voir cependant : Dewez et al., 1993 ; Miller, Haesaerts et al., 2004 ; Draily, 2011 ; Dinnis et Flas, 2016), n'a jamais paru constituer quant à lui un bon candidat. Difficile à classer, MaisièresCanal représente donc un enjeu important pour la compréhension des premières phases du Gravettien. Dans ce cadre, et face au peu de données technologiques disponibles, cette contribution entend apporter de nouveaux éléments susceptibles d'alimenter les discussions, et qui concernent deux des principales composantes de l'industrie lithique : la confection des pointes, et, en amont de celle-ci, le débitage laminaire.

\section{PRÉSENTATION DU SITE}

\section{Localisation}

Le gisement archéologique de Maisières-Canal est situé dans la Province de Hainaut, à trois kilomètres environ au nord-est de la ville de Mons, et à proximité des villages de Maisières, Nimy et Obourg (fig. 1). Situé sur le tracé du Canal du Centre, le site est installé dans la plaine alluviale de la rivière Haine qui s'écoule d'est en ouest vers l'Escaut en suivant une dépression synclinale. 


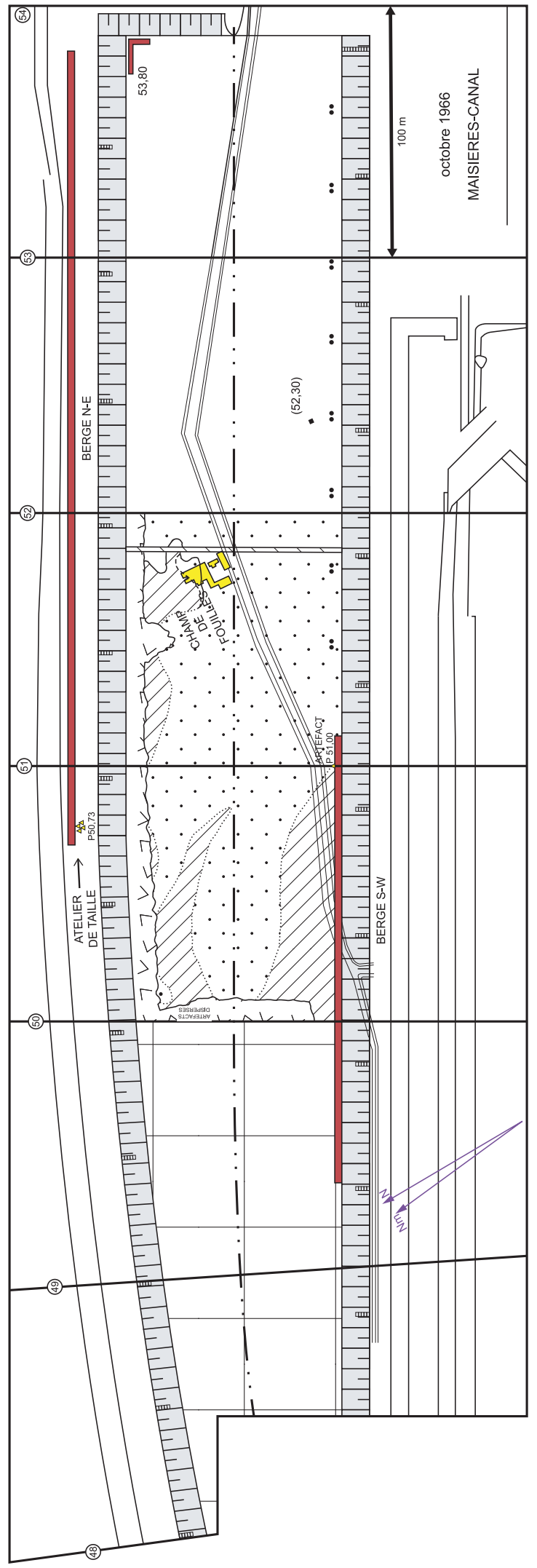

Le site est implanté sur la rive droite de la rivière, et est exposé au sud. À l'emplacement du gisement, la plaine alluviale est située à une altitude de 34 mètres. Un versant très incliné raccorde au nord la plaine alluviale au plateau hennuyer qui se situe à deux kilomètres du site à une altitude d'environ 90 mètres. Le principal locus du gisement - le «Champ de fouille »-se trouve

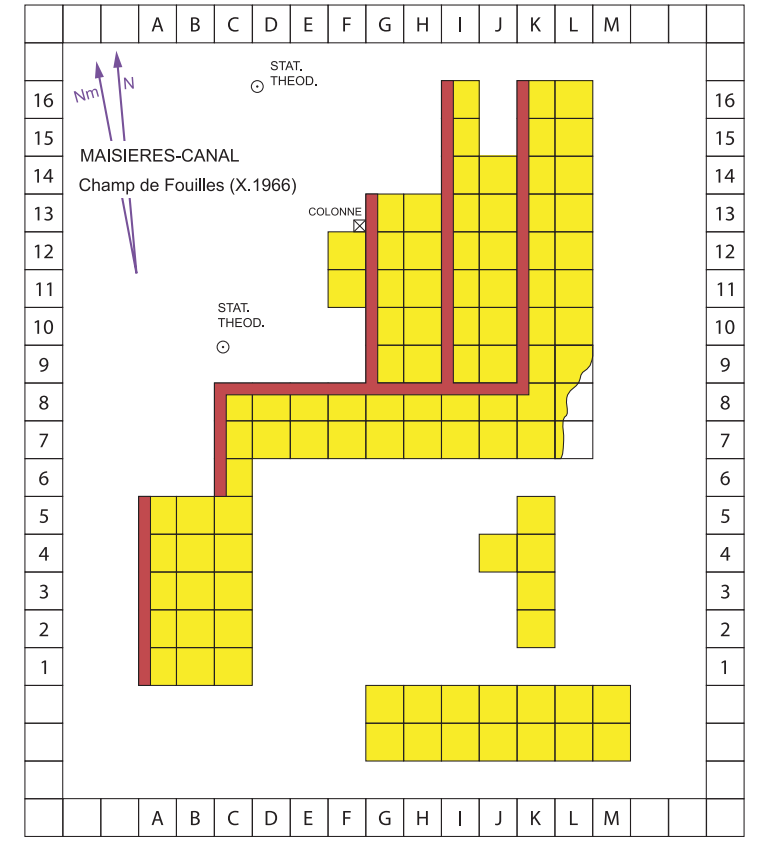

\begin{tabular}{|l|}
$\square$ Occupations gravettiennes \\
$\square$ Emplacement des levés stratigraphiques \\
$\square$ Parois du canal \\
$\square$ Surface bétonnée \\
$\square$ Sable \\
$\square$ Limons \\
$\square$ Remblais
\end{tabular}

Fig. 2 - Plans de Maisières-Canal (d'après Haesaerts et de Heinzelin, 1979, modifié. DAO : O. Touzé).

Fig. 2 - Site plans for Maisières-Canal (after Haesaerts and de Heinzelin, 1979, modified. CAD: O. Touzé).

dans le fond des terrassements du canal, à une altitude de 29 mètres, soit plusieurs mètres sous le niveau actuel de la plaine alluviale (fig. 2). Le site s'étend également plus haut sur la berge nord-est du canal, où un second locus dénommé « Atelier de taille de la Berge Nord-Est 》 fut identifié vers 34 mètres d'altitude (Haesaerts et De Heinzelin, 1979, p. 7). 


\section{Historique des fouilles}

Le site est découvert en 1966 par G. Bois d'Enghien lors de travaux d'élargissement du Canal du Centre (Haesaerts et De Heinzelin, 1979, p. 7). Lors de ses prospections, l'inventeur du gisement entreprend la réalisation de plusieurs sondages qui lui permettent de collecter un grand nombre de vestiges lithiques et osseux rapidement attribués au Périgordien supérieur du fait de la présence de « pointes de la Font-Robert » (Hubert, 1968). Le canal devant être remis sous eau, une fouille de sauvetage est menée la même année par l'Institut royal des Sciences naturelles de Belgique (IRSNB), sous la direction de F. Twiesselmann, avec la participation de la Société de Recherche préhistorique en Hainaut (Hubert, 1968 ; De Heinzelin, 1973a, p. 3). La zone dite du Champ de fouille est fouillée en 1966, confirmant l'existence d'une occupation gravettienne. Au cours de cette opération, une autre concentration de vestiges liée à la même occupation est identifiée par J. De Heinzelin dans le locus baptisé Atelier de taille de la Berge Nord-Est, ce qui entraîne deux nouvelles opérations dirigées par P. Haesaerts en 1966 et 1967. Les dernières opérations de terrain s'échelonnent entre septembre 1967 et novembre 1968 , et permettent le relevé de la coupe de la Berge Nord-Est et le prélèvement de colonnes palynologiques (Haesaerts et De Heinzelin, 1979, p. 7).

Entre 2000 et 2002, une nouvelle fouille est entreprise sous la direction de R. Miller par le service de Préhistoire de l'université de Liège, en collaboration avec l'IRSNB. La remise sous eau du canal interdisant l'accès au locus du Champ de fouille, l'opération entend déterminer l'extension de l'Atelier de taille de la Berge Nord-Est. Un petit ensemble d'environ 150 vestiges lithiques gravettiens est collecté (Miller, Guillaume et al., 2004), et un atelier de débitage aurignacien inédit est identifié et fouillé à une dizaine de mètres de l'atelier gravettien (Miller, Haesaerts et al., 2004).

\section{Stratigraphie}

Les coupes relevées à Maisières-Canal dans les années 1960 par J. De Heinzelin et P. Haesaerts, ont permis d'établir l'une des séquences de référence pour la fin du Pléistocène en Belgique (Haesaerts et al., 2016). La succession des dépôts lithologiques s'avère très complexe avec plus de 90 unités stratigraphiques distinguées (Haesaerts et De Heinzelin, 1979).

$\mathrm{Au}$ Champ de fouille, l'occupation gravettienne est contenue dans l'unité stratigraphique M.H. située dans la partie inférieure d'un dépôt colluvial humifère correspondant à une phase modérément froide signalant un léger réchauffement par rapport au dépôt précédent (M.F.). Les autres unités (M.G., M.I. et M.J.) composant le dépôt auquel appartient M.H. ont également livré du matériel gravettien, probablement légèrement remanié. Des vestiges ont été enfin découverts en quantités très variables dans les trois unités postérieures au colluvionnement (M.M., M.N. et M.O.). Celles-ci sont cependant toutes liées à des processus susceptibles d'avoir remanié du matériel archéologique issu de M.H., aussi l'hypothèse de vestiges en position secondaire a-t-elle été retenue par les fouilleurs en raison des fortes similitudes rapprochant le matériel découvert dans ces unités, celui mis au jour en M.H. et dans le dépôt colluvial, et celui dont la position stratigraphique est incertaine ou inconnue, en ce compris les artefacts récoltés par G. Bois d'Enghien. Le matériel gravettien découvert au Champ de fouille proviendrait ainsi d'un seul et même niveau d'occupation (De Heinzelin, 1973a ; Haesaerts et De Heinzelin, 1979).

Sur la berge nord-est, le niveau gravettien est contenu dans le tiers inférieur de l'unité N.D.C. Cette unité est interprétée comme le témoin d'un climat froid et humide, mais marquant cependant un léger réchauffement par rapport au pergélisol de l'unité N.D.B. sous-jacente. Les vestiges reposaient à plat dans l'unité N.D.C., et ne semblent pas avoir subi de déplacements verticaux puisque ni les unités inférieures, ni les unités supérieures n'ont livré de documents gravettiens. Si l'absence de connexion physique articulant le locus gravettien de la berge à celui identifié en contrebas dans le Champ de fouille empêche l'observation de la continuité des dépôts, la contemporanéité des documents archéologiques issus de ces locus est néanmoins postulée en raison de leur position dans des couches comparables au plan sédimentaire, et s'inscrivant dans des séquences paléoclimatiques semblables, mais aussi du fait des similitudes rapprochant les vestiges lithiques (Haesaerts et De Heinzelin, 1979).

Aucune trace du niveau gravettien n'a été détectée dans la coupe de la berge sud-ouest, suggérant par-là que l'occupation ne devait pas s'étendre dans la plaine alluviale très au-delà de la zone du Champ de fouille. Seuls de rares artefacts isolés ont été retrouvés en position secondaire dans les unités S.Q.A. et S.S.B.

\section{Datations}

L'occupation gravettienne de Maisières-Canal a été datée à plusieurs reprises à partir d'échantillons collectés au Champ de fouille. Sur les treize dates disponibles aujourd'hui (De Heinzelin, 1973a, p. 45 ; Haesaerts et Damblon, 2004 ; Jacobi et al., 2010), dix ont été obtenues récemment par AMS et ultrafiltration à partir d'échantillons d'os et d'ivoire (Jacobi et al., 2010). Ces résultats permettent d'envisager une succession d'évènements.

L'occupation anthropique tout d'abord, peut être appréhendée à partir de six dates parmi lesquelles celle de $27950 \pm 170 \mathrm{BP}(\mathrm{OxA}-18007)$ est considérée comme étant la plus fiable, car l'association de l'os de renne à partir duquel elle a été réalisée avec le niveau d'occupation ne fait aucun doute. Ce résultat $s$ 'avère très proche de la date de $27965 \pm 260 \mathrm{BP}(\mathrm{GrN}-5523)$ obtenue sur humates en 1967 immédiatement sous l'unité M.H. renfermant les vestiges gravettiens (De Heinzelin, 1973a, p. 45). Il coïncide assez bien également avec la date de $27780 \pm$ 160 BP (OxA-18012) obtenue à partir d'un os de lièvre 


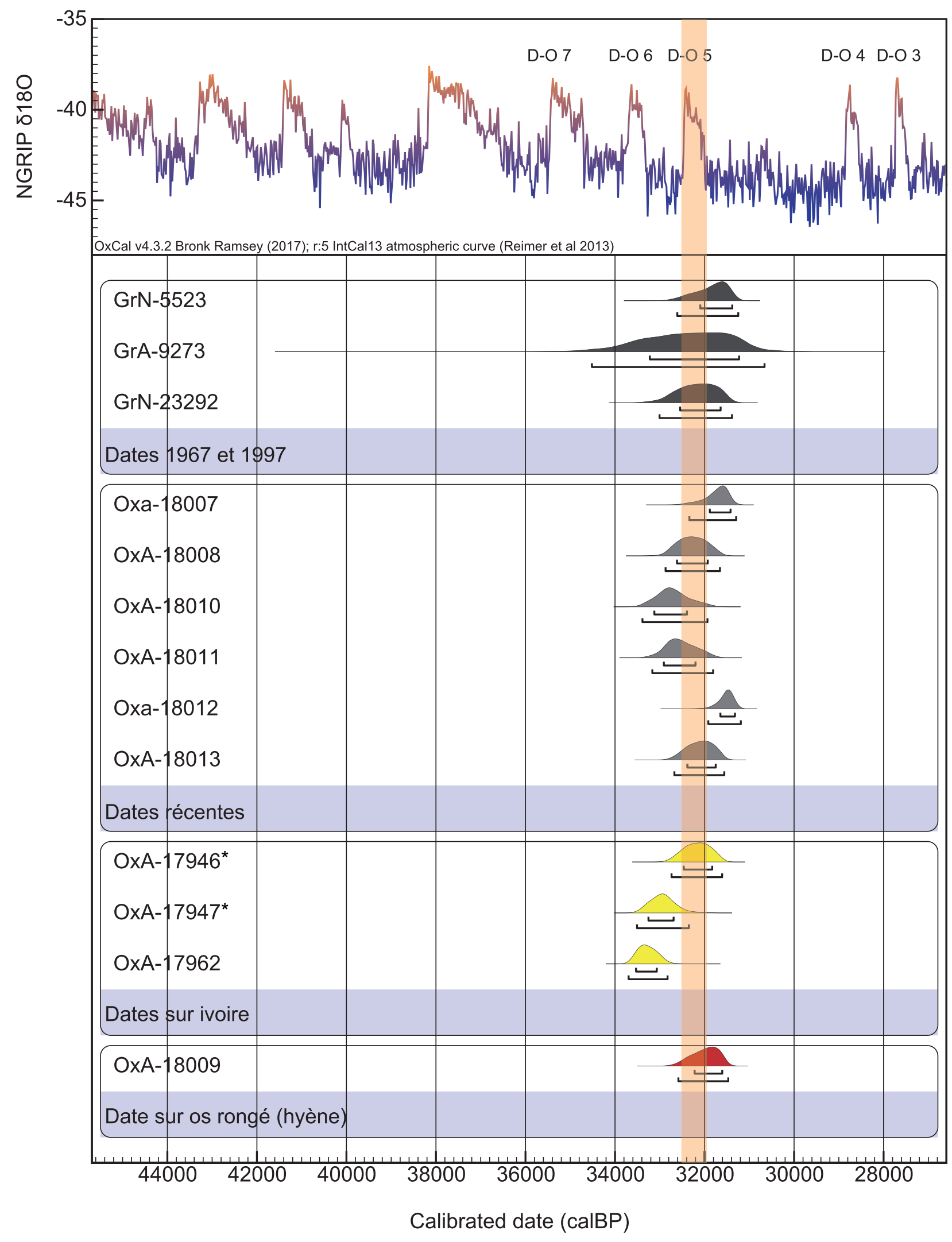

Fig. 3 - Modélisation bayésienne des datations 14C (OxCal).

Fig. 3 - Bayesian modeling of the $14 \mathrm{C}$ dates (OxCal).

raclé. La calibration de ces différents résultats suggère que l'occupation de Maisières-Canal serait intervenue vers $31600 \mathrm{cal}$. BP, soit légèrement après l'évènement de Dansgaard-Oeschger 5 (fig. 3), ce qui semble à peu près en accord avec l'enregistrement stratigraphique qui indique une phase de légère amélioration climatique.

Les trois dates réalisées sur ivoire renvoient quant à elles vers un évènement significativement plus ancien 
que l'occupation du site par l'Homme. Deux d'entre elles proviennent d'échantillons prélevés sur une même défense de mammouth, tandis que la troisième a été réalisée à partir d'un artefact en ivoire. En écartant la plus jeune des deux dates obtenues sur la défense, les dates réalisées sur ivoire avoisinent 33200 cal. BP, et permettent ainsi d'envisager le dépôt naturel de restes de mammouth sur le site avant son occupation au Gravettien (Jacobi et al., 2010).

Enfin, une dernière date produite à partir d'un carpien de mammouth rongé suggère le passage d'une hyène sur le site. D'après le résultat obtenu, cet évènement serait nettement plus proche dans le temps de l'occupation gravettienne que du dépôt antérieur des restes de mammouth.

\section{Matériel étudié}

Le niveau gravettien de Maisières-Canal a livré un matériel lithique très important composé de plusieurs dizaines de milliers de pièces (tabl. 1). Ce matériel est aujourd'hui réparti entre plusieurs institutions. Dans leur très grande majorité, les vestiges lithiques sont conservés à l'Institut royal des Sciences naturelles de Belgique. Ceux-ci sont à la fois issus des prospections de G. Bois d'Enghien, et des fouilles conduites par ce même institut dans les années 1960. Le matériel réuni lors des fouilles de l'IRSNB a fait l'objet de prêts limités, et certaines pièces sont ainsi actuellement en possession d'autres institutions muséales de Belgique. Quelques pièces lithiques sont ainsi prêtées au Préhistomuseum de Ramioul, ce à quoi il faut ajouter un lot de vingt-trois autres artefacts prêté à l'ancien musée du Centenaire de Mons. Enfin, une petite partie de la collection Bois d'Enghien, représentant 84 pièces lithiques et quelques pièces osseuses, est conservée au British Museum.

Pour les besoins de l'étude, nous nous sommes concentrés sur le matériel issu du Champ de fouille. Ce matériel s'avère sans commune mesure avec celui issu de l'Atelier de taille de la Berge Nord-Est $(\mathrm{n}=637$, dont seulement sept outils et trois nucléus), que ce soit du point de vue quantitatif $(n=34626)$ ou qualitatif (représentation de tous les stades des chaînes opératoires, plusieurs centaines d'outils et de nucléus ; De Heinzelin, 1973a). Nous avons pris en compte aussi bien la collection émanant des fouilles IRSNB, que celle résultant des prospections de G. Bois d'Enghien. Outre les séries principales conservées à l'IRSNB, les pièces conservées au British Museum et au Préhistomuseum de Ramioul (qui proviennent également du Champ de fouille), ont été incluses dans l'étude.

L'analyse du matériel lithique a été entreprise à partir d'un échantillon réunissant 91 nucléus (soit un tiers de la catégorie), 913 lames et lamelles brutes, (soit un cinquième des produits lamino-lamellaires bruts), et l'ensemble des outils retouchés. S'agissant des lames et lamelles non retouchées, nous avons privilégié les produits entiers ainsi que les fragments suffisamment allongés pour pouvoir être considérés comme

\begin{tabular}{|l|c|c|c|}
\cline { 2 - 4 } \multicolumn{1}{c|}{} & $\begin{array}{c}\text { Collections } \\
\text { Bois d'Enghien }\end{array}$ & $\begin{array}{c}\text { Collections } \\
\text { IRSNB }\end{array}$ & Total \\
\hline Outils retouchés & 791 & 883 & 1674 \\
\hline Lames & 280 & 3701 & 3981 \\
\hline Lamelles & 18 & 563 & 581 \\
\hline Eclats & 435 & 13851 & 14286 \\
\hline Nucléus & 121 & 298 & 419 \\
\hline Chutes de burin & 72 & 397 & 469 \\
\hline Esquilles et débris & 346 & 10941 & 11287 \\
\hline Non classé & 115 & 1814 & 1929 \\
\hline Total & 2178 & 32448 & 34626 \\
\hline
\end{tabular}

Tabl. 1 - Décompte du matériel lithique du Champ de fouille par collection (d'après de Heinzelin, 1973, modifié).

Table 1 - Total counts for lithic material from Champ de fouille by collection (after de Heinzelin, 1973, modified).

relativement représentatifs des produits complets. Nous nous sommes par ailleurs efforcés de tenir compte de toutes les dimensions, morphologies et statuts techniques possibles des lames. Selon la même logique, nous avons retenus les nucléus les plus lisibles, en excluant ceux n'offrant qu'une image très partielle des dernières actions réalisées, que ce soit en raison de l'état fragmentaire des pièces, ou du fait de l'effacement de ces actions suite à un outrepassement.

\section{Matières premières}

Plusieurs types de silex ont été exploités à MaisièresCanal. La présence du silex campanien noir de la Craie d'Obourg affleurant à moins de deux kilomètres, et celle, plus discrète, du silex gris campanien supérieur de la Craie de Spiennes, disponible sept kilomètres au sud et célèbre pour son exploitation minière au Néolithique, ont été très vite soulignées (De Heinzelin, 1973a, p. 42-43; Otte, 1979a). Récemment, le recours à des méthodes d'analyses physico-chimiques a permis l'identification d'un troisième type de silex : le silex de Nouvelles, présent dans un étage intermédiaire entre les craies d'Obourg et de Spiennes, et accessible au sud du bassin de Mons à l'instar du silex de Spiennes (Moreau et al., 2016). L'exploitation de ces différents silex permet de définir un territoire d'approvisionnement pouvant s'étendre jusqu'à 10 kilomètres autour du site, ce qui conduit à envisager une stratégie d'approvisionnement régionale concentrée exclusivement sur le bassin de Mons.

Si une présence marginale de matériaux exogènes a été cependant envisagée à quelques reprises, leurs provenances n'ont pas pu être déterminées (De Heinzelin, 1973a, p. 43 ; Miller, 2001, p. 63-64), à l'exception de rares pièces en phtanite qui furent associées à la région d'Ottignies et Céroux-Mousty dans le Brabant wallon, $50 \mathrm{~km}$ au nord-est du gisement (Miller, 2001, p. 64). Toutefois, un diagnostic récent tend à contredire cette attribution (Moreau et al., 2013), et la présence de phtanite parmi les éléments composant certaines unités 


\begin{tabular}{|l|c|c|}
\hline \multicolumn{1}{|c|}{ Types } & Nombre & $\%$ \\
\hline Pointes de Maisières & 121 & 12,8 \\
\hline Pointes pédonculées & 56 & 5,9 \\
\hline Pointes à cran & 8 & 0,8 \\
\hline $\begin{array}{l}\text { Fragments distaux } \\
\text { de pointes à retouches rasantes }\end{array}$ & 20 & 2,1 \\
\hline Lames appointées & 9 & 1 \\
\hline Total pointes & 214 & 22,6 \\
\hline Grattoirs & 44 & 4,7 \\
\hline Racloirs & 5 & 0,5 \\
\hline Burins dièdres & 196 & 20,7 \\
\hline Burins sur troncature & 73 & 7,7 \\
\hline Burins sur cassure & 57 & 6,0 \\
\hline Burins sur pan naturel & 3 & 0,3 \\
\hline Burins mixtes & 46 & 4,9 \\
\hline Burins indéterminés & 7 & 0,7 \\
\hline Perçoirs & 15 & 1,6 \\
\hline Encoches & 4 & 0,4 \\
\hline Denticulés & 2 & 0,2 \\
\hline Lames tronquées & 8 & 0,8 \\
\hline Lames à un bord retouché & 82 & 8,7 \\
\hline Lames à deux bords retouchés & 33 & 3,5 \\
\hline Eclats retouchés & 42 & 4,4 \\
\hline Outils multiples & 11 & 1,2 \\
\hline Fragments d'outils indéterminables & 8 & 0,8 \\
\hline Pièces à dos & 83 & 0,3 \\
\hline Autres pièces pédonculées & 9 & 1 \\
\hline Autres pièces à cran & 945 & 77,4 \\
\hline Total autres outils & & 100 \\
\hline Total & 21 \\
\hline
\end{tabular}

Tabl. 2 - Décompte de l'outillage retouché.

Table 2 - Count of retouched tools.

stratigraphiques du Champ de fouille sous- (M.C.), et sus-jacentes (M.N.) au niveau gravettien ne permet pas d'exclure que ce matériau ait été lui aussi collecté au sein du bassin de Mons.

\section{L'outillage lithique retouché et les supports recherchés}

L'outillage retouché gravettien de Maisières-Canal comprend 945 pièces (tabl. 2). Ce résultat correspond au décompte des seuls supports dont la transformation par retouche nous a paru intentionnelle. Les pièces présentant des esquillements possiblement d'ordre fonctionnel ou taphonomique ne sont donc pas reprises dans ce décompte. Ce dernier s'inscrit cependant dans le même ordre de grandeur que les décomptes proposés précédemment par M. Otte (1979a, p. 69), et par D. Pesesse et D. Flas (2012). Les outils retouchés sont principalement composés de deux grandes catégories typologiques : les burins (40,4\%) et les pointes $(22,6 \%)$. La catégorie des burins, bien que

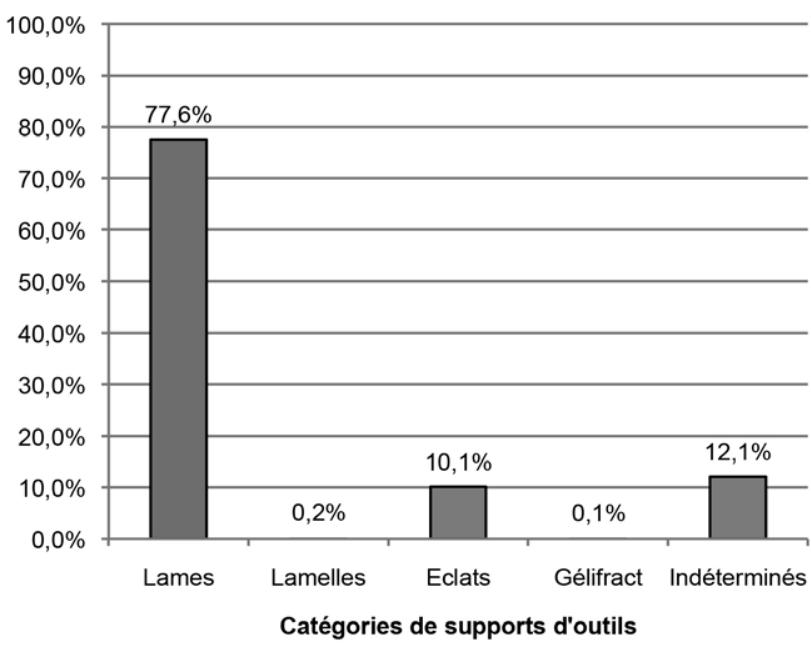

Fig. 4 - Distribution des supports d'outils retouchés.

Fig. 4 - Distribution of the categories of blanks transformed into retouched tools.

diversifiée, est nettement dominée par les burins dièdres dont les exemplaires simples et doubles représentent plus de $20 \%$ de l'ensemble des outils retouchés.

L'outillage retouché indique par ailleurs que l'obtention de produits laminaires constitue l'objectif principal du débitage $(\mathrm{n}=733$ soit $77,6 \%$ des supports d'outils ; fig. 4). L'examen des lames entières suggère la recherche de produits rectilignes ou faiblement courbes. Les lames complètes les plus longues peuvent avoisiner $15 \mathrm{~cm}$, mais une telle dimension demeure exceptionnelle. La largeur des lames est pour l'essentiel comprise entre 16 et $30 \mathrm{~mm}$, cette fourchette réunissant un total de 895 lames brutes et outils sur lames (fig. 5). Les outils sur lames s'avèrent cependant mieux représentés dans les classes de largeurs supérieures à $25 \mathrm{~mm}(\mathrm{n}=455$, soit $62,1 \%$ des outils laminaires). L'épaisseur des produits laminaires est comprise essentiellement entre 4 et $12 \mathrm{~mm}$ (fig. 6), mais la plupart des outils retouchés présentent une épaisseur plutôt élevée, supérieure ou égale à $10 \mathrm{~mm}$ ( $\mathrm{n}=398$, soit $54,3 \%$ des outils laminaires). Les observations qui précèdent indiquent ainsi que les produits les plus larges, et d'une relative épaisseur, ont été manifestement privilégiés pour la préparation de l'outillage retouché.

Des éclats ont également été sélectionnés pour la fabrication d'outils (environ $10 \%$ ), mais l'obtention de ces supports apparaît essentiellement dépendante de la production laminaire dont ils sont des sous-produits. L'extrême sous-représentation des outils retouchés sur lamelles constitue, quant à elle, un trait remarquable de l'industrie de Maisières-Canal. Hautement singulier en contexte Paléolithique supérieur ancien (voir par exemple Le Brun-Ricalens, 2005 ; Rigaud, 2007-2008 ; Goutas et al., 2011 ; Bodu et al., 2013 ; Roussel et al., 2016), cet aspect ne résulte pas d'un biais lié aux méthodes de fouilles. Les fouilles conduites par l'IRSNB ont en effet permis la récolte d'une portion significative de la fraction fine du matériel comprenant une dizaine de milliers de pièces inférieures à deux centimètres, ainsi que des centaines de lamelles et de chutes de burin (De Heinzelin, 1973a). 


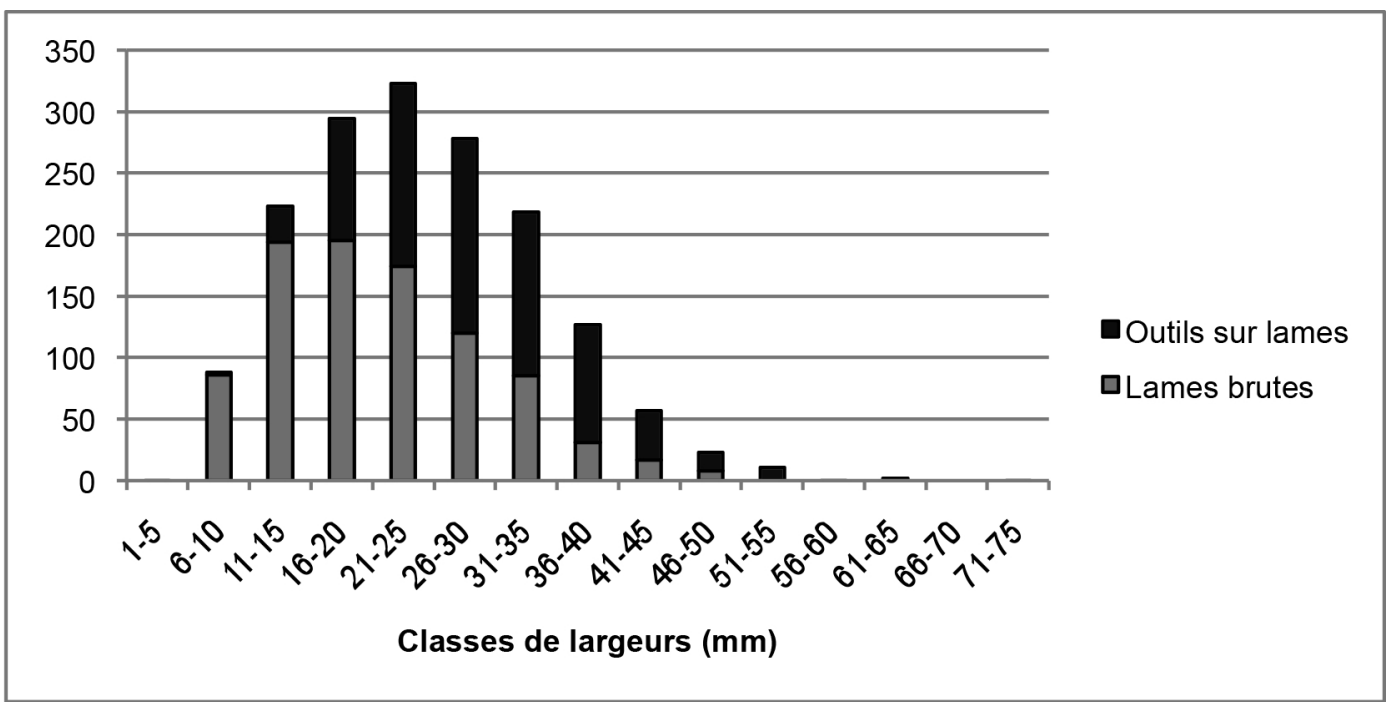

Fig. 5 - Distribution des largeurs des lames brutes et des outils retouchés sur lames.

Fig. 5 - Distribution of the widths of blades and retouched tools made on blades.

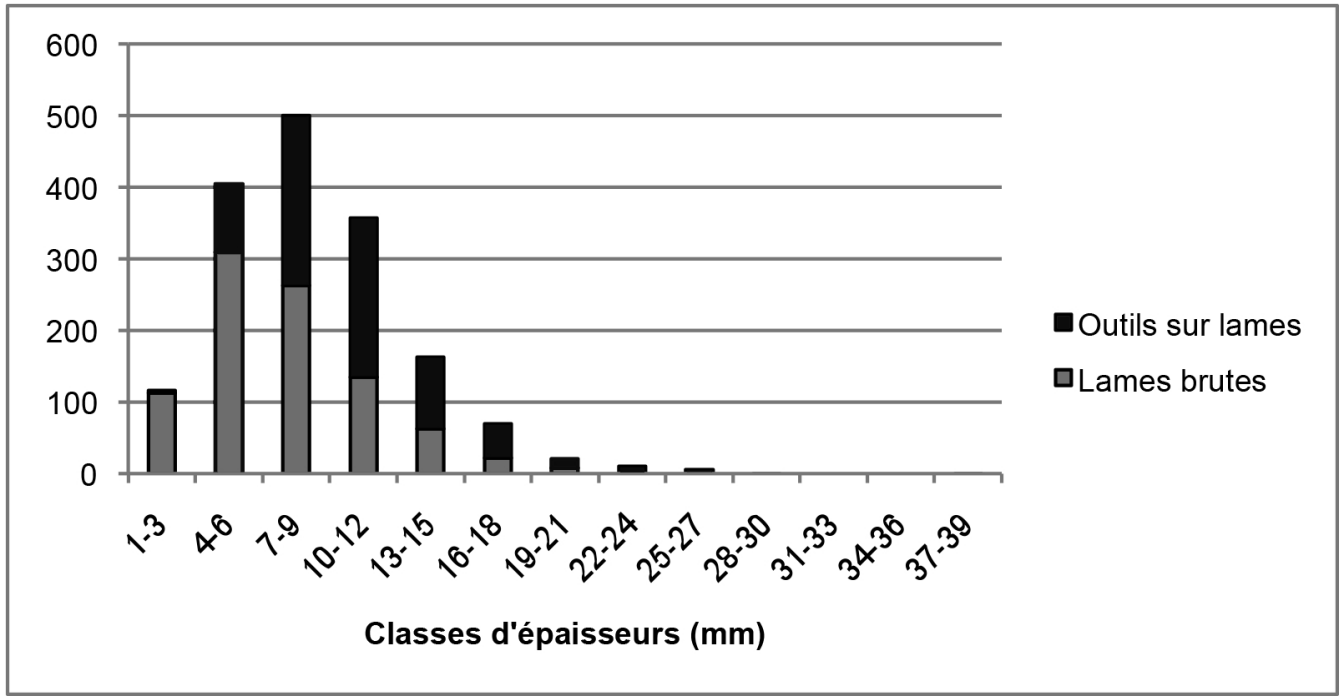

Fig. 6 - Distribution des épaisseurs des lames brutes et des outils retouchés sur lames.

Fig. 6 - Distribution of the thicknesses of blades and retouched tools made on blades.

\section{LES POINTES}

\section{Les différents groupes morphologiques de pointes}

La catégorie générique des pointes peut être subdivisée en différents groupes morphologiques. On peut ainsi distinguer un groupe de pointes pédonculées ${ }^{1}$ (fig. 7-8), un groupe de pointes à cran (fig. 10, $\mathrm{n}^{\circ} 3$ ), et un groupe de pointes ne présentant aucun aménagement visant à conférer une forme particulière aux parties proximales (fig. 9 et $10, \mathrm{n}^{\text {os }} 1-2$ ). Ces dernières pointes ont dans un premier temps été regroupées sous les termes descriptifs de «pointes à face plane " (De Heinzelin, 1973a) et de « pointes à retouches plates » (Otte, 1979a). Afin de souligner leur spécificité, notamment par rapport aux pointes à retouches rasantes appartenant à d'autres ensembles chrono-culturels du Paléolithique supérieur, le type « pointe de Maisières » fut finalement introduit par
M. Otte (Otte, 1979b, p. 560), et définitivement adopté au fil des travaux ultérieurement consacrés à MaisièresCanal.

Bien que les pointes pédonculées, les pointes à cran et les pointes de Maisières soient clairement discernables sur le plan formel, elles ont néanmoins pour point commun de présenter des retouches dorsales rasantes d'intensité variable, ce qui démontre qu'une certaine parenté technique relie ces trois types (Otte, 1979a et 1979b). En l'absence de ces retouches spécifiques, nous avons d'ailleurs préféré classer un petit nombre de pointes $(n=9)$ ne présentant par ailleurs ni pédoncule, ni cran, comme simples lames appointées ${ }^{2}$.

L'identification et le décompte des différents types de pointes est étroitement fonction de leur état de conservation, car les incertitudes sont fréquentes face à des individus fragmentaires. Ainsi, par exemple, vingt fragments distaux de pointes à retouches rasantes ont été décomptés à part, dans la mesure où l'absence des parties proximales empêche toute possibilité de classement. 

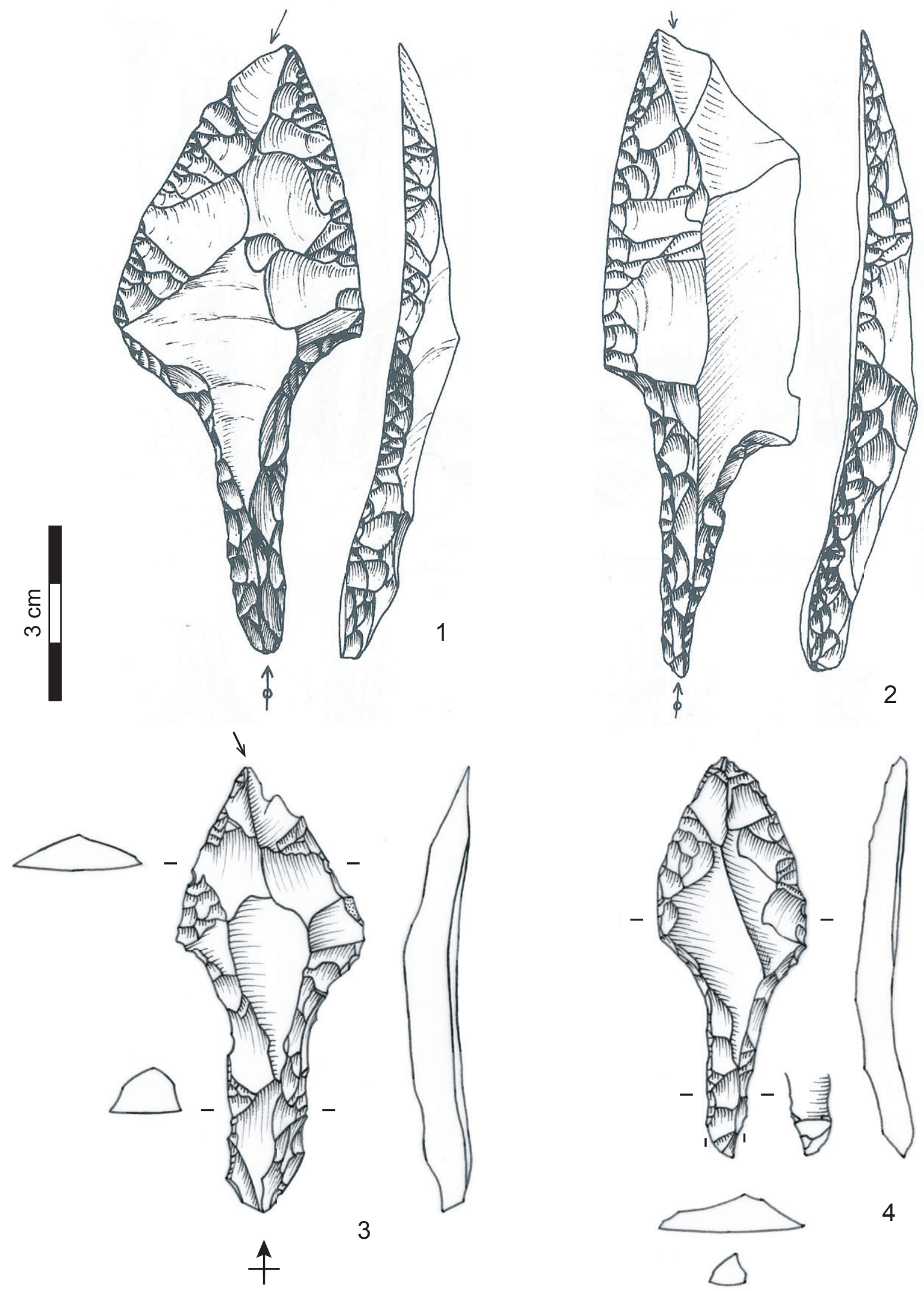

Fig. 7 - Pointes pédonculées (1-2 : M. Otte, 1979b ; 3-4 : O. Touzé).

Fig. 7 - Tanged points (1-2: M. Otte, 1979b; 3-4: O. Touzé). 

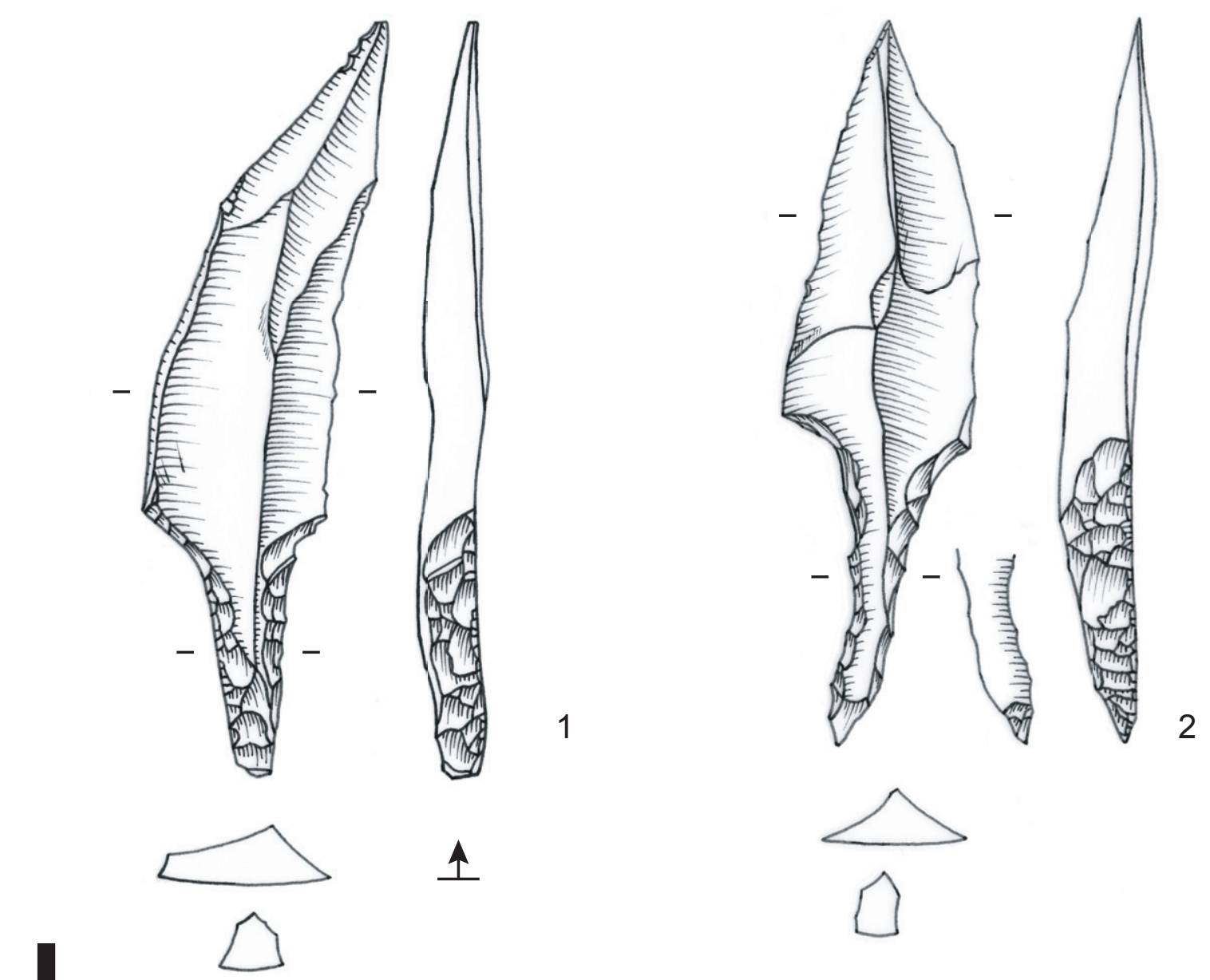

$\left.\begin{array}{c}\varepsilon \\ 0\end{array}\right]$
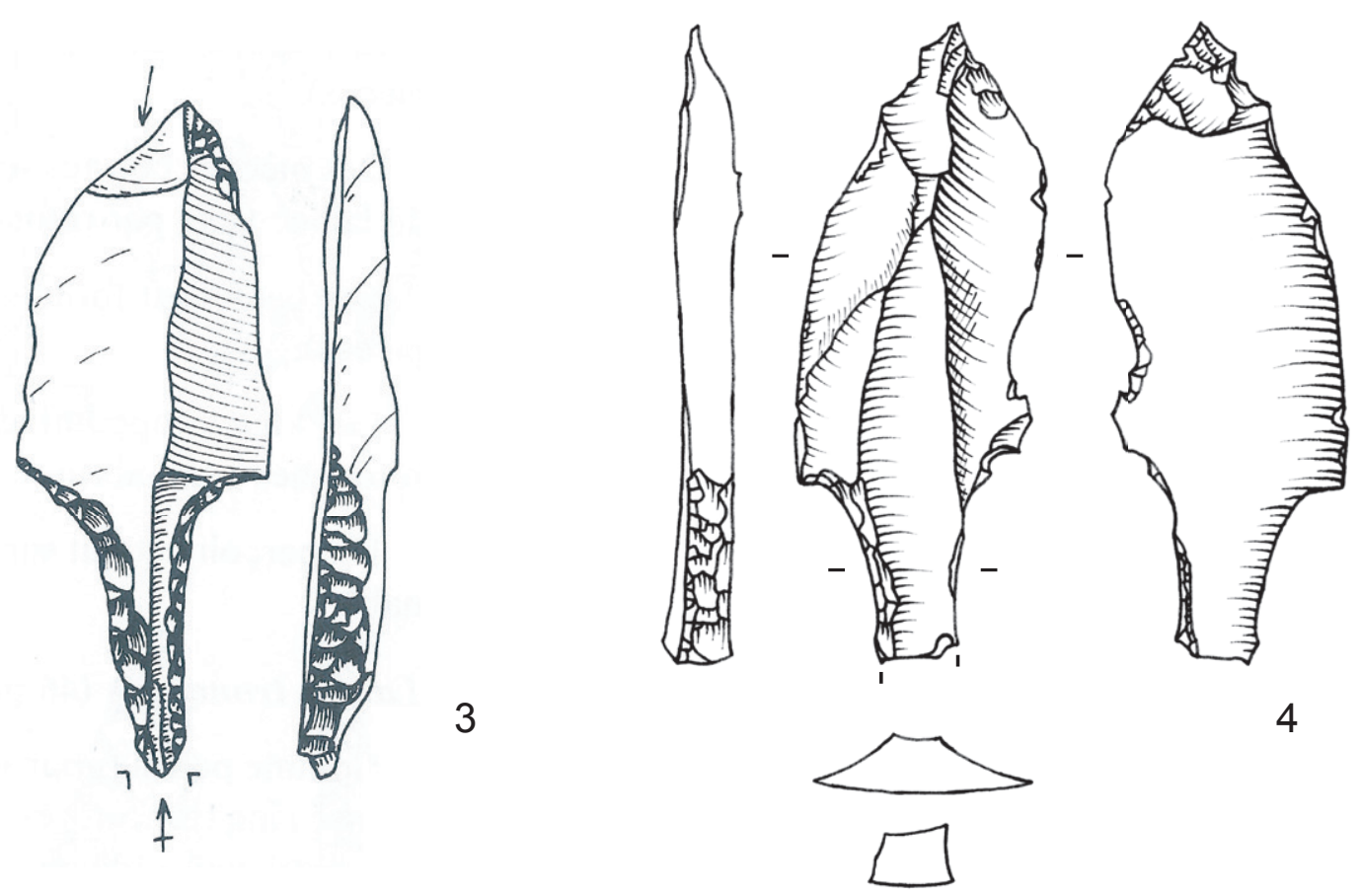

Fig. 8 - Pointes pédonculées (1-2 et $4:$ O. Touzé ; $3:$ M. Otte, 1979b).

Fig. 8 - Tanged points (1-2 and 4: O. Touzé; 3: M. Otte, 1979b). 

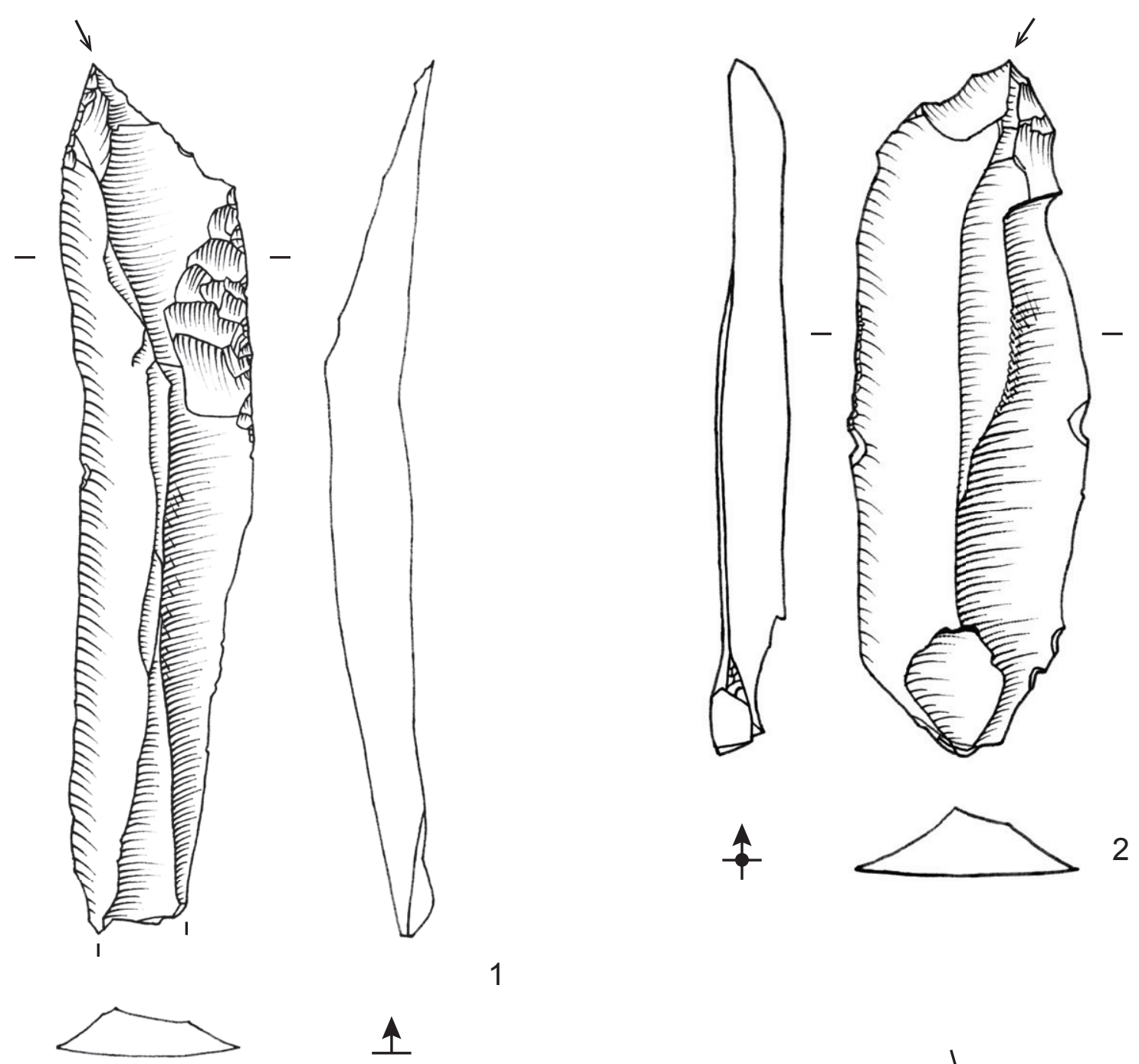

1
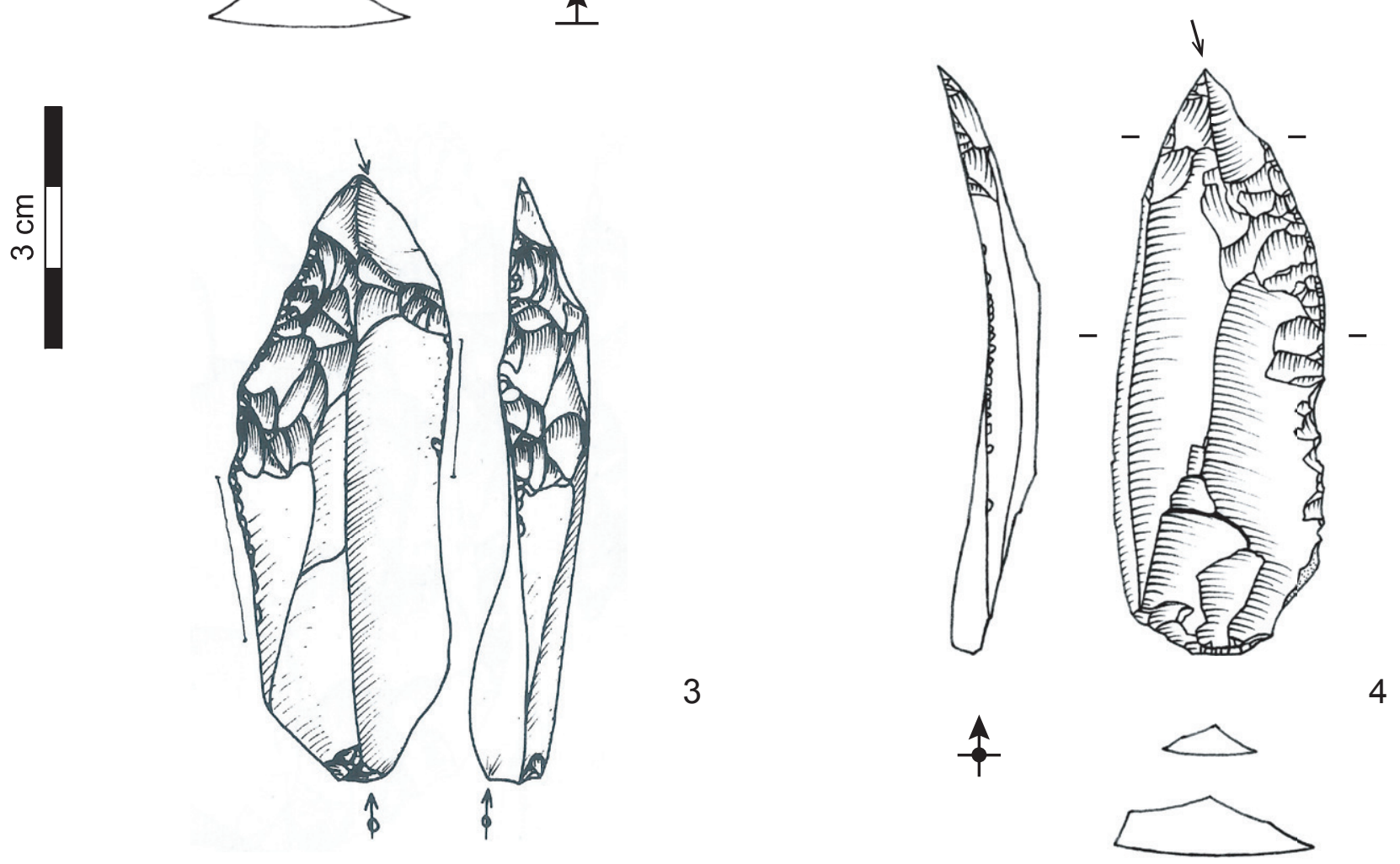

Fig. 9 - Pointes de Maisières (1-2 et 4 : O. Touzé ; 3 : M. Otte, 1979b).

Fig. 9 - Maisières points (1-2 and 4: O. Touzé; 3: M. Otte, 1979b). 

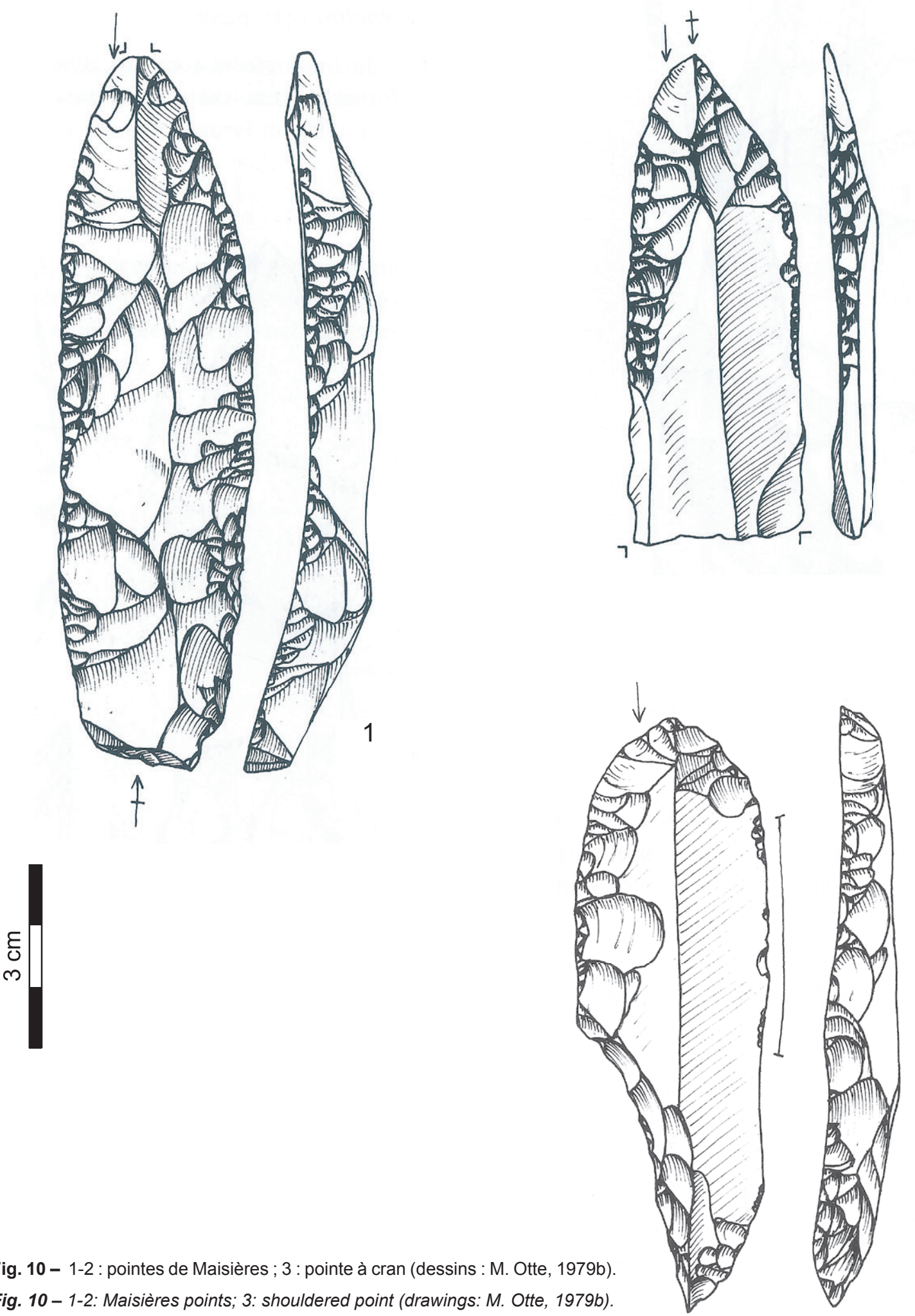

Fig. 10 - 1-2: pointes de Maisières ; 3 : pointe à cran (dessins : M. Otte, 1979b)

Fig. 10 - 1-2: Maisières points; 3: shouldered point (drawings: M. Otte, 1979b).

En tenant exclusivement compte des pièces déterminables, les pointes de Maisières apparaissent à la fois comme le groupe de pointes le plus important $(n=121)$, et également comme l'une des principales composantes typologiques parmi les outils retouchés (12,8\%; tabl. 2). Les pointes pédonculées sont bien représentées également ( $\mathrm{n}=56$, soit $5,9 \%$ des outils retouchés), mais elles demeurent nettement sous-représentées par rapport aux précédentes. Les pointes à cran $(n=8)$, elles, constituent un groupe marginal. Le décompte détaillé de chaque groupe est donné dans le tableau 3. Du fait des problèmes de diagnostic résultant de la fragmentation des pointes, les chiffres qui précèdent représentent des seuils minimums, en ce sens qu'ils sous-estiment sans aucun doute le nombre réel d'individus associés à chaque catégorie. 


\begin{tabular}{|l|c|c|c|}
\hline \multicolumn{1}{|c|}{ Etat de conservation } & Pointe de Maisières & Pointe pédonculée & Pointe à cran \\
\hline Fragment proximo-mésial & 21 & 2 & - \\
\hline Fragment mésial & 12 & 3 & - \\
\hline Fragment mésio-distal & 41 & 18 & 2 \\
\hline Pièce entière / sub-entière & 47 & 33 & 6 \\
\hline Total & 121 & 56 & 8 \\
\hline
\end{tabular}

Tabl. 3 - États de conservation des pointes à retouches rasantes.

Table 3 - States of preservation of points with flat retouch.

\section{Sélection des supports}

La détermination de la nature des supports sélectionnés est limitée dans nombre de cas par deux éléments : la transformation des supports et la fragmentation des artefacts. Dans le premier cas, le caractère régulièrement envahissant ou couvrant de la retouche dorsale rasante entraîne logiquement la disparition des négatifs permettant de déterminer la nature du support. Dans le second cas, certaines pièces s'avèrent simplement trop fragmentaires pour qu'une détermination du support puisse être raisonnablement proposée. Ainsi, 14,5\% des supports de pointes n'ont pu être déterminés. Dans $18,2 \%$ des cas par ailleurs, la nature laminaire des supports a pu être établie, mais les négatifs préservés n'ont pas permis de préciser le statut exact des lames. $\mathrm{Au}$ total, près d'un tiers des supports n'ont donc pu être diagnostiqués précisément, aussi les résultats qui suivent sont-ils partiellement représentatifs.

À l'instar de ce qui est observé pour l'ensemble de l'outillage retouché, les différents types de pointes à retouche rasante sont très largement confectionnés sur des supports laminaires $(81,3 \%)$. Les lames issues du plein débitage sont sélectionnées en priorité (41,1\% des supports), mais des lames de statut différent ont été également transformées. Parmi elles, les lames sous-crête $(8,4 \%)$ et les lames antérolatérales $(7,5 \%)$ sont les mieux représentées. Le choix des supports apparaît toutefois plus sélectif pour les pointes pédonculées que pour les pointes de Maisières puisque, contrairement à ces dernières, les pointes pédonculées ne sont qu'exceptionnellement préparées sur des lames non issues du plein débitage $(\mathrm{n}=2)$. Les éclats n'ont quant à eux été sélectionnés qu'exceptionnellement ( $\mathrm{n}=9$, soit 4,2 \% des supports), et uniquement dans le cadre de la préparation de pointes de Maisières.

De manière générale, les dimensions des différents types de pointes se caractérisent par un continuum tel que la définition objective de sous-ensembles à partir de la distribution des valeurs métriques est impossible. Cette distribution présente en outre assez peu de différences entre les deux principaux groupes de pointes. La distribution des largeurs (fig. 11) et des épaisseurs (fig. 12) des pointes de Maisières et des pointes pédonculées traduit ainsi seulement de légères divergences entre les deux groupes pour certaines classes dimensionnelles. Ces variations semblent cependant peu signifiantes quant aux modalités de sélection des supports. En revanche, et bien que cela concerne un nombre limité d'individus, la présence exclusive des pointes de Maisières dans les classes d'épaisseurs supérieures à $16 \mathrm{~mm}$, et dans les classes de largeurs supérieures à $45 \mathrm{~mm}$ (à l'exception d'une pointe pédonculée dont la largeur de $57 \mathrm{~mm}$ est exceptionnelle par rapport à l'ensemble de la catégorie) pourrait aller dans le sens d'une sélection plus souple des supports de pointes de Maisières. La distribution des longueurs des pièces complètes montre une sousreprésentation des pointes pédonculées dans les classes comprises entre 71 et 95 mm (fig. 13). Il paraît cependant délicat de trop inférer à partir de cette observation étant donné le grand nombre d'outils pédonculés fragmentés non déterminables.

Les caractères morphologiques généraux des supports laminaires admettent également une certaine variabilité (Pesesse et Flas, 2012). Ainsi, si les lames sélectionnées présentent le plus souvent un profil rectiligne, elles peuvent également être légèrement courbes ou torses. Lorsqu'elle est présente, la torsion demeure cependant limitée. Plusieurs pointes montrent enfin que la sélection des supports a été parfois orientée vers des lames effilées en partie distale (fig. 8). Un tel choix peut s'expliquer assez facilement par l'adéquation entre le caractère pointu des supports bruts et les propriétés fonctionnelles attendues des pointes lithiques.

\section{Méthode de transformation des supports}

Le degré de transformation des supports de pointes est très variable. Le plus souvent limité, il peut aussi s'avérer très important auquel cas les retouches investissent alors l'essentiel, voire la totalité de la face supérieure du support (fig. $7, n^{\text {os }} 1$ et 3 ; fig. $10, n^{\circ} 1$ ). Dans une telle situation, la retouche rasante n'est plus seulement employée pour ajuster la morphologie du support, mais bien plutôt pour reconfigurer entièrement celui-ci. Lorsqu'elle est envahissante ou couvrante, la retouche rasante permet en effet de modifier simultanément la longueur, la largeur et l'épaisseur du support, en plus de la délinéation et de l'angulation de ses bords. En d'autres termes, c'est donc le volume même du support qui est transformé selon une logique opératoire qui répond alors plus du façonnage que de la retouche. L'étude intégrée des pointes transformées selon une telle démarche (fig. 14 et 15), et des déchets en résultant (fig. 16), montre que ce façonnage comprend une succession d'étapes 


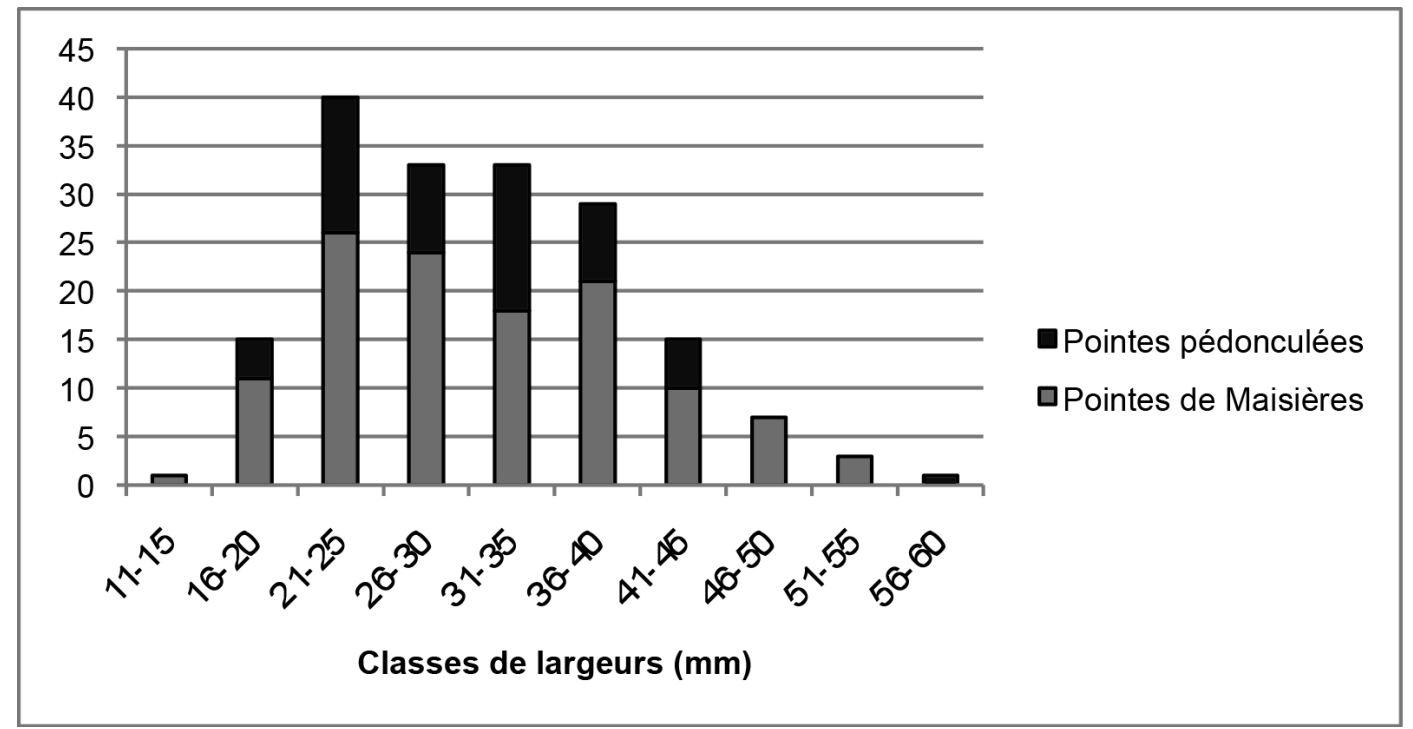

Fig. 11 - Distribution des largeurs des pointes de Maisières et des pointes pédonculées.

Fig. 11 - Distribution of the widths of Maisières points and tanged points.

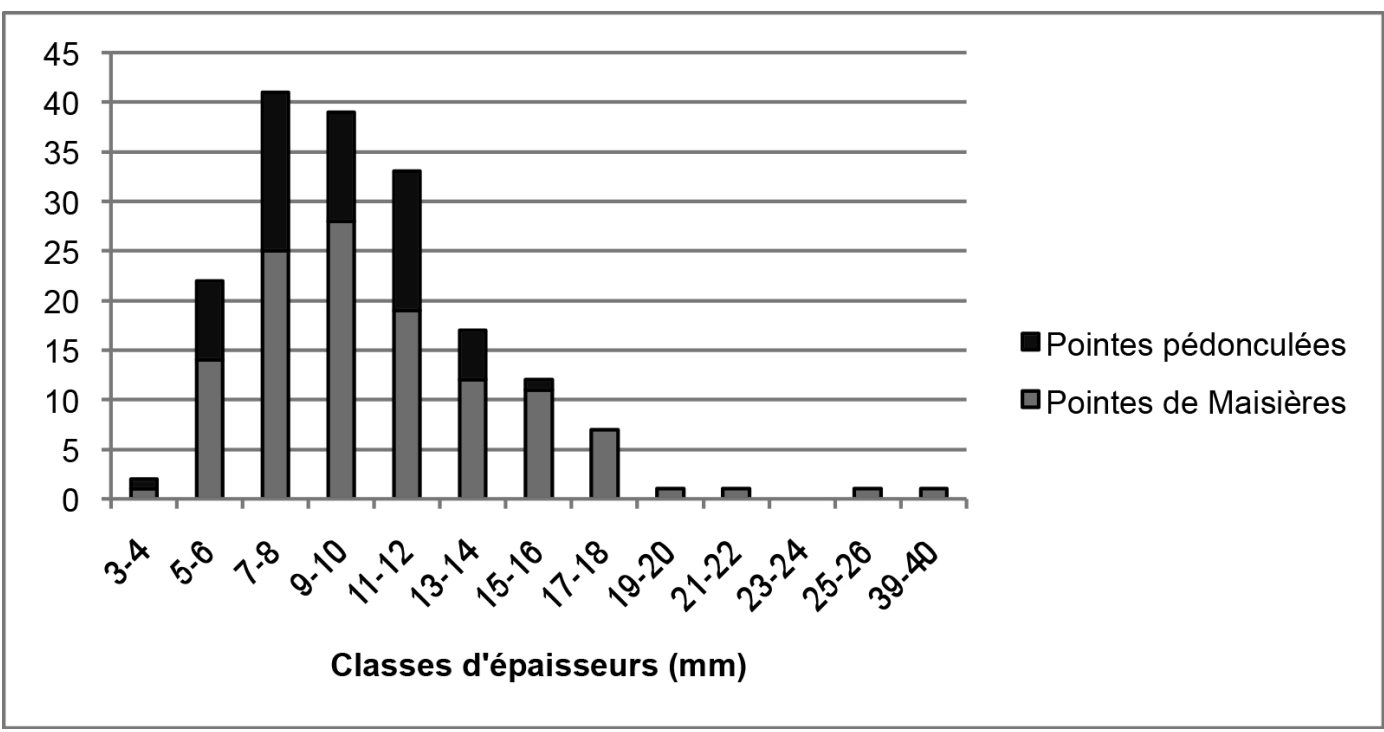

Fig. 12 - Distribution des épaisseurs des pointes de Maisières et des pointes pédonculées.

Fig. 12 - Distribution of the thicknesses of Maisières points and tanged points.

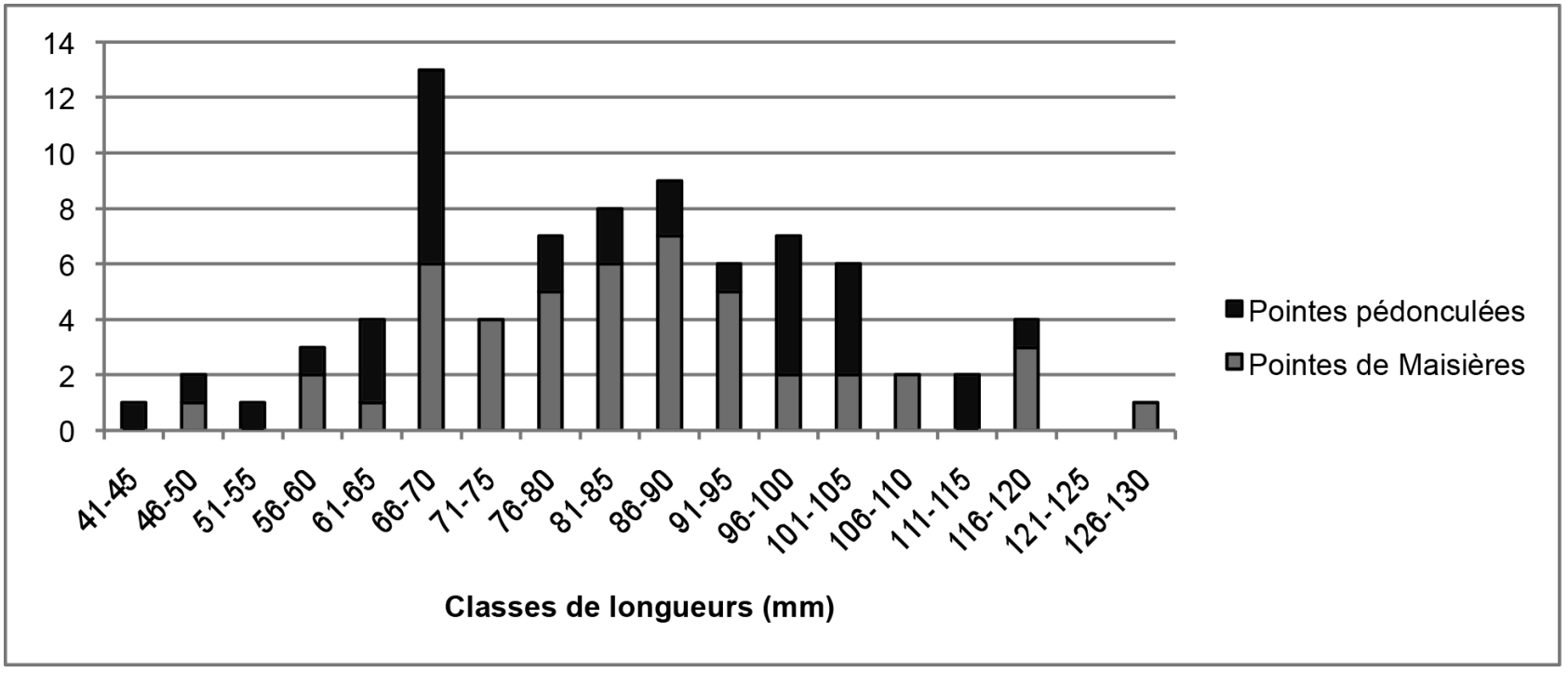

Fig. 13 - Distribution des longueurs des pointes de Maisières et des pointes pédonculées entières.

Fig. 13 - Distribution of the lengths of intact Maisières points and tanged points. 

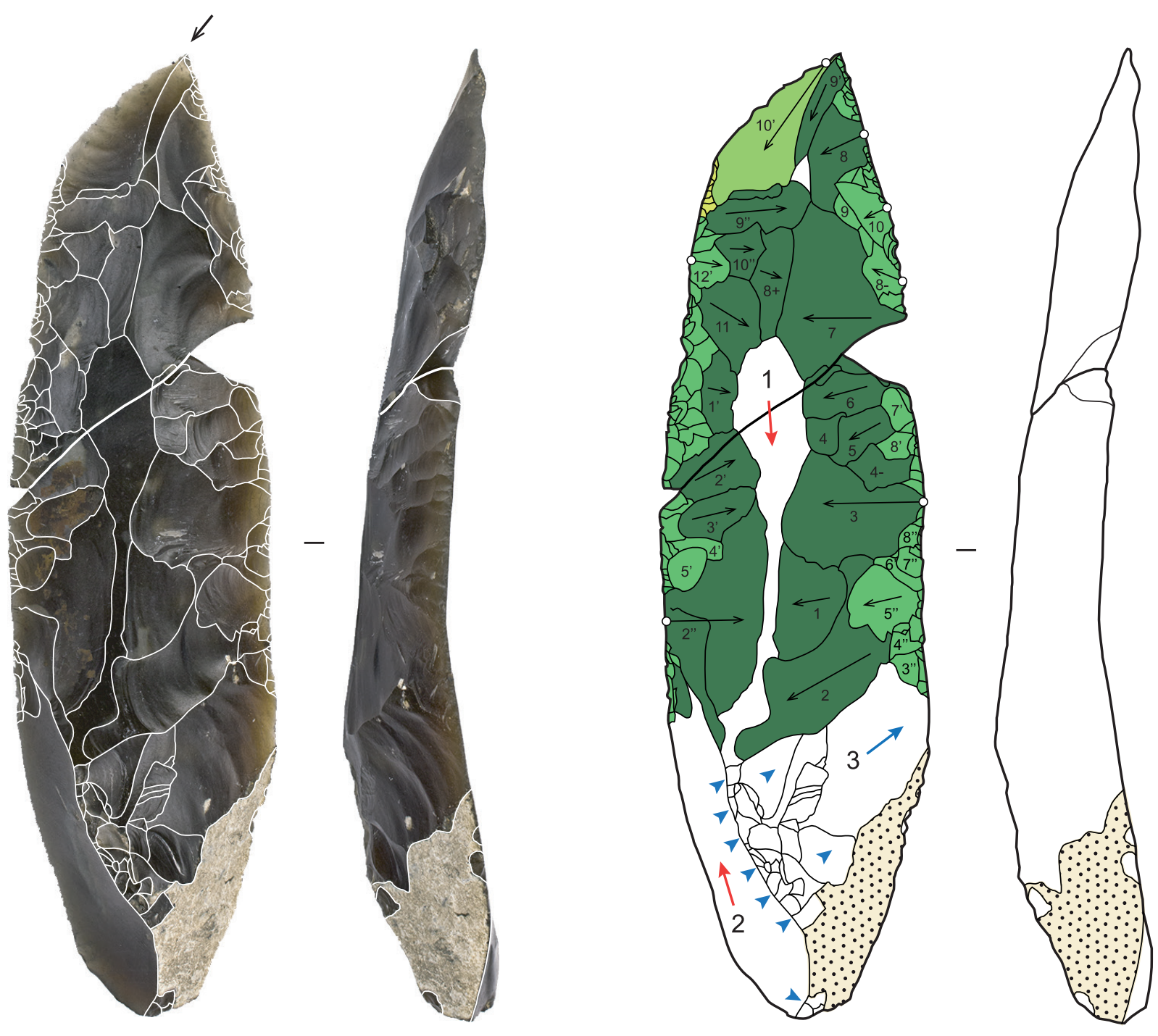

$\uparrow$

Fig. 14 - Schéma diacritique du façonnage d'une pointe de Maisières.

Fig. 14 - Diacritical drawing of the shaping sequence of a Maisières point.

dont chacune possède un rôle particulier et indispensable au bon déroulement de la confection des pointes. Il apparaît ainsi que le façonnage de ces dernières est effectué selon une véritable méthode possédant sa chaîne opératoire, ses techniques, et ses contraintes propres. Les différences relevées dans l'étendue des retouches d'une pointe à l'autre, démontrent cependant que l'emploi de cette méthode est éminemment souple, celle-ci étant complètement ou partiellement appliquée selon les cas.

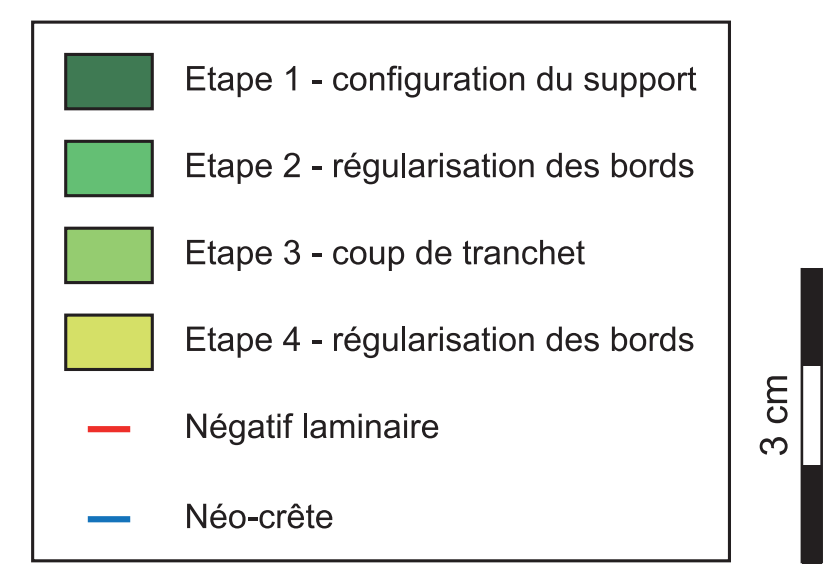

Les figures 17 et 18 proposent des schémas synthétisant la succession d'opérations intervenant dans la préparation des pointes. Celle-ci peut être décrite comme suit :

Étape $\mathrm{n}^{\circ} 1$ : abrasion directe du bord à retoucher. En ouvrant l'angle formé par la jonction des faces supérieure et inférieure du support (fig. 18), cette étape permet de renforcer la zone devant subir la percussion, et donc de prévenir toute altération de celle-ci. L'abrasion est cependant réalisée de sorte que l'angle de bord demeure 

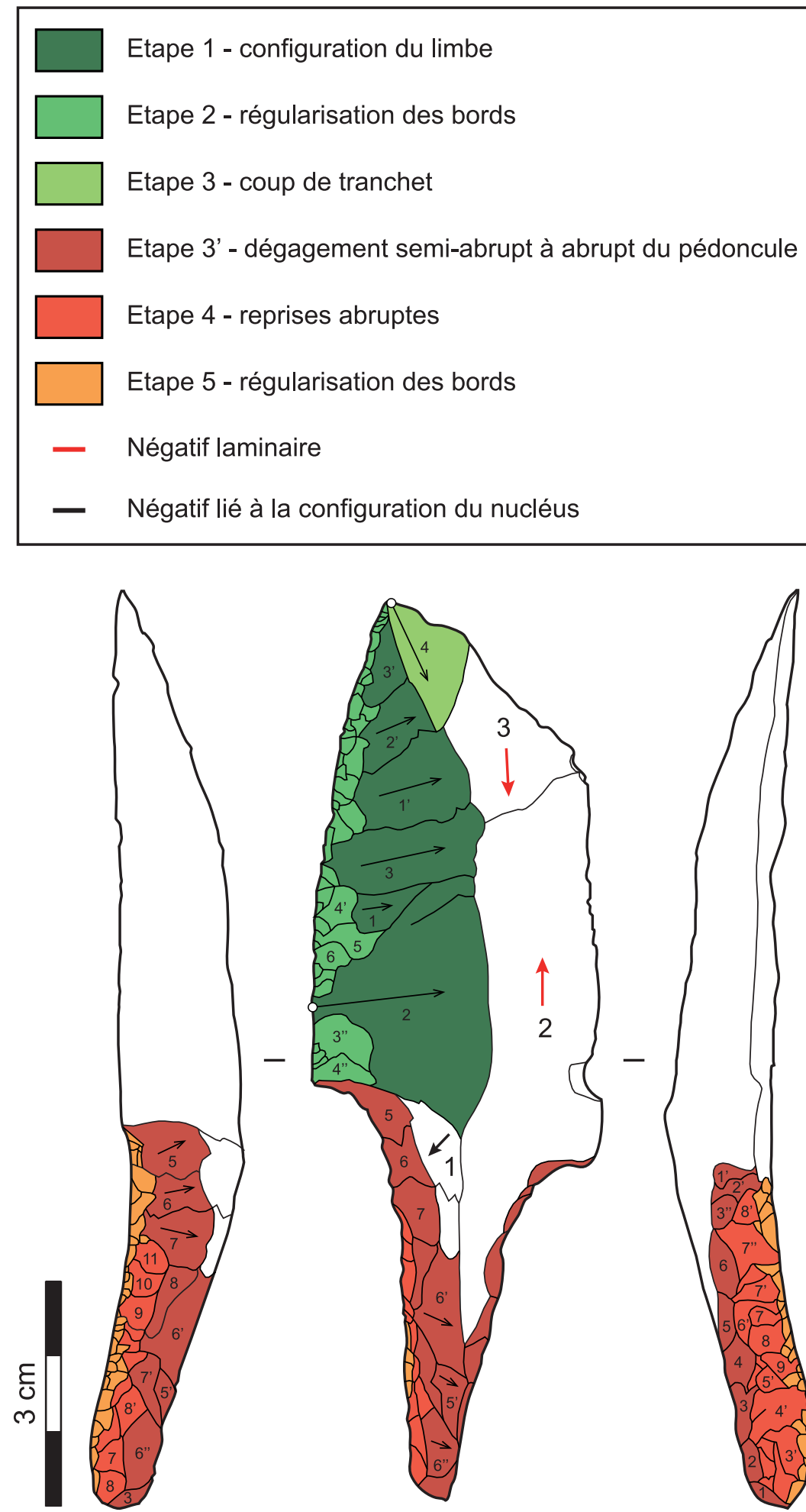

aigu ; s'il est obtus, l'enlèvement qui doit suivre ne peut pas être détaché.

Étape $\mathrm{n}^{\circ} 2$ : première série de retouches rasantes directes. À cette étape du façonnage, la surface devant être retouchée est concave puisqu'elle correspond au négatif d'un enlèvement laminaire ayant précédé l'extraction du support (l'abrasion réalisée à l'étape $\mathrm{n}^{\mathrm{o}} 1$ installe cependant une micro-convexité à l'extrémité du bord qui permet au percuteur de venir « accrocher » ce dernier). Cette concavité contraint le développement

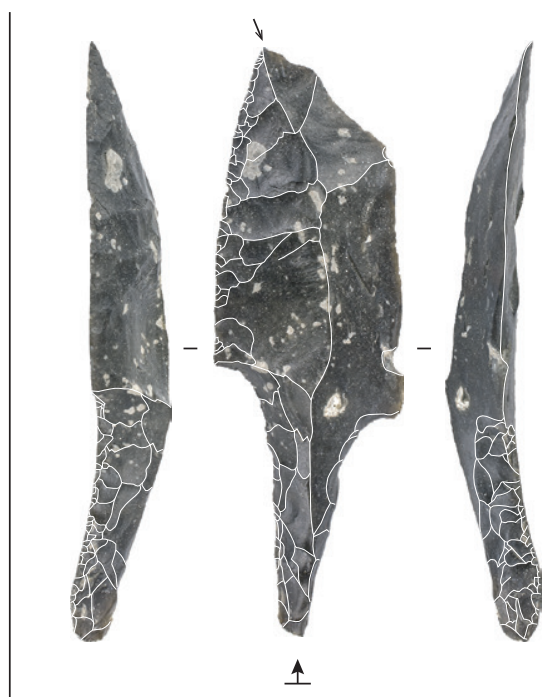

Taille: $1 / 2$
Fig. 15 - Schéma diacritique du façonnage d'une pointe pédonculée.

Fig. 15 - Diacritical drawing of the shaping sequence of a tanged point. longitudinal de l'onde de fracture, aussi les premiers enlèvements détachés sont nécessairement courts. Leurs faces inférieures présentant un profil convexe, ces enlèvements peuvent aisément être confondus avec de simples esquilles. Le principal élément permettant de les identifier est l'inclinaison prononcée du talon ${ }^{3}$ par rapport à la face supérieure. Ces premières retouches rasantes ont pour but d'aménager une micro convexité au centre de la surface retouchée, indispensable pour que des enlèvements plus longs puissent être ensuite détachés. 

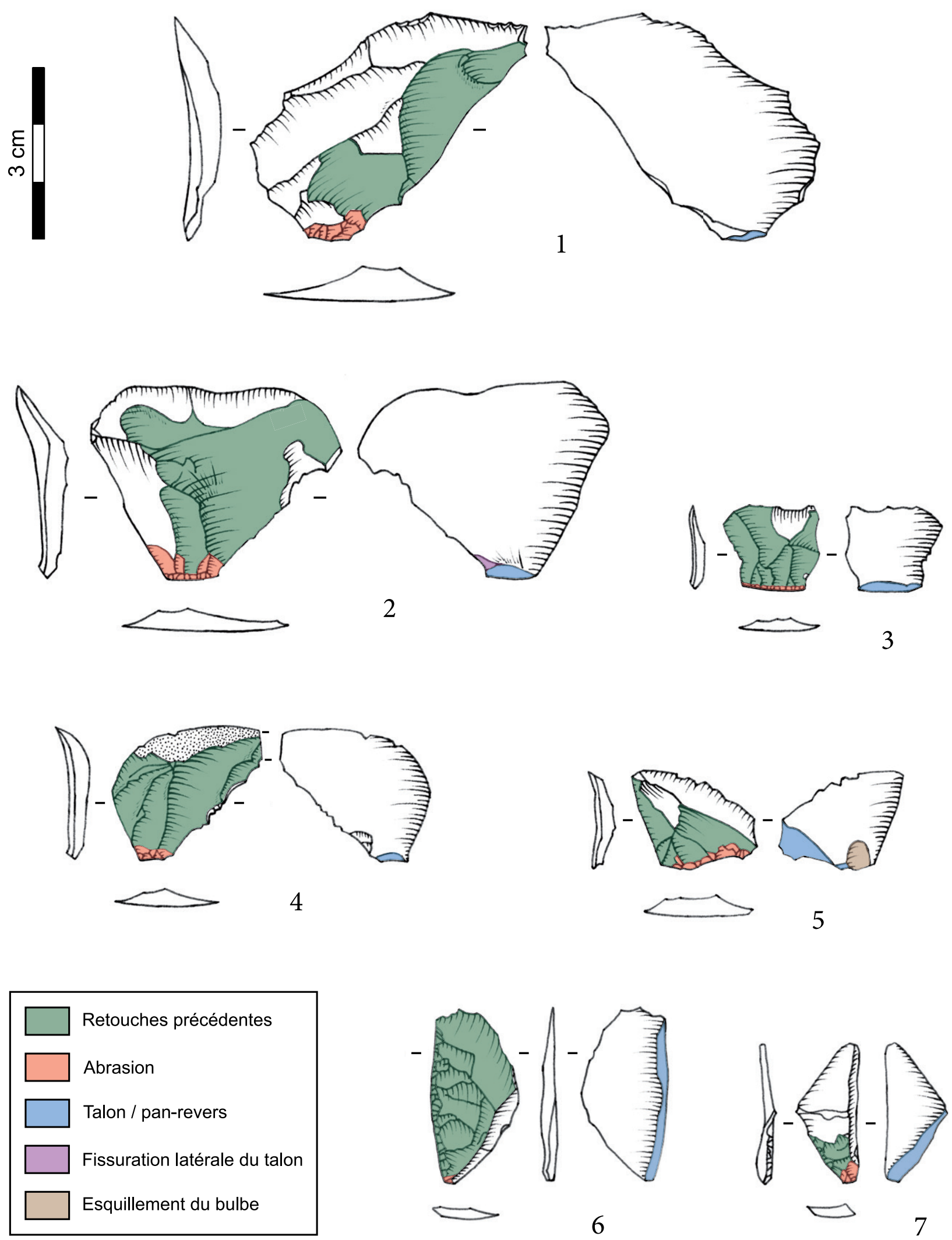

Fig. 16 - 1-5 : éclats de façonnage de pointes à retouches rasantes ; 6-7 : éclats de coups de tranchet.

Fig. 16 - 1-5: shaping flakes of points with flat retouch; 6-7: tranchet blow flakes.

Pour être efficace, la micro convexité doit être toutefois installée à une distance suffisamment courte de la nervure délimitant cette surface, et il peut s'avérer nécessaire de multiplier les étapes $n^{\text {os }} 1$ et 2 pour y parvenir.
Étape $\mathrm{n}^{\circ} 3$ : nouvelle abrasion directe du bord retouché.

Étape $n^{0} 4$ : une fois les conditions réunies (micro convexité aménagée et bord abrasé), détachement de longs éclats outrepassant la nervure de la face 


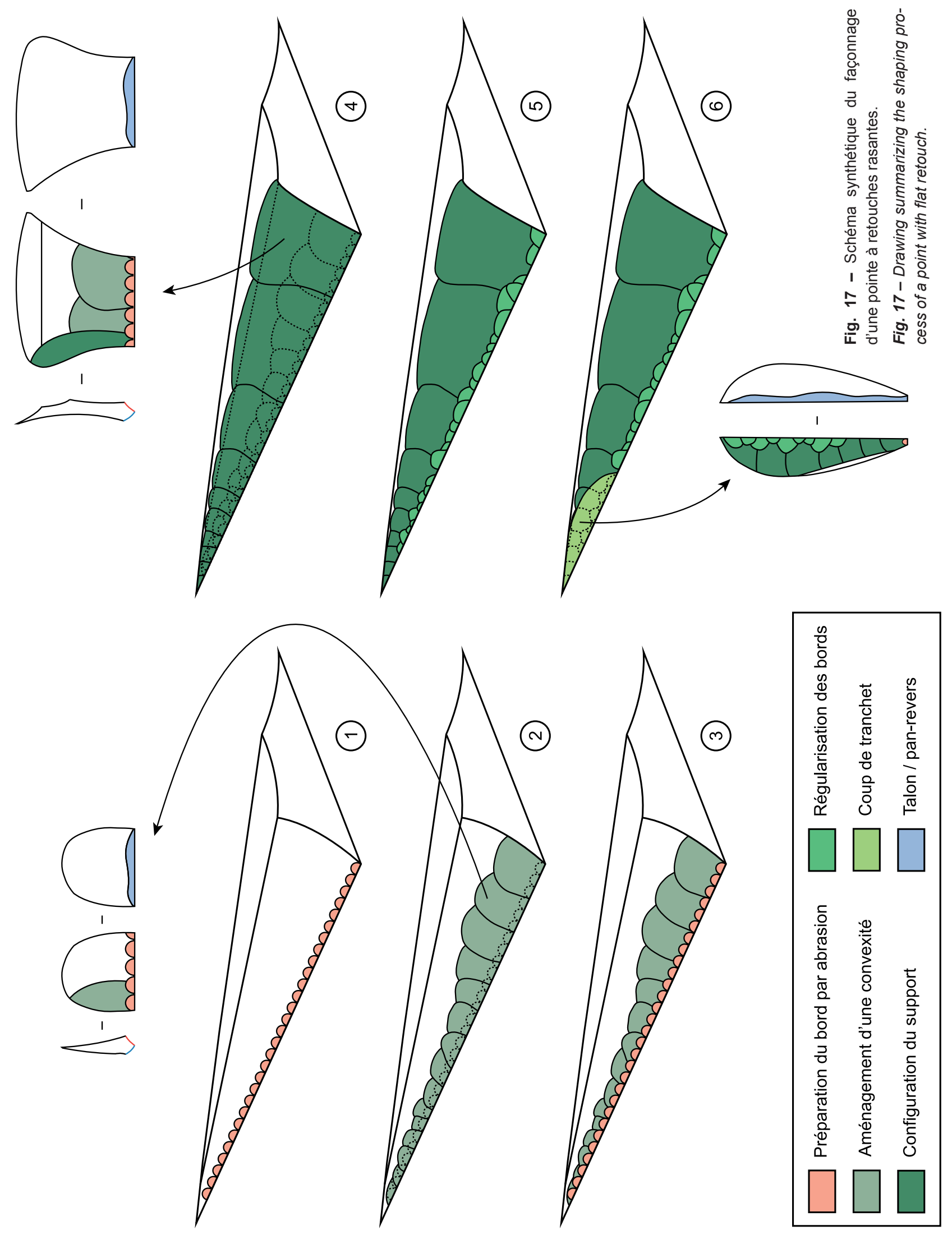

supérieure du support délimitant la surface retouchée. La notion d'outrepassement n'est évidemment pas utilisée ici dans son acception la plus courante, soit celle d'un accident de taille - lequel peut du reste survenir également lors du façonnage (voir infra). Elle ne correspond pas non plus aux outrepassements intentionnels documentés pour certains façonnages bifaciaux (Inizan et Tixier, 1978 ; Aubry et al., 2008). À Maisières-Canal, l'outrepassement de nervure résulte d'une action intentionnelle visant à détacher un enlèvement suffisamment long pour, littéralement, passer outre une nervure de la face supérieure du 


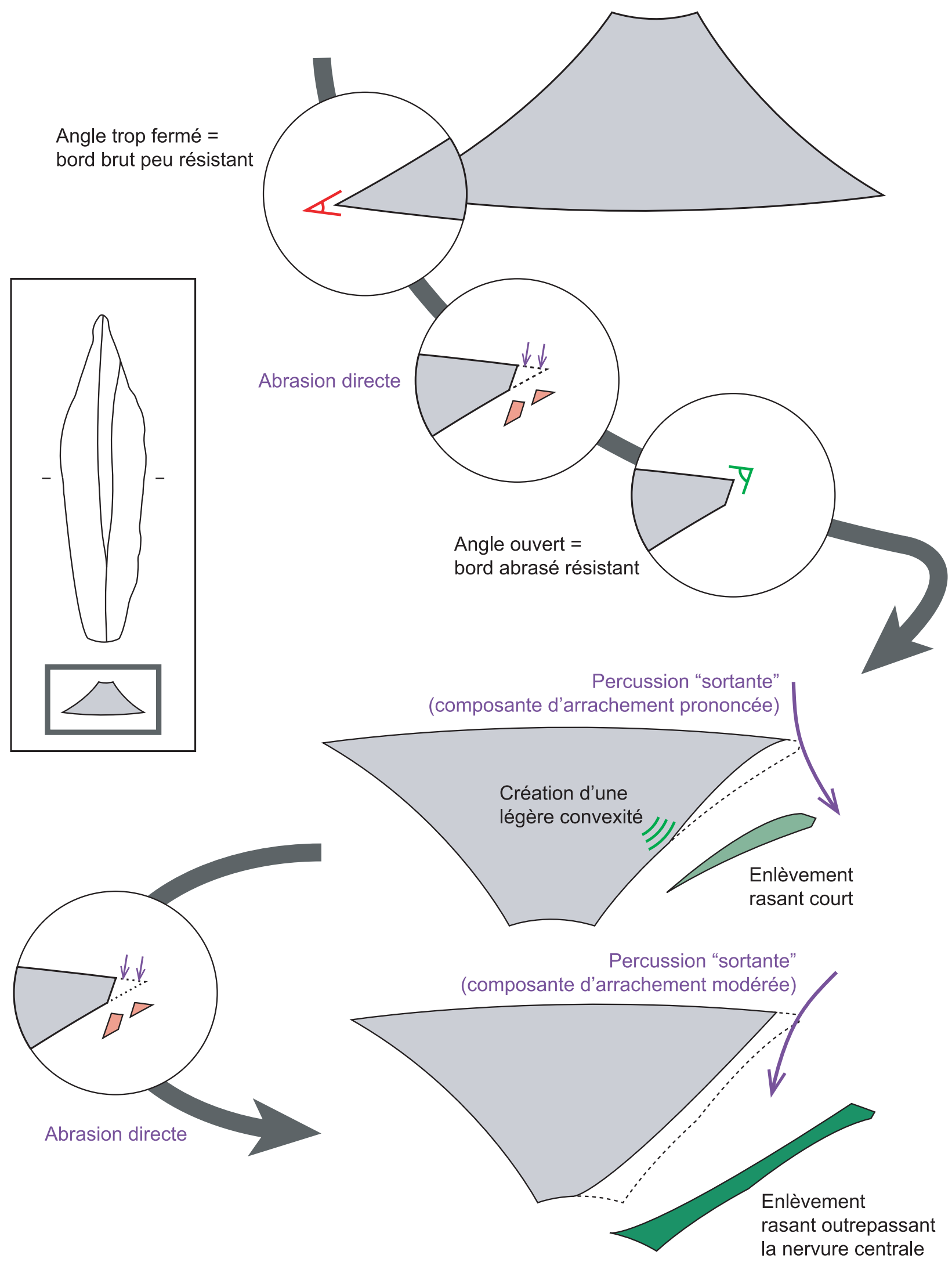

Fig. 18 - Succession et rôles des gestes techniques intervenant dans le façonnage des pointes.

Fig. 18 - Sequence and roles of the technical gestures involved in the shaping of points.

support. Les éclats de retouche outrepassants sont aisés à identifier en raison de leur profil concave (qui résulte de l'outrepassement de nervure) associé, comme à l'étape $\mathrm{n}^{\mathrm{o}} 2$, à un talon très incliné et aux stigmates liés à l'abrasion du bord du support (fig. 16, nos 1-5). Parmi ces éclats, certains individus très larges (fig. 16, $\mathrm{n}^{\text {os }} 1-2$ ) sont vraisemblablement associés au façonnage des parties mésiale ou proximale des pointes. Parce qu'elles 
requièrent un soin particulier, les parties distales sont préparées en effet par des retouches plus étroites.

Étape $\mathrm{n}^{0} 5$ : détachement de nouveaux enlèvements rasants directs afin d'effacer les irrégularités (microdenticulation $\mathrm{du}$ bord) créées par les enlèvements outrepassants. Dans la mesure où l'objectif de cette étape consiste uniquement à régulariser la délinéation du bord, les enlèvements sont souvent très courts et ne nécessitent pas forcément d'abrasion préalable contrairement à ceux des étapes $\mathrm{n}^{\text {os }} 2$ et 4.

Étape $\mathrm{n}^{\circ} 6$ : détachement d'un coup de tranchet ou « enlèvement plan sommital » (Otte, 1979a, p. 71). Cet enlèvement est détachéà partir de l'apex, et peut être orienté vers le bord droit $(n=42)$ ou vers le bord gauche $(n=28)$. Une pointe pédonculée présente deux coups de tranchet pratiqués successivement à gauche puis à droite de l'apex. Ce cas est cependant unique, et pourrait correspondre à une réfection de l'outil. Le coup de tranchet est pratiqué indifféremment sur les différents types de pointes, mais son occurrence ne concerne toutefois qu'une partie d'entre elles (pointes de Maisières : $\mathrm{n}=39$; pointes pédonculées : $\mathrm{n}=23$; pointes à cran $: \mathrm{n}=4$; fragments distaux $: \mathrm{n}=5$ ). La fonction du coup de tranchet paraît résider dans l'affûtage de l'extrémité distale d'un des bords, associé à la création d'un apex trièdre acéré. Cet enlèvement ne semble pas être destiné en revanche à raviver un tranchant usagé. Du reste, en-dehors de l'exception déjà signalée, aucune pointe n'atteste la répétition du coup de tranchet. Les éclats de coups de tranchet montrent une préparation très discrète par abrasion de la zone de percussion (fig. 16, $\mathrm{n}^{\text {os }}$ 6-7). Éventuellement, une retouche limitée à la zone modifiée par le coup de tranchet peut être ensuite pratiquée afin d'ajuster la délinéation du bord.

$\mathrm{Au}$ vu de ce qui vient d'être décrit, le caractère exclusivement direct de toute intervention menée sur le support, qu'il s'agisse des étapes d'abrasion préparatoire, ou des étapes de retouche proprement dites, constitue l'une des principales caractéristiques de la méthode de confection des pointes. Les contraintes rencontrées tiennent quant à elles, d'une part, au caractère concave des surfaces à retoucher qui demandent parfois de multiplier les retouches préparant les enlèvements outrepassant les nervures centrales, et, d'autre part, à la nécessité de préserver le caractère aigu (et donc tranchant) des bords à chaque génération de retouche. Sur ce dernier point, il faut insister sur les conséquences de l'abrasion précédant les enlèvements rasants. Ayant comme objectif de renforcer la zone à percuter, l'abrasion entraîne nécessairement des angles de bord ouverts. Une difficulté de la méthode réside donc dans la contradiction apparente entre les étapes d'abrasion qui ouvrent les angles de bord, et les étapes de retouches rasantes qui, à l'inverse, les referment - les premières étant cependant indispensables au succès des secondes.

Enfin, bien que la préparation des supports soit réalisée au dépend de leur face supérieure, une retouche rasante inverse complémentaire est parfois observée. Quatorze pointes de Maisières sont dans ce cas, auxquelles il faut ajouter trois pointes pédonculées présentant une telle retouche au niveau du limbe. Les pointes à cran et les fragments distaux ne sont en revanche pas concernés. La retouche inverse intervient surtout au niveau de l'apex, mais elle peut également être pratiquée en partie proximale ou mésiale sur les pointes de Maisières. Elle paraît utilisée principalement pour diminuer l'angle d'un bord lorsqu'un pan de la face supérieure du support se révèle trop abrupt par rapport à la face inférieure, et en cela difficile à retoucher par enlèvements directs. Lorsqu'elle est employée en partie proximale du support, la retouche inverse peut aussi avoir pour rôle la réduction de la convexité du bulbe.

\section{Application de la méthode et variabilité des supports}

La préparation des pointes lithiques à Maisières-Canal implique des degrés très variables de transformation des supports. De fait, la retouche rasante peut aussi bien être entièrement couvrante que marginale. L'étendue de cette retouche constituant un indicateur du degré de transformation des supports, nous avons cherché à en proposer une évaluation objectivée. Pour ce faire, ont été prises en compte les seules parties mésio-distales des pointes, dans la mesure où, dans le cas des pointes pédonculées et à cran, les parties proximales sont presque exclusivement préparées par retouche abrupte ou semi-abrupte. Ce choix a également un sens du point de vue fonctionnel, car c'est à la préparation des parties mésio-distales que revient d'assurer la mise en place des capacités perforante et tranchante des pointes. Dans le cas des pointes pédonculées et des pointes à cran, la partie mésio-distale - ou « limbe » - est définie comme la zone située au-dessus des crans, ou au-dessus du cran le plus haut pour les pointes pédonculées sur lesquelles les crans ne sont pas situés à la même hauteur. Dans le cas des pointes de Maisières, en l'absence du repère que constituent les crans, la partie mésio-distale est définie comme la moitié supérieure de l'outil. Afin de «mesurer» l'étendue de la retouche rasante sur la face supérieure, un gradient comportant cinq stades, et inspiré du gradient classique (Inizan et al., 1995, p. 89), a été utilisé :

Marginale : retouche très courte ajustant de manière très ponctuelle la délinéation du bord.

Courte : retouche plus étendue, mais qui n'atteint cependant pas les nervures de la face supérieure du support.

Longue : retouche suffisamment étendue pour atteindre et dépasser une nervure de la face supérieure. La retouche de la partie mésio-distale demeure cependant partielle.

Envahissante : retouche outrepassant les nervures centrales et investissant l'essentiel de la face dorsale.

Couvrante : retouche investissant intégralement la face dorsale.

Dans $16,7 \%$ des cas, les pointes lithiques présentent une retouche envahissante $(n=16)$ ou couvrante $(n=17)$. Cependant, dans plus de $70 \%$ des cas, les supports de pointes ont fait l'objet d'une retouche courte $(n=87)$ 


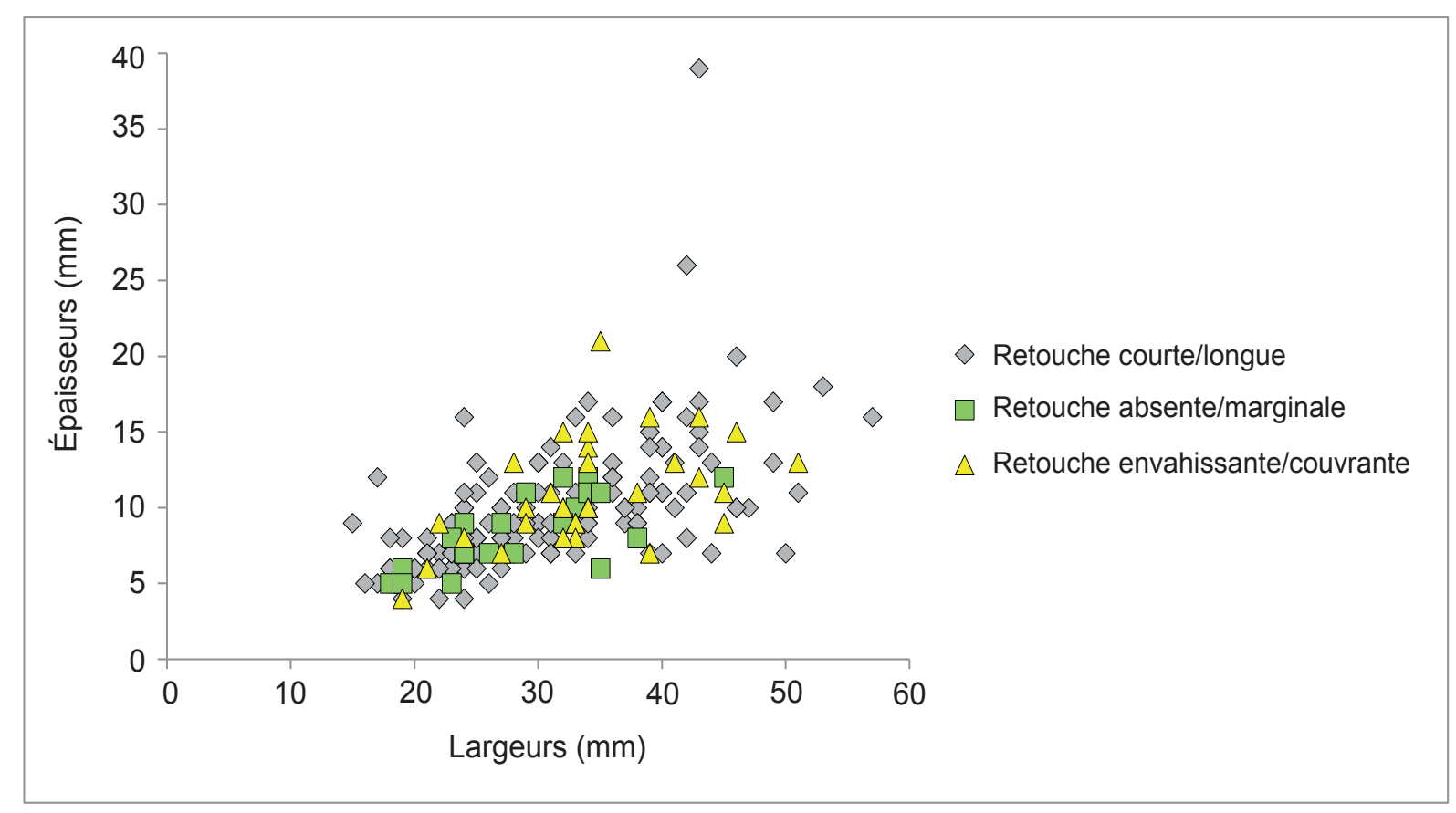

Fig. 19 - Dispersion du rapport largeur/épaisseur des pointes à retouches rasantes

(pointes de Maisières, pédonculées, à cran, et fragments distaux) en fonction de l'étendue des retouches.

Fig. 19 - Width/thickness ratio of points with flat retouch

(Maisières, tanged and shouldered points, and distal fragments of points) as a function of the extent of retouch.

ou longue $(n=43)$, c'est-à-dire d'une transformation limitée si on laisse de côté la préparation d'un pédoncule ou d'un cran pour les types de pointes concernés. Ces résultats indiquent ainsi que la sélection des supports est opérée de telle sorte que la morphologie de ceux-ci soit peu, ou modérément éloignée de celles des outils finis, ce qui permet par suite de restreindre les opérations de transformation. Cette observation s'exprime le plus nettement avec les pointes présentant une retouche marginale $(n=16)$, ou un limbe brut $\left(n=6\right.$; fig. $\left.8, n^{\circ} 1\right)$, lesquelles représentent $11,1 \%$ des pointes.

La mise en relation de l'étendue de la retouche rasante et du rapport largeur/épaisseur des pointes montre que les pièces portant une retouche envahissante ou couvrante tendent à être plus larges ou plus épaisses que celles présentant une retouche marginale, ou celles dont le limbe n'a pas été retouché (fig. 19). Ce résultat suggère donc que l'étendue de la retouche dépend étroitement des dimensions initiales du support brut : plus un support s'avère volumineux plus sa transformation est susceptible d'être importante. Un support trop irrégulier au regard des propriétés de l'outil désiré peut ainsi faire l'objet d'un véritable façonnage unifacial reconfigurant entièrement ses caractéristiques volumétriques et morphologiques. À l'inverse, si le support choisi ne nécessite pas de lourdes modifications, la méthode est appliquée de manière limitée. Elle est alors susceptible d'être simplifiée, en particulier s'il n'est pas nécessaire de procéder aux longues retouches outrepassant les nervures centrales. Dans ce cas, la méthode n'est pas employée dans la perspective d'un façonnage, mais bien dans celle d'une retouche visant à ajuster, ou corriger certains défauts du support. L'emploi de cette méthode est donc très souple.

\section{Technique(s) de percussion}

L'examen des talons des éclats de retouche montre que ceux-ci se caractérisent le plus souvent par une épaisseur pluri-millimétrique, une lèvre marquée, un bord inférieur régulier, et l'absence de cônes de percussion (fig. 20, $\left.\mathrm{n}^{\text {os }} 1-5\right)$. Sur de rares pièces, une fissuration latérale est également observée (fig. 16, $\mathrm{n}^{\mathrm{o}} 2$ ). Ces stigmates évoquent ainsi l'utilisation d'un percuteur organique (Pelegrin, 2000). Afin de détacher des enlèvements peu épais, et pour préserver le caractère tranchant des bords, les retouches sont effectuées en percussion directe tangentielle, ou " sortante », c'est-à-dire selon un geste permettant au percuteur de «fuir » la surface percutée après contact. Dans ce cadre, l'utilisation d'un percuteur organique disposant d'une certaine plasticité permet de favoriser l'efficacité du geste, et de limiter le risque d'endommagement des bords percutés.

Dans quelques cas, le caractère infra-millimétrique et irrégulier des talons, parfois associés à la présence de points de percussion (fig. 20, $\mathrm{n}^{\circ} 6$ ) ou d'esquillements du bulbe (fig. 16, $\mathrm{n}^{\circ} 5$ ), paraît signaler l'emploi ponctuel d'un percuteur minéral tendre (Pelegrin, 2000). Remarquons toutefois que les rides fines et serrées qui constituent l'un des marqueurs les plus univoques de la percussion minérale tendre ne sont pas observées sur les éclats de retouche, alors même que l'aspect discriminant de ce critère pour le débitage de produits laminaires (Pelegrin, 2000) a été récemment renforcé par la reproduction expérimentale de racloirs Quina impliquant l'usage de gestes proches de ceux pratiqués dans le façonnage des pointes à Maisières-Canal (Roussel et al., 2009). Le même travail a en outre montré que l'esquillement 

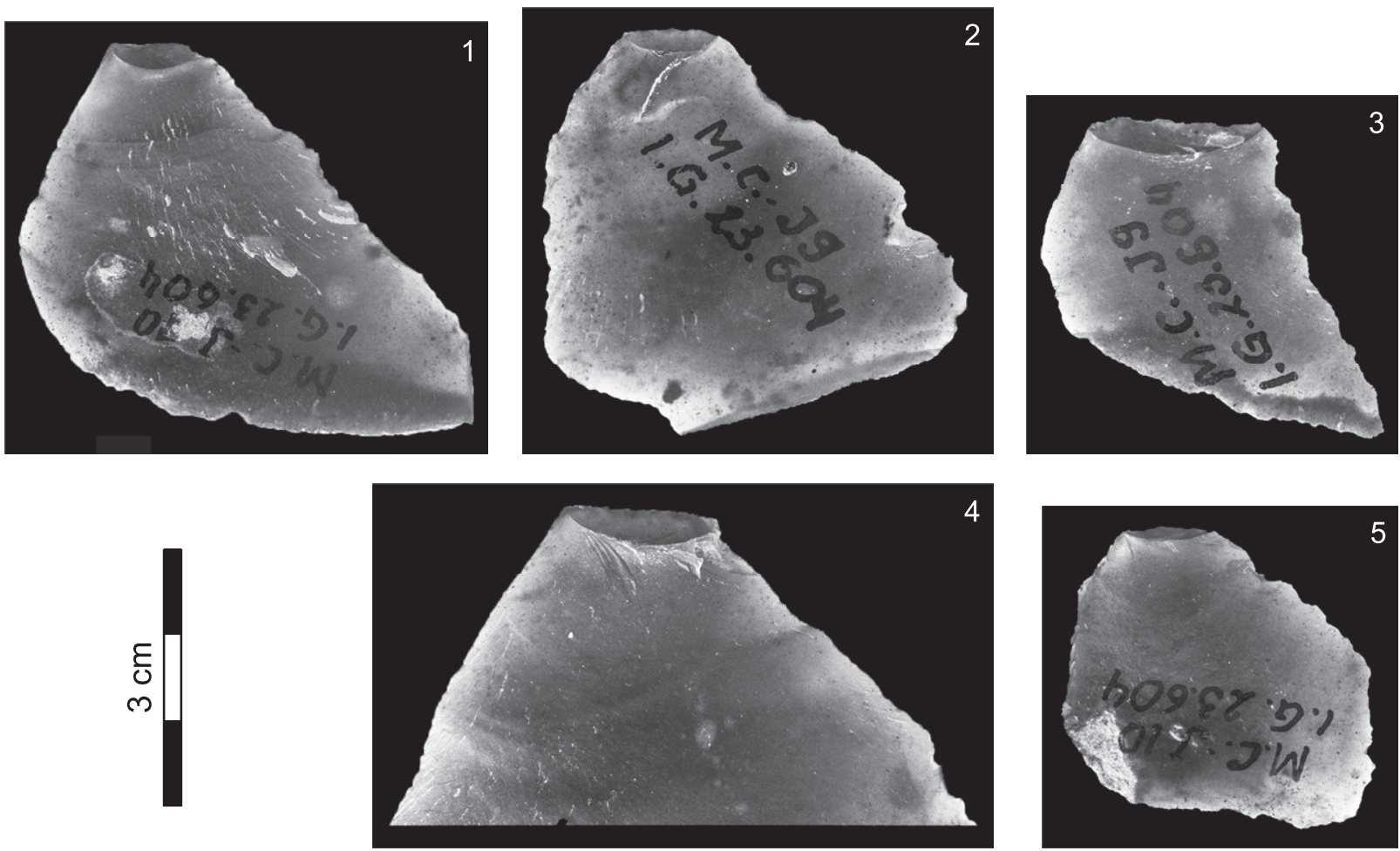

\section{Cas de percussion organique:}

- talon pluri-millimétrique

- lèvre marquée

- ligne postérieure du talon régulière

- pas de point d'impact visible

\section{Cas possible de percussion tendre minérale:}

- talon infra-millimétrique

- ligne postérieure du talon irrégulière

- point d'impact visible

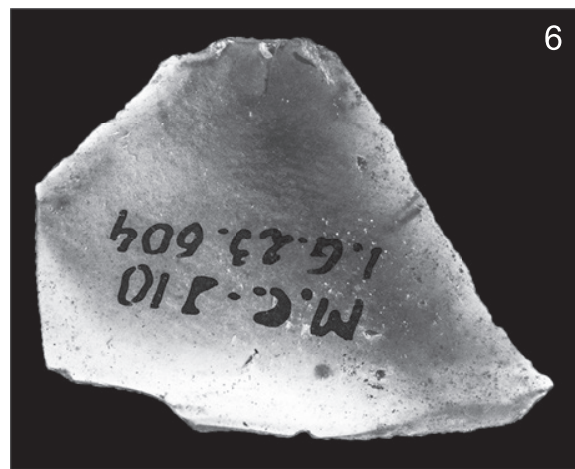

Fig. 20 - Techniques de percussion des éclats de façonnage.

Fig. 20 - Percussion techniques of shaping flakes.

du bulbe - autre critère considéré comme diagnostique de la percussion minérale tendre - peut également être obtenu en percussion organique directe au bois de cerf. Ainsi, il n'est donc pas exclu à ce stade que les quelques combinaisons de traces évoquant la percussion minérale tendre puissent en fait résulter d'une percussion organique, et, par suite, que la préparation des pointes lithiques ait été conduite uniquement au percuteur organique (en association avec un abraseur de nature vraisemblablement minérale).

\section{Accidents}

Des accidents surviennent parfois en cours de façonnage. Les rebroussés, pour peu qu'ils soient d'importance limitée, peuvent être effacés par de nouvelles retouches sans trop de difficulté. Lorsqu'il survient, ce type d'accident n'altère pas en tout cas les caractéristiques fonctionnelles des pointes, et il ne représente donc pas un problème majeur de ce point de vue. Tout au plus peut-il donc constituer une gêne pour la suite du façonnage. 


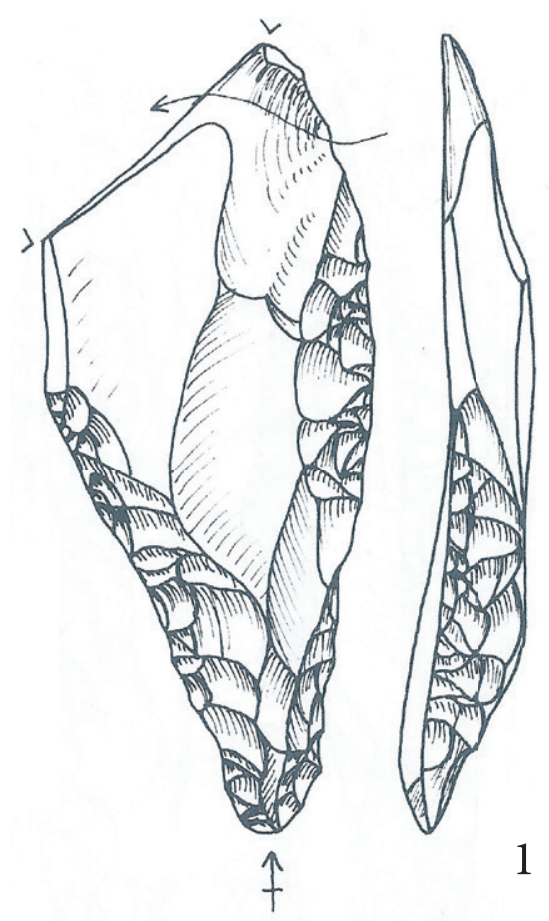

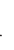
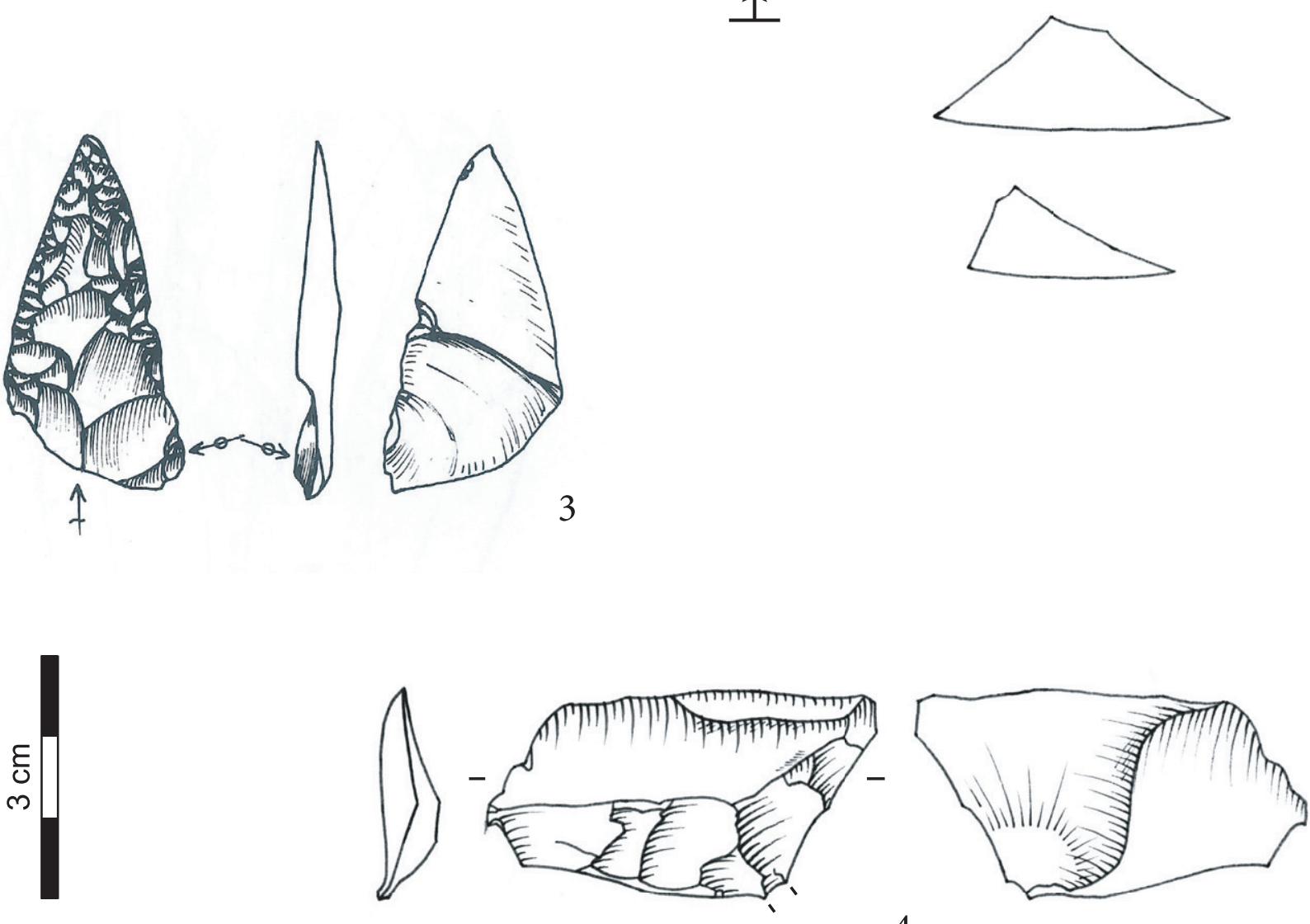
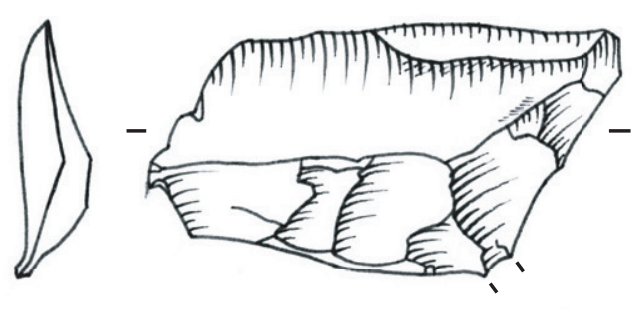

4

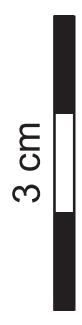

: outil pédonculé inacheve, 2 : pièce à cran (outil pédonculé inachevé ?)

3-4 : éclats de façonnage accidentellement outrepassés (1 et $3:$ M. Otte, 1979b ; 2 et $4:$ O. Touzé).

Fig. 21 - 1: unfinished tanged tool; 2: shouldered piece (unfinished tanged tool?);

3-4: accidentally overshot shaping flakes (1 and 3: M. Otte, 1979b; 2 and 4: O. Touzé). 
À l'inverse, l'outrepassement - cette fois entendu dans son sens premier, celui d'un accident involontaire (fig. 21, $\mathrm{n}^{\text {os }} 1,3$ et 4$)$ - s'avère rédhibitoire et entraîne l'abandon $\mathrm{du}$ support en cours de transformation (fig. 21, $\mathrm{n}^{\mathrm{o}} 1$ ). L'outrepassement provoque en effet une perte significative de matière qui s'avère difficile, sinon impossible à compenser, en particulier lorsque l'accident intervient au niveau de zones critiques de l'outil, comme l'apex (fig. 21, $\mathrm{n}^{\circ}$ 3). Si l'identification d'un outrepassement accidentel permet de diagnostiquer la présence de pointes inachevées, la reconnaissance de celles-ci n'est cependant pas toujours aisée. Ainsi, sans qu'il soit possible de le démontrer formellement, certains supports peu retouchés pourraient correspondre à des pointes abandonnées en cours de préparation (fig. $21, \mathrm{n}^{\circ} 2$ ).

\section{Préparation du pédoncule}

Le pédoncule est préparé par retouches directes, bien que quelques rares cas de retouches partiellement croisées soient également relevés $(n=4)$. En outre, parmi les trente-cinq individus complets et fragments proximomésiaux de pointes pédonculées, une retouche rasante inverse est observée en partie proximale dans douze cas. À l'instar des pointes de Maisières, cette retouche est pratiquée afin de régulariser la face inférieure du support, notamment en éliminant la convexité du bulbe. La mise en forme du pédoncule entraîne généralement la suppression du talon qui n'est préservé que sur cinq pointes pédonculées.

Lorsque les stigmates d'aménagement des pédoncules rencontrent (à hauteur des crans) ceux associés à la préparation des limbes, les premiers apparaissent toujours façonnés après les seconds (fig. 15). Cependant, la partie du support destinée à être configurée en pédoncule peut faire l'objet d'un façonnage couvrant préalable par retouches directes, s'inscrivant dans la continuité de la préparation du limbe. Cette option est adoptée quand le support sélectionné est trop large et trop épais pour que l'aménagement du pédoncule puisse être entrepris immédiatement par retouche abrupte. Dans ce cas de figure, l'angle de bord risquerait en effet d'atteindre trop tôt le seuil critique de $90^{\circ}$, empêchant alors une réduction suffisante de la largeur du support. La modification de la zone du pédoncule par retouches couvrantes permet donc de réduire progressivement la largeur du support, avant que la mise en forme finale du pédoncule soit ensuite réalisée par des retouches d'inclinaison plus abrupte (fig. 22).

Les pédoncules mesurent en moyenne $40,3 \mathrm{~mm}$ de long (pédoncules complets), 9,7 $\mathrm{mm}$ de large et 7,3 $\mathrm{mm}$ d'épaisseur. Les valeurs extrêmes sont quant à elles de 62 et $22 \mathrm{~mm}$ pour la longueur (pédoncules complets), 16 et $6 \mathrm{~mm}$ pour la largeur, et 12 et $3 \mathrm{~mm}$ pour l'épaisseur. Ces valeurs pointent une absence de standardisation dimensionnelle. Le taux approximatif de réduction de la largeur des supports par la préparation des pédoncules, ainsi que le rapport entre la longueur des supports et celle des pédoncules, peuvent être calculés par les formules suivantes ${ }^{4}$ :

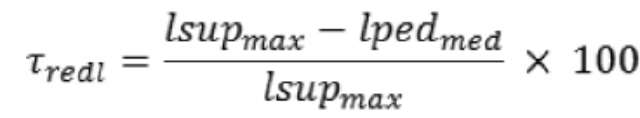

Où :

$\tau_{\text {redl }}=$ taux approximatif de réduction de la largeur

$l s u p_{\max }=$ largeur maximum du support

lped $_{\text {med }}=$ largeur au milieu du pédoncule

$R_{\text {Lped } / \text { Lsup }}=\frac{\text { Lped }}{\text { Lsup }} \times 100$

Où :

$R_{\text {Lped } / \text { Lsup }}=$ rapport longueur pédoncule/longueur support

Lped $=$ longueur du pédoncule

Lsup = longueur du support

Les résultats suggèrent que la largeur initiale des supports est en moyenne réduite des deux tiers (66\%) durant la préparation d'un pédoncule, avec un écart important cependant entre les taux minimal (44\%) et maximal (82\%). La hauteur du pédoncule, quant à elle, représente en moyenne la moitié de celle du support (48\%), avec des valeurs minimale et maximale situées respectivement au tiers (35\%) et aux deux tiers (63\%).

\section{Fonction(s) des pointes}

La remarquable qualité de conservation du matériel lithique à Maisières-Canal a favorisé la réalisation d'analyses fonctionnelles. Le rôle du pédoncule comme composant d'un dispositif d'emmanchement, rapidement soupçonné (Otte et Caspar, 1987), a ainsi été ultérieurement validé par l'identification de combinaisons de traces diagnostiques (Rots, 2002a). La fonction des pointes lithiques a été également approchée dans plusieurs travaux récents, et la présence d'éléments apicaux d'armes destinées à la chasse a pu être soulignée à partir de l'examen (le plus souvent macroscopique) de leurs fractures (Rots, 2002b, p. 540-541; Pesesse et Flas, 2012), combiné à l'analyse de certains caractères morpho-métriques et à une recherche expérimentale préliminaire (Milks, 2010 ; Milks et al., 2016). Si ces travaux s'opposent sur l'estimation de la proportion de pointes utilisées comme armatures, la reconnaissance de ces dernières vient cependant supporter les conclusions tirées au sujet des pointes de la Font-Robert du SudOuest français (Lansac, 2002). Il importe de relever par ailleurs qu'aucune étude microscopique systématique des traces d'impact n'a été publiée jusqu'à présent. Eu égard à l'importante variabilité morpho-dimensionnelle des pointes, d'autres fonctions ne sont toutefois pas à exclure, comme le confirme l'identification de deux 

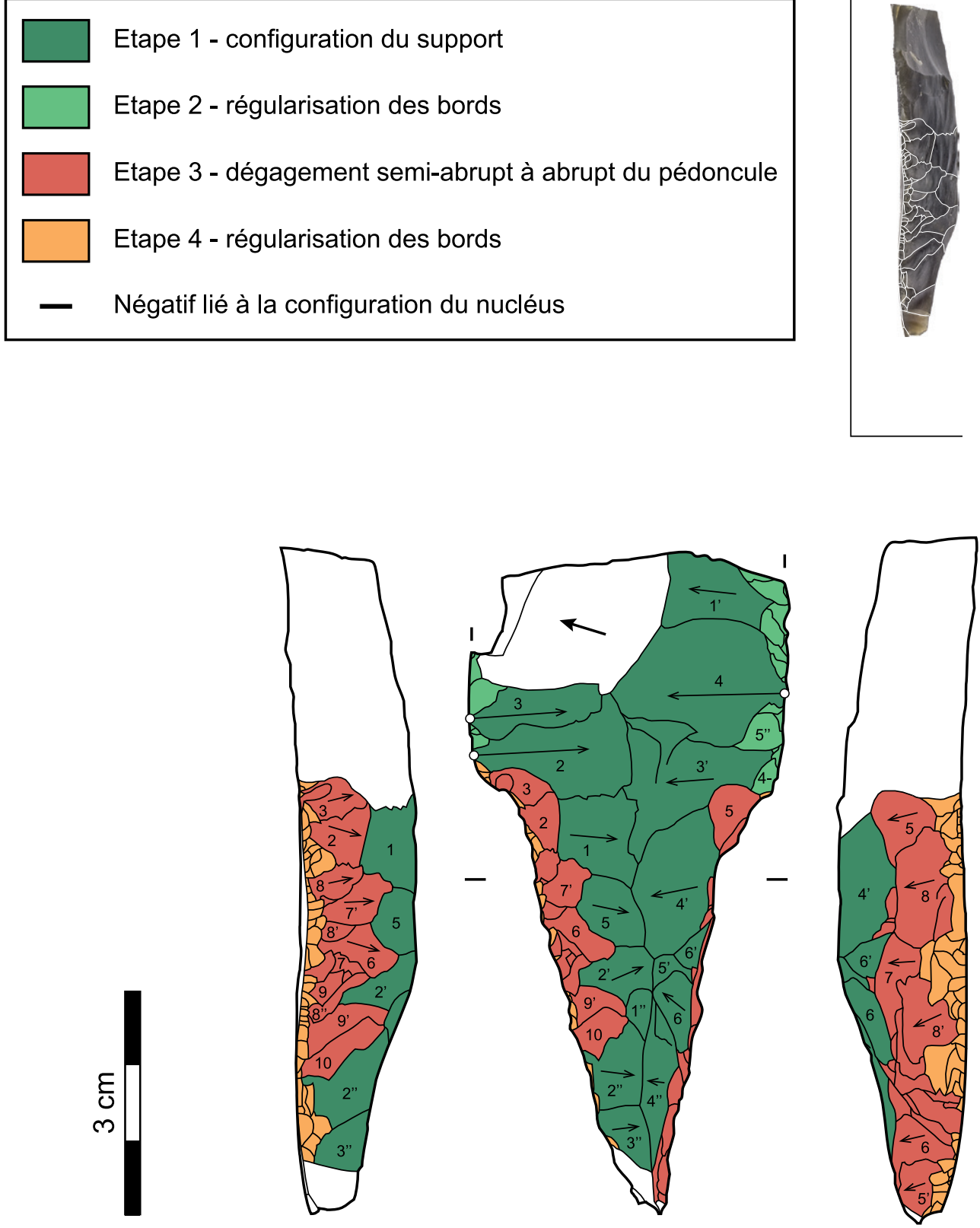

Fig. 22 - Fragment d'outil pédonculé avec retouches couvrantes sur le pédoncule.

Fig. 22 - Tanged tool fragment with invasive retouch on the tang.

couteaux de boucherie dans le groupe des pointes pédonculées (Rots, 2002b, p. 541).

\section{LE DÉBITAGE LAMINAIRE}

$\mathrm{D}$ ifférentes stratégies d'exploitation des nucléus laminaires ont été suivies. Bien que plusieurs éléments (état d'exploitation avancé de la plupart des nucléus, reconfiguration du volume, présence de débitages malhabiles ou improductifs) rendent délicate toute évaluation précise de leurs fréquences respectives, l'une de ces stratégies occupe une place très particulière et paraît commander l'essentiel des débitages les plus aboutis (fig. 23).

\section{Sélection des volumes}

Bien que la question de la morphologie des rognons collectés soit difficilement appréhendable compte tenu de l'état d'exploitation généralement avancé des nucléus, il semble que ceux-ci soit fréquemment de forme " globuleuse ", et d'aspect régulier avec des surfaces opposées subparallèles et présentant peu de relief. Dans certains cas néanmoins, des blocs présentant des concavités ou des convexités localement prononcées ont également été exploités. Parmi les rognons récoltés, certains présentent en outre des surfaces diaclasiques, et parfois des stigmates de gélifraction. Quant à la longueur des blocs, l'examen des nucléus conforte la limite établie à partir des lames : ceux-ci ne devaient pas excéder une quinzaine de centimètres (la hauteur maximale mesurée est de 15,1 cm). 


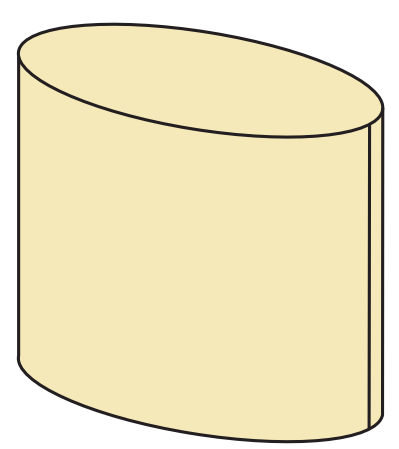

(1)

Sélection d'un bloc disposant de faces larges et étroites

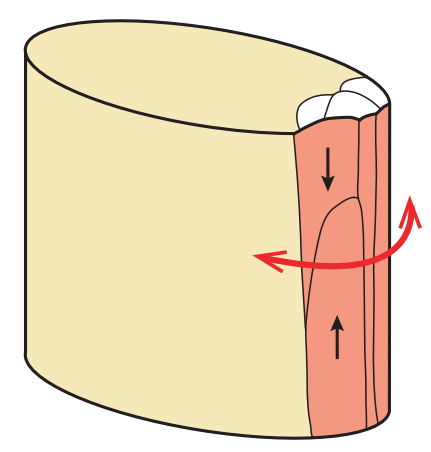

(4)

Séquence de débitage sur la face étroite et installation d'une nervure à la jonction face étroite/face large

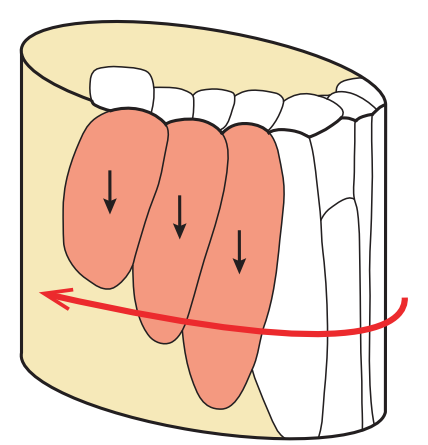

(7)

Investissement progressif de la face large au cours d'une séquence unipolaire

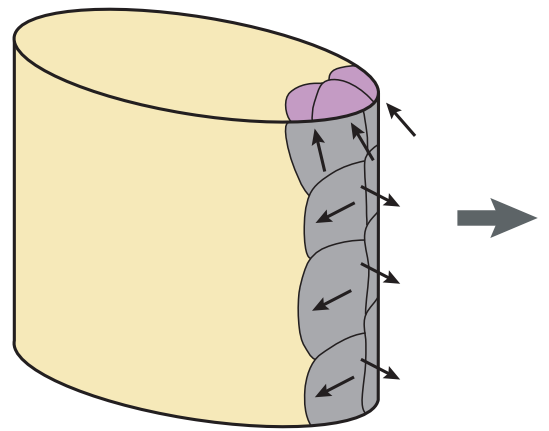

(2)

Installation d'une crête et d'un plan de frappe sur une face étroite

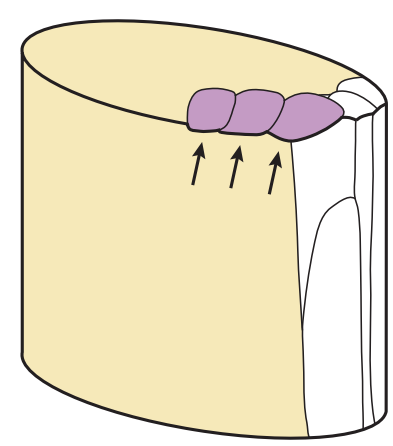

(5)

Réorientation d'un plan de frappe vers une face large

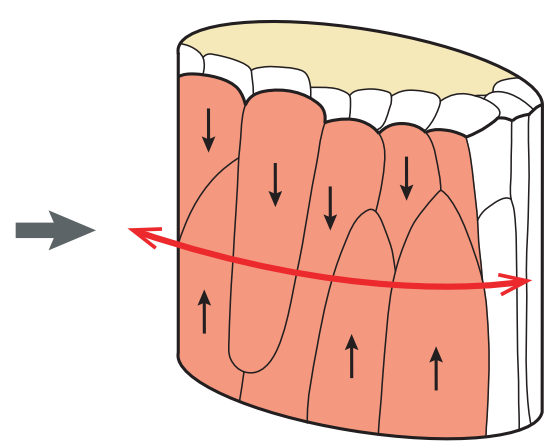

(8)

Débitage bipolaire sur la face large et réduction du volume par sa largeur
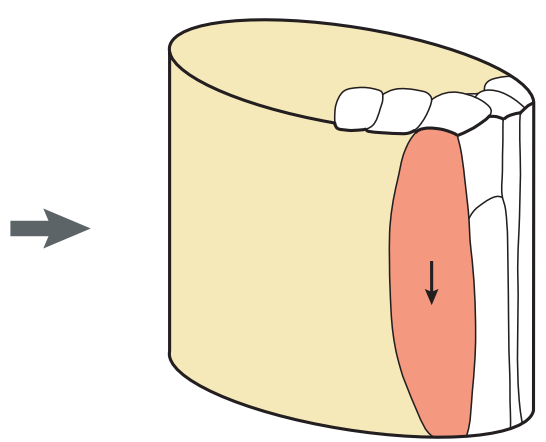

(6)

Débordement vers la face large

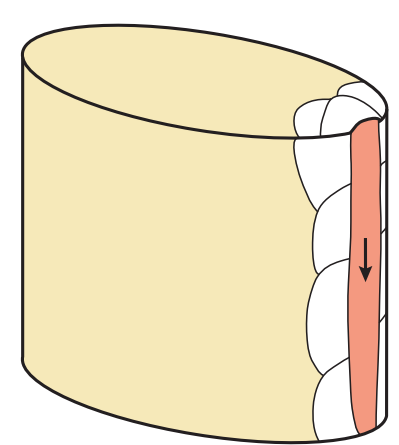

(3)

Entame du débitage par détachement de la crête

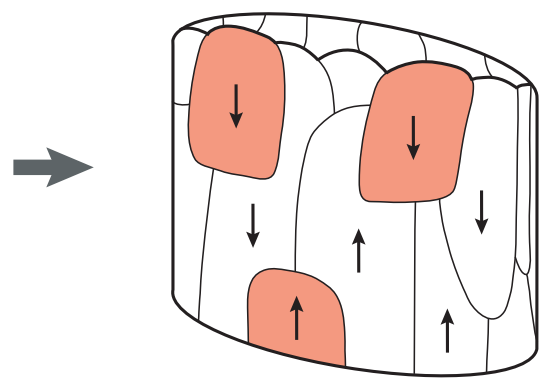

(9)

Arrêt du débitage suite à l'obtention d'éclats larges et rebroussés

Fig. 23 - Reconstitution du schéma opératoire laminaire

Fig. 23 - Reconstruction of the operative scheme for blade production. 


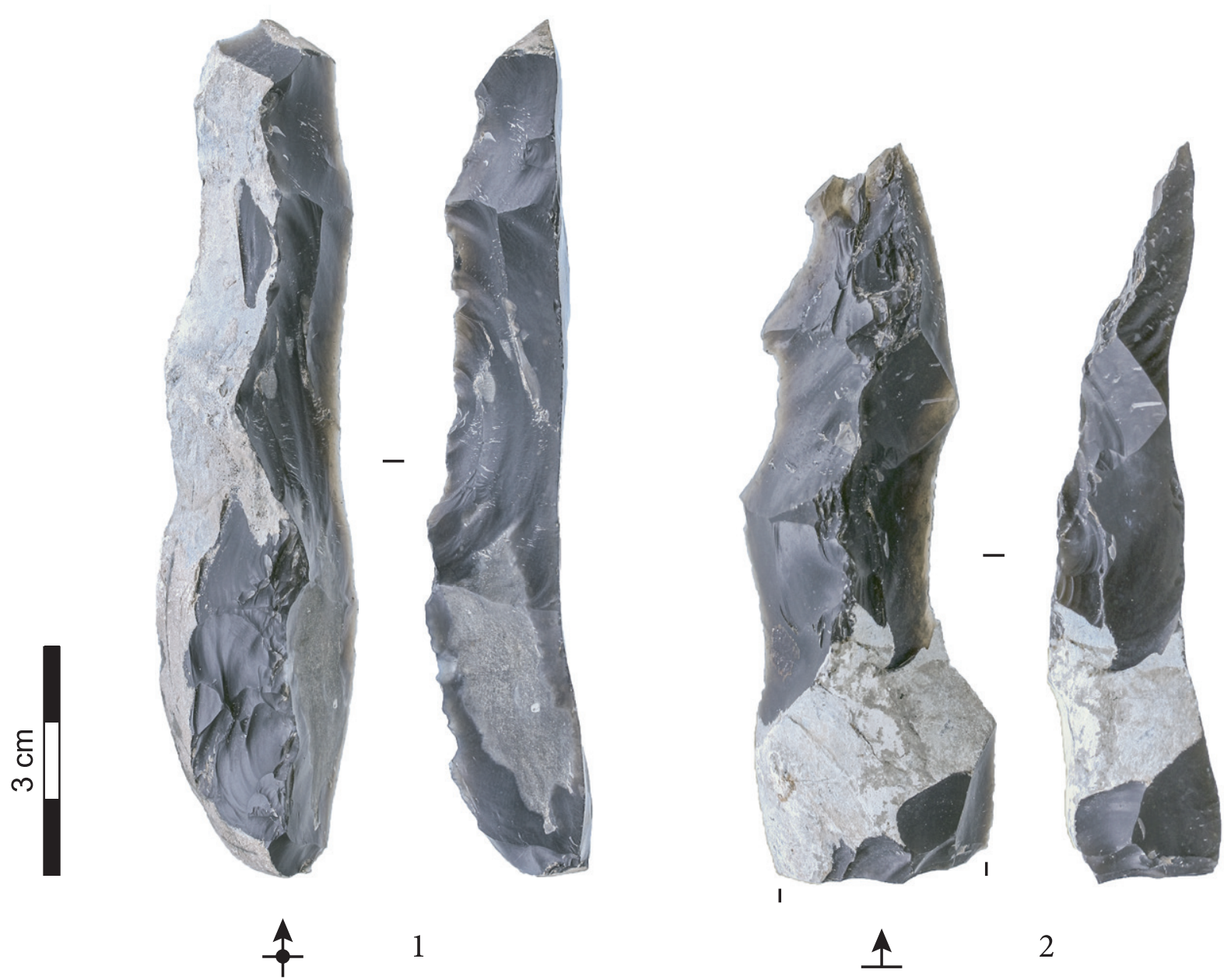

Fig. 24 - 1 : lame à crête ; 2 : entame mixte.

Fig. 24 - 1: crested blade; 2: partially crested blade.

\section{Préparation des blocs et initialisation}

La préparation des blocs est variable, mais demeure généralement partielle laissant ainsi subsister des plages corticales d'extension plus ou moins importante. Cette étape ne semble en tout cas jamais impliquer une mise en forme intégrale des volumes, ce qui peut s'expliquer par la sélection en amont de rognons plutôt réguliers ne nécessitant pas un lourd investissement à ce stade de la chaîne opératoire.

Sur les 91 nucléus examinés, douze ont été abandonnés à un stade précoce d'exploitation. Parmi ceux-ci, neuf présentent un dos entièrement ou partiellement cortical, et seuls deux ont fait l'objet d'une préparation par crête dorsale (un cas) et postéro-latérale (un cas). Sur sept d'entre eux, les vestiges d'une crête d'entame sont cependant toujours visibles, démontrant par-là que l'aménagement d'une crête antérieure est la solution généralement adoptée pour mettre le volume partiellement en forme, et entamer ensuite le débitage. Cette crête est installée sur une face étroite et cintrée du bloc, et le débitage débute ainsi de manière « frontale ». De fait, sur les dix-huit nucléus permettant de déterminer le positionnement de l'entame par rapport à la morphologie générale des blocs, quatorze montrent que le débitage est initié sur une face étroite. Dans un cas, l'entame a été détachée dans une zone intermédiaire entre une face étroite et une face large du nucléus, tandis que dans les trois cas restants l'entame a été extraite directement sur une face large. Cette dernière option a été toutefois appliquée à de petits blocs de longueur inférieure à $8 \mathrm{~cm}$, afin semble-t-il d'extraire rapidement les produits les plus larges possibles. Ces débitages se révèlent cependant improductifs, ne fournissant qu'un nombre très limité d'éclats plus ou moins allongés, voire quelques rares lames.

Sur les 913 lames brutes examinées, quarante-neuf lames à crête et quatre entames corticales ont pu être identifiées. Les premières possèdent deux versants le plus souvent ( $\mathrm{n}=29$; fig. $\left.24, \mathrm{n}^{\circ} 1\right)$, mais les crêtes à un seul versant sont également fréquentes $(n=20)$. Dans ce dernier cas de figure, la mise en place de la nervure-guide profite souvent de l'existence préalable d'une surface diaclasique relativement plane jouxtant une autre surface diaclasique ou corticale, et définissant naturellement ainsi une arête plus ou moins régulière. Les rognons présentant des faces étroites naturellement très cintrées, autorisent régulièrement le tailleur à n'opérer qu'une préparation limitée sous forme d'une crête partielle à un, ou à deux versants. En résulte l'obtention d'entames mixtes associant une plage corticale et une crête d'extension longitudinale variable (fig. 24, $\mathrm{n}^{\circ} 2$ ). 


\section{Progression du débitage}

Suite à l'extraction de l'entame sur une face étroite du nucléus, une première séquence laminaire est effectuée. Celle-ci peut être conduite à partir de deux plans de frappe opposés, ou bien à l'aide d'un seul plan de frappe, et fournit des supports relativement étroits. Le principal objectif de cette séquence réside dans l'implantation d'une nervure régulière à la jonction entre la face étroite exploitée, et l'une des faces les plus larges du nucléus. L'aménagement de cette nervure constitue l'un des critères déterminants pour le succès des opérations ultérieures, son rôle étant d'assurer l'extension de la surface de débitage vers cette dernière face. Afin de procéder à cette opération, une réorientation du plan de frappe s'avère cependant indispensable. En effet, à ce stade de la chaîne opératoire l'inclinaison du, ou des plans de frappe, est conçue de façon à permettre l'initialisation du débitage sur le petit côté du nucléus, et n'offre donc pas des conditions d'angle propres à permettre l'investissement d'une face adjacente. L'examen des nucléus témoignant de cette réorientation suggère que celle-ci implique le détachement d'une, ou de plusieurs petites tablettes partielles assez peu épaisses.

Une fois les conditions réunies, le débitage investitalors l'une des faces larges du nucléus selon une progression dissymétrique (Valentin et al., 2014) impliquant le détachement successif de produits laminaires jusqu'à la seconde face étroite du bloc restée jusque-là inexploitée (fig. 25 et 26). Les nucléus faisant généralement l'objet d'une préparation limitée, les premiers produits laminaires détachés sur la face large doivent présenter des plages corticales étendues. Ces produits fournissent une première série de supports larges, et installent conjointement les nervures indispensables à la poursuite du débitage. D'après les quelques indications fournies sur ce point par les nucléus, il semble que les premiers temps de l'exploitation de la face large ne mobilisent qu'un seul plan de frappe.

\section{Gestion du débitage}

Suite à l'implantation de la table sur une face large, une gestion bipolaire est rapidement mise en place et le débitage est maintenu sur cette face jusqu'à l'abandon du nucléus. La largeur de table dont dispose alors le tailleur permet d'assurer l'extraction de supports laminaires larges grâce à l'étalement latéral des ondes de fracture (fig. 27). La gestion bipolaire, quant à elle, permet tout à la fois de contrôler l'évolution de la carène, et de faciliter le nettoyage des accidents pouvant obstruer la table. Les plans de frappe ne sont généralement pas hiérarchisés, bien que certaines séquences de débitage puissent impliquer une nette dissociation des rôles joués par chacun d'entre eux. Ces séquences sont alors à mettre en relation avec l'obtention de produits de première intention hautement prédéterminés. Les enlèvements laminaires sortent au-delà du milieu de la table sans pour autant filer jusqu'à son extrémité, ce qui, en complément de l'usage alternant des plans de frappe, permet de conserver une carène peu marquée en évitant la création progressive d'une convexité en milieu de table. Conjointement avec leur faible cintrage, cette caractéristique des tables laminaires favorise l'obtention de lames très peu arquées et d'épaisseur modérée.

L'exploitation de surfaces larges dont le cintre peu prononcé diminue très rapidement au fil de la production laminaire implique un surcroît de contrainte en termes de gestion des convexités. Disposer d'un cintre suffisant pour garantir la récurrence du débitage représente ainsi la principale difficulté de la production laminaire, laquelle peut fréquemment livrer des éclats larges, plus ou moins courts, et parfois rebroussés (fig. 27, no 3 ). Ces derniers peuvent être cependant interprétés comme des sous-produits, car ils ne constituent pas un objectif de la production. Ils caractérisent d'ailleurs bien souvent la fin du débitage des nucléus parvenus à un stade avancé d'exploitation. L'entretien du cintre est réalisé en limite de table, c'est-à-dire au niveau de la jonction entre cette dernière et les faces étroites du nucléus, au moyen de lames débordant sur les flancs (fig. 28). Le détachement de ces lames peut être précédé par la mise en place d'une néo-crête impliquant un simple ajustement de nervure, ou bien une reconfiguration significative de la jonction table/ flanc. Dans la plupart des cas, l'implantation d'une néocrête affecte la partie proximale des supports à détacher ( $\mathrm{n}=94$ sur 131 néo-crêtes examinées, dont trente-deux néo-crêtes proximales, trente-trois néo-crêtes proximomésiales, et vingt-neuf néo-crêtes intégrales), ce qui peut s'expliquer par la nécessité de définir précisément la zone devant être percutée. Cet aspect est bien illustré par ailleurs par un petit groupe de lames néo-crêtes ( $\mathrm{n}=6$; fig. 29) qui témoigne de l'emploi d'un procédé s'apparentant au « facettage latéralisé oblique » reconnu dans le Rayssien (Klaric, 2003). Ce procédé consiste à déplacer de quelques millimètres vers le centre de la table la zone opérant la jonction entre le plan de frappe, la table et l'un des flancs. Son usage est en outre souvent concomitant d'un surcreusement latéral du plan de frappe visant à faire saillir la zone à percuter. Bien que limité, l'emploi du facettage latéralisé oblique suggère que les opérations de recintrage font l'objet d'une attention particulière.

\section{Abandon des nucléus}

La fin du débitage est bien souvent décidée après l'obtention en série d'éclats rebroussés, et plus généralement de produits non désirés correspondants à des éclats larges et plus ou moins allongés. En raison des convexités souvent réduites de la table, le nettoyage de rebroussés peut exiger des opérations dispendieuses en matière première qui peuvent justifier un abandon plus ou moins prématuré du nucléus. De fait, les nucléus parvenus à exhaustion sont rares. Parce que le débitage progresse dans la largeur, et non pas dans l'épaisseur du bloc, les nucléus abandonnés à un stade avancé d'exploitation se caractérisent par une section large et aplatie (fig. 30). 

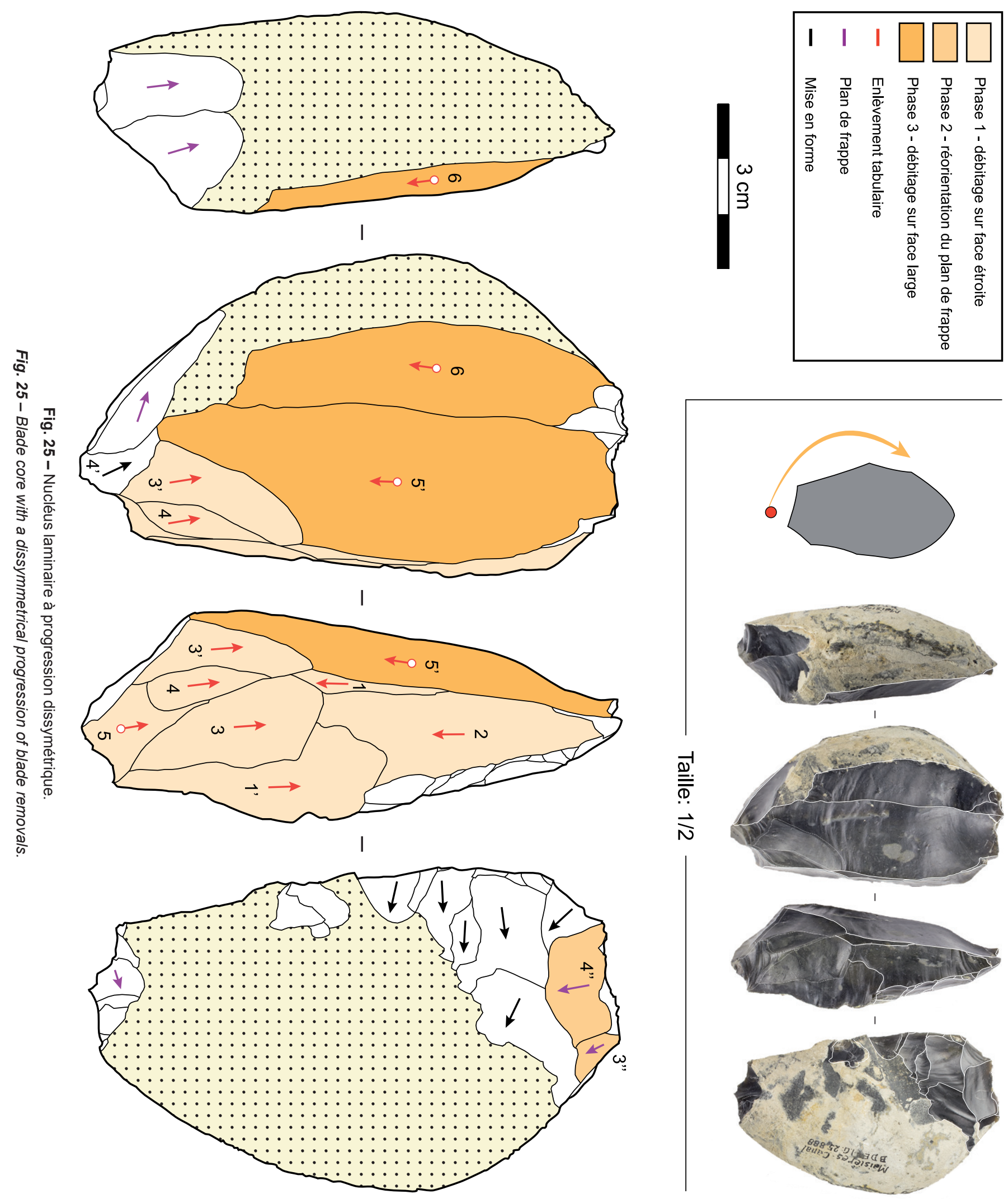

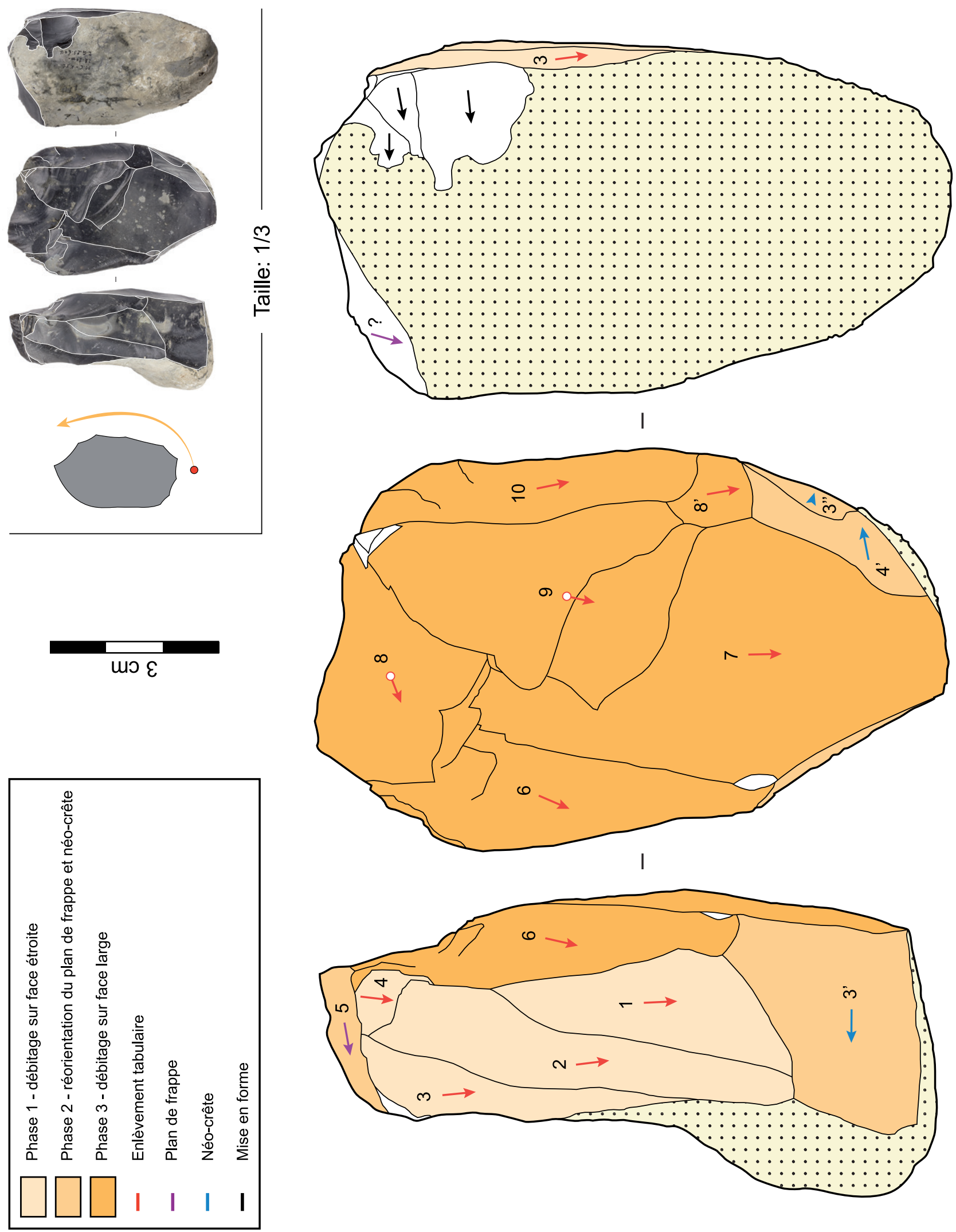

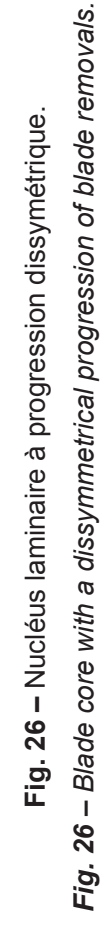



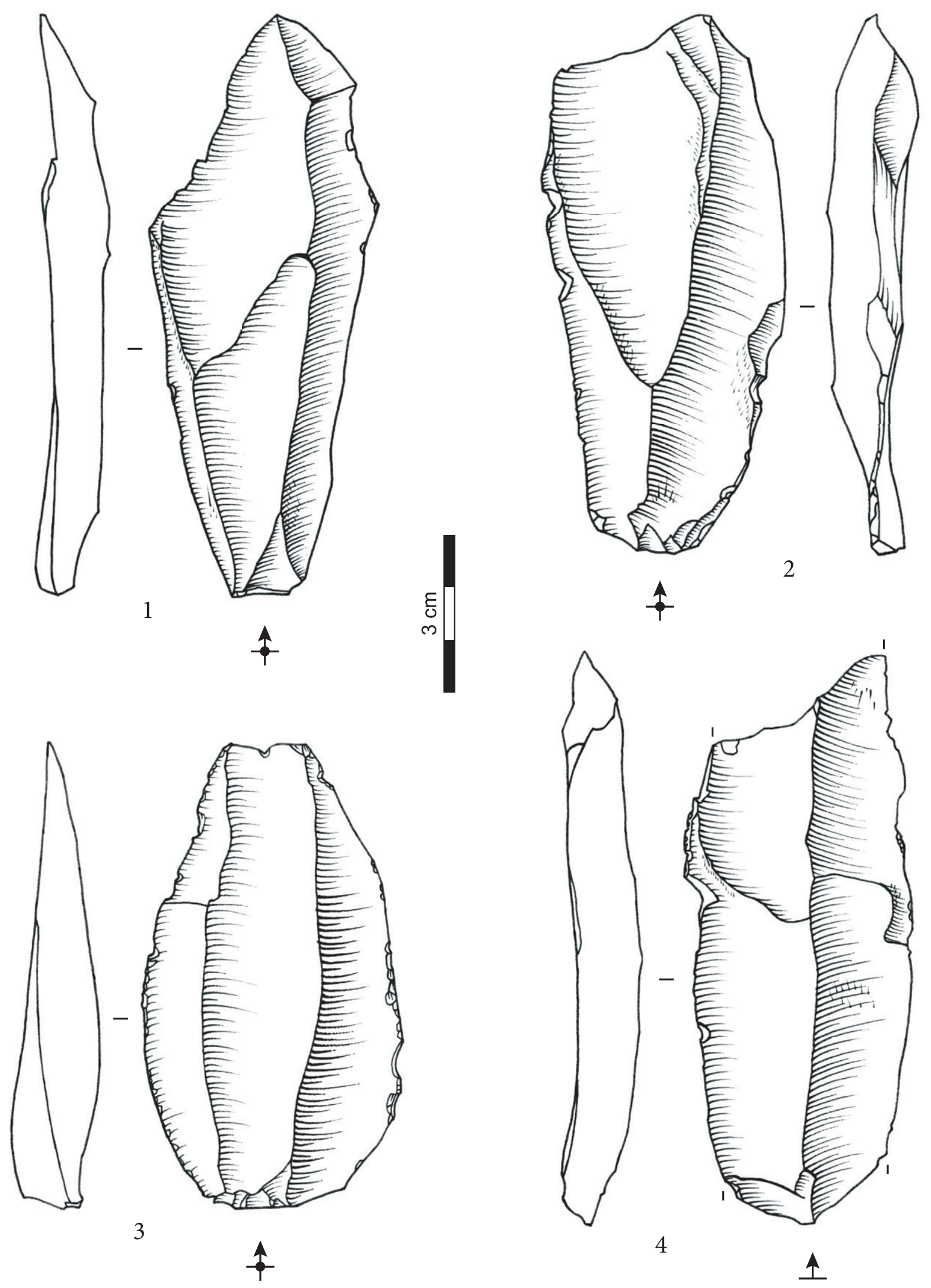

Fig. 27 - 1-2 et 4 : lames ; 3 : éclat issu d'un plein débitage laminaire.

Fig. 27 - 1-2 and 4: blades; 3: flake detached during a blade production sequence. 

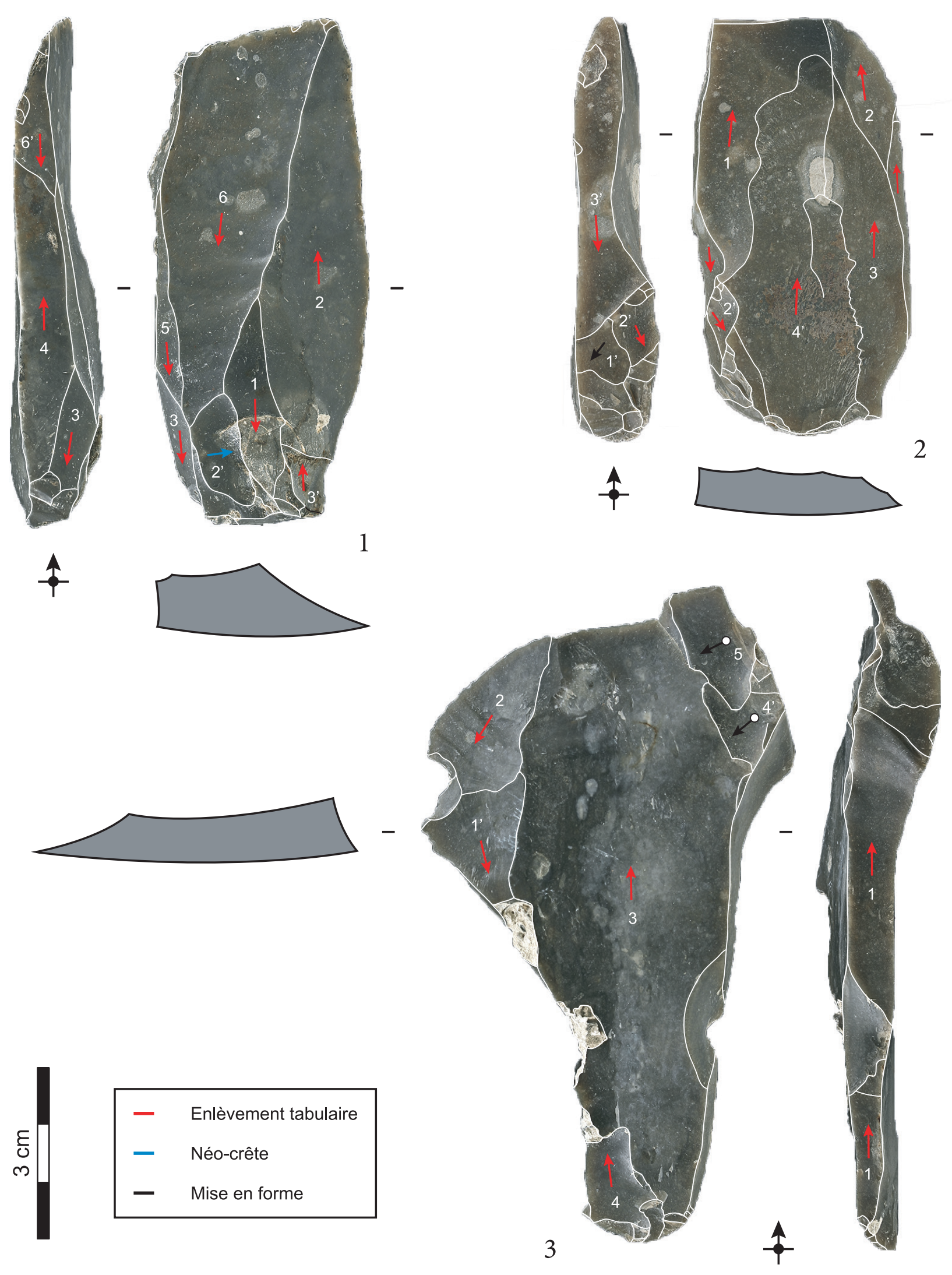

Fig. 28 - Lames débordantes.

Fig. 28 - Lateral blades. 


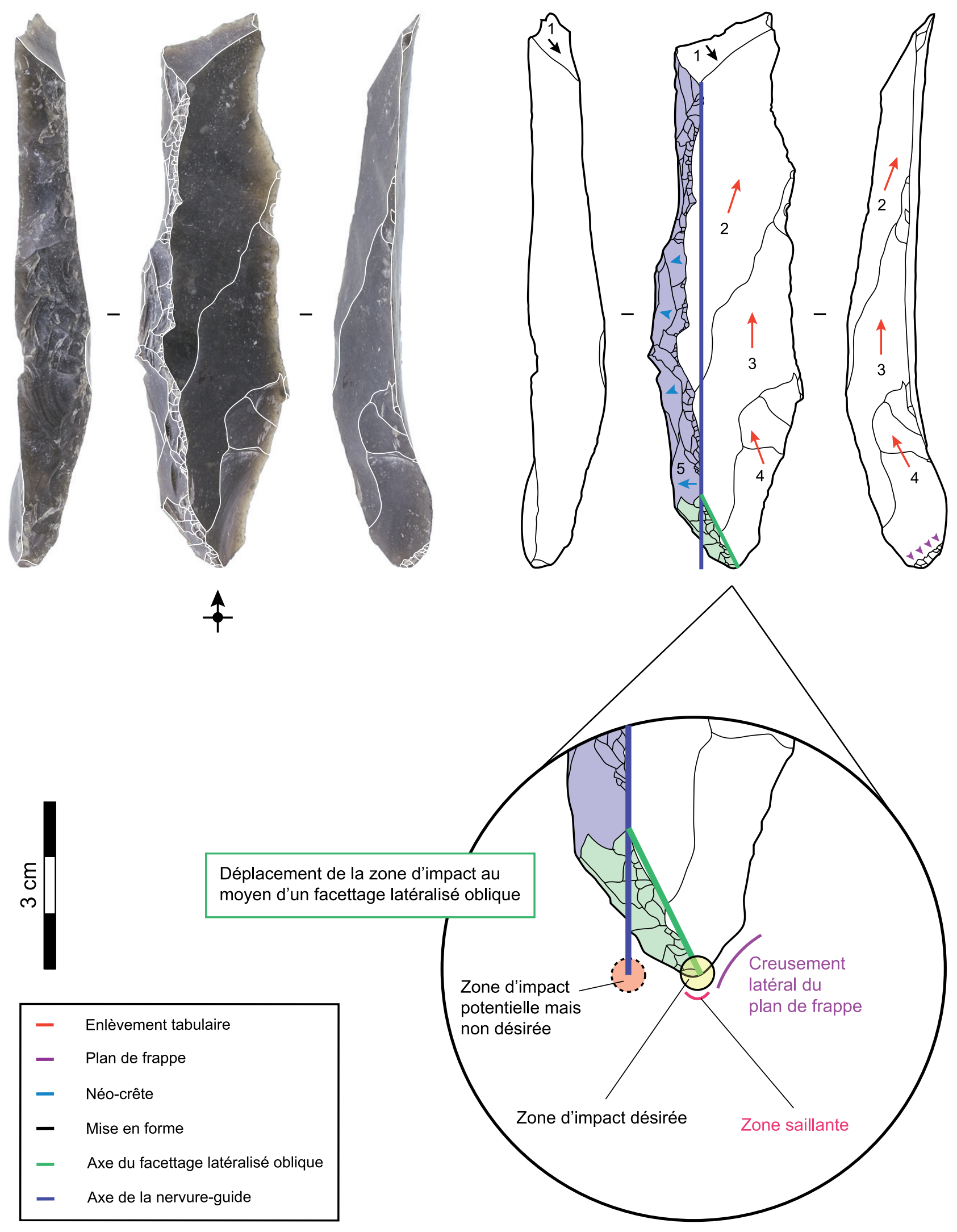

Fig. 29 - Lame néo-crête à facettage latéralisé oblique.

Fig. 29 - Neo-crested blade with oblique lateral faceting. 

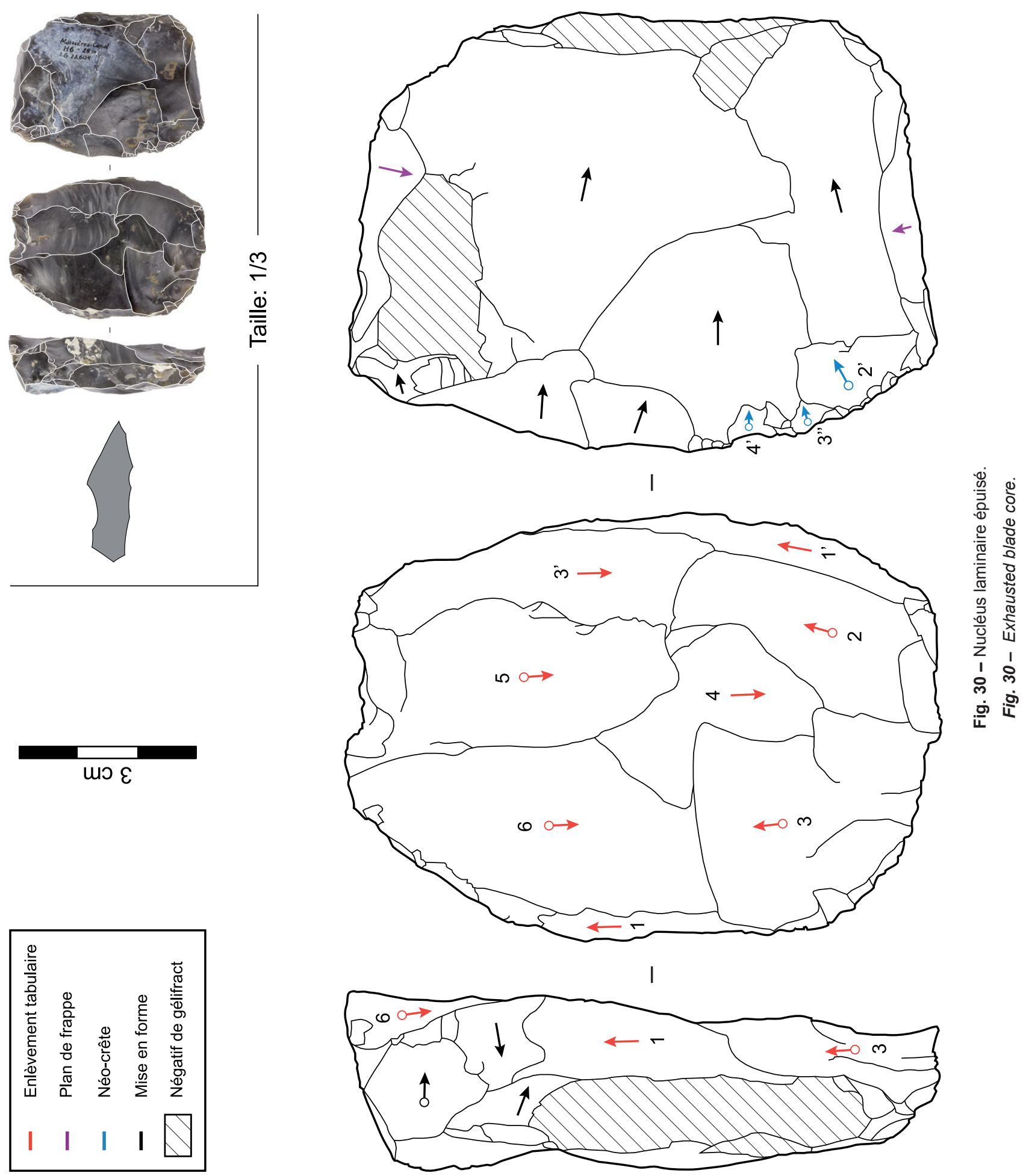

Le dos présente des négatifs transversaux par rapport à l'axe longitudinal de la table correspondants à l'un des versants de la crête d'entame, ou à une reprise de ce même versant par une néo-crête. La position de ce versant est une conséquence directe de la progression dissymétrique du débitage en début de chaîne opératoire.

\section{Modalités de percussion}

Les modalités de percussion ont été caractérisées à partir d'un échantillon de $10 \%$ des lames et lamelles dont l'extrémité proximale est conservée. Nous avons ainsi procédé à l'analyse de 285 pièces sur les 2844 produits lamino-lamellaires concernés d'après les décomptes disponibles (De Heinzelin, 1973a, p. 16 ; Otte, 1979b, p. 532 ; tabl. 4).

L'examen des talons fait ressortir une nette domination des talons lisses $(56,8 \%)$, puis des talons facettés $(24,9 \%)$. Ces deux morphologies représentent plus de quatre talons observés sur cinq, résultat qui s'accorde bien avec la morphologie des plans de frappe des nucléus : sur 158 plans de frappe observés, 102 sont lisses, seize entièrement facettés, et vingt-six partiellement facettés 


\begin{tabular}{|l|c|c|c|c|}
\hline \multicolumn{1}{|c|}{ Collections } & Produits entiers & Fragments proximaux & Total & Sources \\
\hline IRSNB & 1674 & 789 & 2463 & de Heinzelin, 1973, p. 16 \\
\hline Bois d'Enghien & 293 & 88 & 381 & Otte, 1979b, p. 532 \\
\hline Total & 1967 & 877 & 2844 & \multicolumn{1}{|c}{} \\
\cline { 1 - 4 } & & & \multicolumn{2}{|c|}{}
\end{tabular}

Tabl. 4 - Décompte des pièces entières et des fragments proximaux parmi les produits lamino-lamellaires.

Table 4 - Count of intact pieces and proximal fragments among blades and bladelets.

ou lisses. Préalablement à la percussion, le bord du plan de frappe fait généralement l'objet d'une préparation par abrasion, le plus souvent dirigée vers la table $(\mathrm{n}=88$ sur 185 cas déterminables, soit 47,6\%) et rarement poussée jusqu'au « doucissage » $(\mathrm{n}=9)$. Les cas de préparations effectuées en direction du plan de frappe sont fréquents également, et consistent généralement en un facettage. Cinquante-huit talons ne présentent aucune trace de préparation, ce phénomène étant en bonne partie lié à des percussions effectuées en retrait du bord du plan de frappe.

La détermination des techniques de percussion a été conduite selon les critères définis par J. Pelegrin (2000), en considérant comme diagnostiques les talons combinant au moins deux critères évocateurs d'une même technique. Les 285 talons observés ont permis de diagnostiquer un usage quasi-exclusif de percuteurs de pierre. Si la percussion tendre minérale se révèle nettement majoritaire avec $42,1 \%$ des talons observés (fig. 31, $\mathrm{n}^{\circ} 1-4$ ), la percussion dure s'avère elle aussi très bien représentée avec une fréquence de 29,5\% (fig. $31, \mathrm{n}^{\text {os }} 5-6$ ). La fréquence élevée de cette dernière technique peut contribuer à expliquer la relative épaisseur de certains supports de pointes dans la mesure où son emploi nécessite une zone de contact située en retrait du bord du plan de frappe. Sur ce point, soulignons que la double reconnaissance de la percussion tendre minérale et de la percussion dure ne sous-entend pas forcément le recours à des outils différents. Nous formulons en effet l'hypothèse que l'identification de ces techniques est probablement la résultante de l'application des deux versions d'emploi possibles d'un percuteur de pierre tendre telles que décrites par J. Pelegrin. L'une d'elles consiste en effet à percuter « en profondeur du plan de frappe pour des enlèvements relativement épais », et génère des « stigmates [...] similaires à ceux de la percussion à la pierre dure »(Pelegrin, 2000, p. 77). Ainsi, la reconnaissance de la percussion dure dans le débitage laminaire à Maisières-Canal est peut-être moins la conséquence de l'emploi d'un percuteur de pierre dure que de variations dans les modalités d'utilisation de percuteurs de pierre tendre.

Quoiqu'il en soit, percussion tendre minérale et percussion dure couvrent plus de $70 \%$ des talons déterminés, et pratiquement la totalité des talons combinant au moins deux critères évocateurs. L'emploi de la percussion organique est quant à lui rarissime. Les quelques cas recensés pourraient toutefois résulter de la capacité de la percussion tendre minérale à produire des associations de stigmates évoquant cette technique, fait qui a été récemment relevé dans le cas de l'utilisation d'une roche très tendre (Biard et Prost, 2015). Ces observations confirment un diagnostic antérieur sans donnée chiffrée qui soulignait la prégnance de la percussion tendre minérale et de la percussion dure (Pesesse et Flas, 2012, p. 97). Le recours à un percuteur minéral tranche avec la percussion organique mobilisée pour le façonnage des pointes lithiques. Au-delà des évidentes différences en termes d'objectifs techniques, de schémas opératoires, et de temporalité dissociant la phase de production des supports laminaires, et celle de confection des pointes, la césure entre ces deux composantes du système technique lithique s'exprime donc aussi du point de vue des outils manipulés, et par conséquent des techniques mises en œuvre.

\section{CONCLUSION}

$\mathrm{L}$ e réexamen de l'industrie de Maisières-Canal a permis de définir un schéma opératoire laminaire particulier. À la suite d'une phase d'initialisation réalisée sur le petit côté du nucléus, le débitage progresse de manière dissymétrique vers une face large adjacente. Le caractère « surfacique », et non « frontal » de ce schéma a conduit plusieurs auteurs à envisager l'existence de nucléus Levallois (De Heinzelin, 1973a ; Otte, 1979b). Les éléments présentés ici renvoient cependant à un schéma laminaire sans rapport avec le débitage Levallois avec lequel il ne partage tout au plus que le caractère « surfacique ». Fin observateur, J. De Heinzelin relevait d'ailleurs avec pertinence que l'industrie ne comporte « aucun nucléus [levallois] à éclat ou à pointe qui soit vraiment typique » (De Heinzelin, 1973a, p. 17). Les lames, quant à elles, sont détachées à l'aide d'un percuteur minéral, et sont notamment transformées en pointes dont les types principaux sont les pointes de Maisières et les pointes pédonculées. La confection de ces pointes met en œuvre une véritable méthode procédant par enlèvements rasants directs détachés au percuteur organique, et impliquant une succession d'étapes opératoires spécifiques. Cette méthode est appliquée à différents degrés selon l'adéquation entre les caractéristiques de départ du support brut, et celles de l'outil recherché. La transformation peut ainsi être minime ou intégrale, auquel cas l'emploi de cette méthode s'inscrit dans une logique de façonnage du support.

La méthode de préparation des pointes lithiques constitue un marqueur fort de l'industrie de MaisièresCanal qui permet de soutenir un certain nombre de rapprochements proposés avec des pointes (pédonculées 

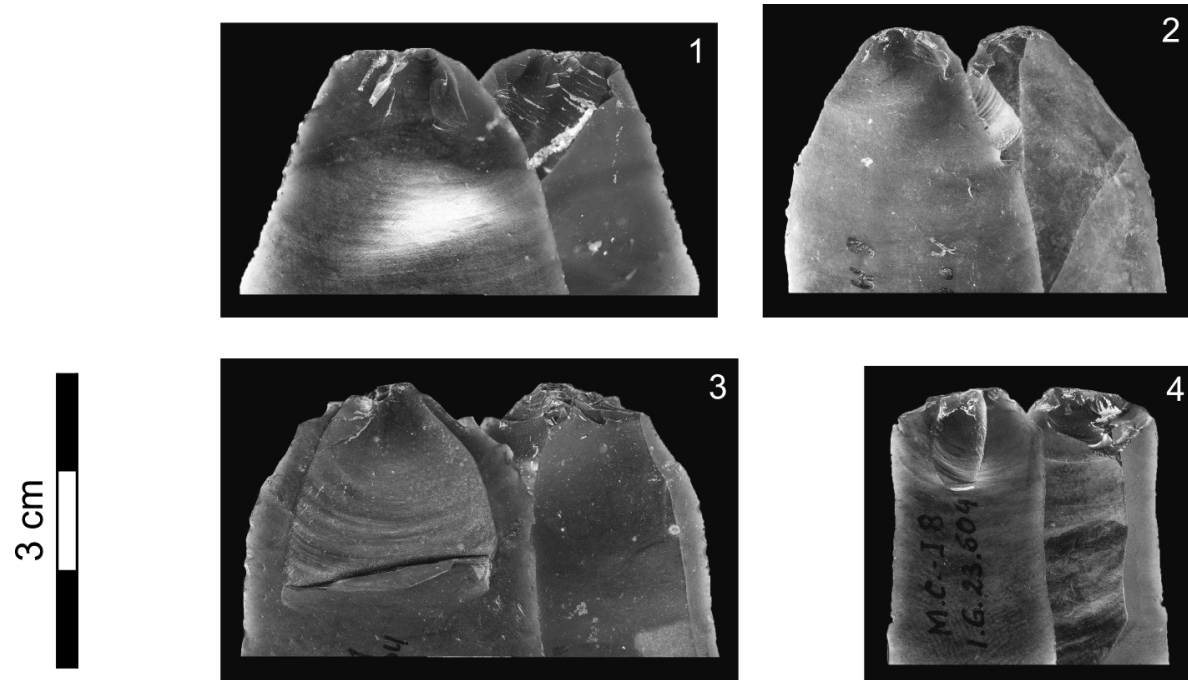

\section{Cas de percussion tendre minérale:}

- talon millimétrique à infra-millimétrique

- point d'impact visible et détouré

- ligne postérieure du talon peu régulière

- lèvre absente

- abrasion de la corniche

- esquillement du bulbe occasionnel
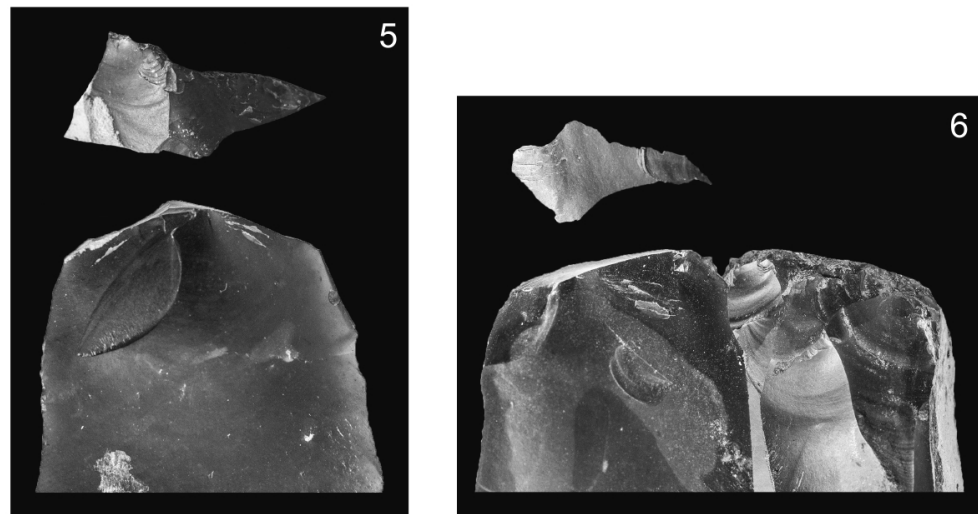

\section{Cas de percussion dure:}

- talon épais (percussion en retrait du bord du plan de frappe) - point d'impact visible, détouré, et débordant nettement de la ligne postérieure du talon

Fig. 31 - Techniques de percussion des produits laminaires.

Fig. 31 - Percussion techniques of blades.

dans la grande majorité des cas) découvertes ailleurs en Belgique, mais aussi en Grande-Bretagne, dans la moitié nord de la France, et au Luxembourg, dans des contextes malheureusement très mal documentés (Schmider, 1971 ; De Heinzelin, 1973a ; Otte, 1979b ; Campbell, 1980 ; Jacobi, 1980 ; Ziesaire, 1986 ; Touzé, Coppe et al., 2016). De fait, ces pointes ne sont jamais associées à des ensembles archéologiques pouvant être considérés clos et homogènes, aussi seule la documentation de Maisières-Canal autorise actuellement une description du schéma de production des supports servant à la confection de ces pointes. Le schéma laminaire de Maisières-Canal apparaît néanmoins très singulier parmi les industries rapportées aux phases anciennes du Gravettien en France (Digan, 2008 ; Pesesse, 
2008a ; Floss et Taller, 2011 ; Surmely et al., 2011) et en Belgique (Touzé, Flas et al., 2016). En Europe centrale, la présence récurrente de nucléus à table large dans le Gravettien ancien mérite d'être signalée, mais plusieurs éléments empêchent cependant tout rapprochement avec l'industrie de Maisières. Les industries d'Europe centrale se caractérisent en effet par l'exploitation de rognons globuleux de petites dimensions induisant le plus souvent une entame sur face large, une gestion principalement unipolaire du débitage associée à une progression « frontale » ou « semi-tournante », la production intégrée de lames et de lamelles, l'usage de la percussion organique (couplé à celui de la percussion tendre minérale), et l'absence de la percussion dure (Moreau, 2010, 2012b et comm. pers.). Autant d'aspects pointant des différences significatives avec Maisières-Canal.

À partir des données obtenues sur la production des pointes lithiques, et sur le débitage laminaire, le système technique lithique représenté sur ce site paraît donc témoigner d'une véritable originalité dans le paysage des premières industries gravettiennes. Cette constatation, et la datation de l'occupation vers 28000 BP, soit aux prémices du Gravettien pour le Nord-Ouest européen, soulèvent la question des trajectoires suivies par les systèmes techniques depuis la fin de l'Aurignacien jusqu'au (supposé) plein développement du Gravettien. D'après les données du Sud-Ouest français, où des industries particulières s'inscrivant dans cette période charnière ont été également reconnues (complexe à pointes de Font-Yves, Bayacien ; Pesesse, 2008a, 2008b, 2009-2010 et 2010), il semble que ces trajectoires aient été manifestement plurielles. Si ces dernières ont comme dénominateur commun le développement de nouveaux types de pointes lithiques (dont au moins une partie a servi d'armatures), la grande diversité des formes produites (pointes pédonculées, pointes de Maisières, pointes de Font-Yves, fléchettes, pointes à dos alternes, pointes de la Gravette...) est remarquable. L'examen approfondi de ce phénomène, et de ses diverses implications par rapport aux registres d'activité impliqués, représente de ce fait un axe de recherche privilégié susceptible d'affiner notre compréhension des dynamiques qui ont animé les sociétés de chasseurs en Europe autour de 29000-28000 BP.
Remerciements : Mes remerciements s'adressent tout d'abord à Ivan Jadin et à l'ensemble du département Anthropologie \& Préhistoire de l'Institut royal des Sciences naturelles de Belgique, ainsi qu'à Nick Ashton et Cécile Jungels pour l'accès aux collections. Je remercie également Justin Coppe, Damien Flas, Damien Pesesse, Antonin Tomasso, et les deux relecteurs anonymes pour leurs très utiles commentaires sur une version antérieure de l'article, ainsi que Rob Dinnis et Noora Taipale pour les corrections du résumé et des légendes en Anglais. Bien entendu, toute erreur ou omission demeure de ma seule responsabilité. Un merci supplémentaire à Rob Dinnis pour son aide au British Museum. Merci aussi à Luc Moreau pour les précisions sur le débitage gravettien ancien d'Europe centrale. Enfin, un merci chaleureux à Justin Coppe et à Noora Taipale pour les échanges fructueux.

\section{NOTES}

(1) Considérant l'existence de différences manifestes entre les modes de préparation des pointes pédonculées de Maisières-Canal et celles des sites classiques du Sud-Ouest français, nous préférons restreindre pour le moment l'emploi du qualificatif " Font-Robert» aux secondes, dans l'attente d'une réévaluation globale de la diversité des pointes pédonculées gravettiennes. Nous rejoignons ainsi d'autres auteurs qui ont également préféré ne pas associer le terme « Font-Robert » à l'industrie de Maisières-Canal (Otte, 1979b ; Pesesse et Flas, 2012).

(2) Ce choix classificatoire ne présume cependant en rien d'une éventuelle différence fonctionnelle avec les pointes de Maisières.

(3) Le talon des éclats de retouche correspond à une portion de la face inférieure du support : il s'agit donc d'un «pan du "revers-support” » (Le Mignot, 2000), ou « pan-revers » (Le Mignot, 1998, cité dans : Klaric, 2003, p. 45).

(4) Le calcul du taux de réduction de la largeur du support est inspiré de la formule proposée par L. Klaric au sujet des pointes de la Gravette (Klaric, 2003, p. 323-324).

\section{RÉFÉRENCES BIBLIOGRAPHIQUES}

Antoine P., Goval É., Jamet G., Coutard S., Moine O., Hérisson D., Auguste P., Guérin G., Lagroix F., Schmidt E., Robert V., Debenham N., Meszner S., BAHAIN J.-J. (2014) - Les séquences loessiques pléistocène supérieur d'Havrincourt (Pas-de-Calais, France) : stratigraphie, paléoenvironnements, géochronologie et occupations paléolithiques, Quaternaire, 25, 4, p. 321-368.

Aubry T., Bradley B., Almeida M., Walter B., João Neves M., Pelegrin J., Lenoir M., Tiffagom M. (2008) - Solutrean Laurel Leaf Production at Maîtreaux: an Experimental Approach Guided by Techno-economic Analysis, World Archaeology, 40, 1, p. 48-66.
Biard M., Prost D. (2015) - Le débitage à la pierre tendre. Exemple de deux postes de taille de l'extrême fin du Paléolithique en Haute-Normandie, Bulletin de la Société préhistorique française, 12, 1, p. 59-73.

Bodu P., Bignon O., Dumarçay G. (2011) - Le gisement des Bossats à Ormesson, région de Nemours (Seine-etMarne) : un site gravettien à faune dans le Bassin parisien, in N. Goutas, L. Klaric, D. Pesesse et P. Guillermin (dir.), $\grave{A}$ la recherche des identités gravettiennes : actualités, questionnements et perspectives, actes de la table ronde sur le Gravettien en France et dans les pays limitrophes (Aix-enProvence, 6-8 octobre 2008), Paris, Société préhistorique française (coll. Mémoire, 52), p. 259-272. 
Bodu P., Chehmana L., Klaric L., Mevel L., Soriano S., Teyssandier N. dir. (2013) - Le Paléolithique supérieur ancien de l'Europe du Nord-Ouest : réflexions et synthèses à partir d'un projet collectif de recherche sur le centre et le sud du Bassin parisien, Actes du colloque de Sens (1518 avril 2009), Paris, Société préhistorique française (coll. Mémoire, 56), $516 \mathrm{p}$.

CAmpbell J. B. (1980) - Le problème des subdivisions $\mathrm{du}$ Paléolithique supérieur britannique dans son cadre européen, Bulletin de la Société royale belge d'anthropologie et de préhistoire, 91, p. 39-77.

Campbell J. B. (1986) - Hiatus and Continuity in the British Upper Palaeolithic: a View from the Antipodes, in D. A. Roe (éd.), Studies in the Upper Palaeolithic of Britain and Northwest Europe, Oxford, Archaeopress, p. 7-42.

De Heinzelin J. (1973a) - L'industrie du site paléolithique de Maisières-Canal, Bruxelles, Institut royal des Sciences naturelles de Belgique (coll. Mémoires, 171), 63 p.

De Heinzelin J. (1973b) - An Example of Upper Palaeolithic Geometry, Antiquity, 47, 188, p. 297-298.

Desbrosse R., KozŁowski J. (1988) - Hommes et climats à l'Âge du Mammouth : le Paléolithique supérieur d'Eurasie centrale, Paris, Masson, $144 \mathrm{p}$

Dewez M. (1989) - Données nouvelles sur le Gravettien de Belgique, Bulletin de la Société préhistorique française, 86 , 5, p. 138-142.

Dewez M., Collcutt S. N., Cordy J.-M., Gilot É., Groessens-Van Dyck M.-C., Heim J., KozŁowski S., KozlowSka E., Lacroix D., Simonet P. (1993) - Recherches à la grotte Walou à Trooz (Province de Liège, Belgique). Premier rapport de fouille, Liège, Société wallonne de Palethnologie (coll. Mémoire, 7), 81 p.

Digan M. (2008) - New Technological and Economic Data from La Vigne-Brun (Unit KL19), Loire: a Contribution to the Identification of Early Gravettian Lithic Technological Expertise, Quartär, 55, p. 115-125.

DinNis R. (2009) - Understanding the British Aurignacian, thèse de doctorat, University of Sheffield, Sheffield, 2 vol., $438 \mathrm{p}$.

DinNis R. (2013) - L'Aurignacien de Grande-Bretagne, in P. Bodu, L. Chehmana, L. Klaric, L. Mevel, S. Soriano et N. Teyssandier, (dir.), Le Paléolithique supérieur ancien de l'Europe du Nord-Ouest : réflexions et synthèses à partir d'un projet collectif de recherche sur le centre et le sud $d u$ Bassin parisien, actes du colloque de Sens (15-18 avril 2009), Paris, Société préhistorique française (coll. Mémoire, 56), p. 473-484

Dinnis R., Flas D. (2016) - Trou du Renard and the Belgian Aurignacian, Proceedings of the Prehistoric Society, 82, p. 1-25.

Draily C. dir. (2011) - La grotte Walou à Trooz (Belgique). Fouilles de 1996 à 2004. Volume 3 : L'archéologie, Namur, Service public de Wallonie, Institut du Patrimoine wallon (coll. Études et Documents - Archéologie, 22), 332 p.

FLAS D. (2000-2001) - Étude de la continuité entre le Lincombien-Ranisien-Jerzmanovicien et le Gravettien aux pointes pédonculées septentrional, Préhistoire Européenne, 16-17, p. 163-189.
Flas D. (2008) - La transition du Paléolithique moyen au supérieur dans la plaine septentrionale de l'Europe, Bruxelles, Société royale belge d'anthropologie et de préhistoire (coll. Anthropologica et Præhistorica, 119), 254 p.

Flas D. (2015) - The Chronocultural Sequence of Belgian Complexes in the European Aurignacian Context, in R. White et R. Bourrillon (éd.) avec la collaboration de F. Bon, Aurignacian Genius: Art, Technology and Society of the First Modern Humans in Europe, actes du colloque international (New York, 8-10 avril 2013) (P@lethnology, 7), p. $57-75$.

Floss H., Taller A. (2011) - Aspects de la technologie lithique du site gravettien d'Azé-Camping de Rizerolles (Saône-et-Loire, France), in N. Goutas, L. Klaric, D. Pesesse et P. Guillermin (dir.), À la recherche des identités gravettiennes : actualités, questionnements et perspectives, Actes de la table ronde sur le Gravettien en France et dans les pays limitrophes (Aix-en-Provence, 6-8 octobre 2008), Paris, Société préhistorique française (coll. Mémoire, 52).

Gautier A., Ballmann P., DE Coninck J. (1973) - La faune du site paléolithique de Maisières-Canal, Bruxelles, Institut royal des Sciences naturelles de Belgique (coll. Mémoires, 172), $29 \mathrm{p}$.

Goutas N., Klaric L., Pesesse D., Guillermin P. dir. (2011) - À la recherche des identités gravettiennes : actualités, questionnements et perspectives, Actes de la table ronde sur le Gravettien en France et dans les pays limitrophes (Aix-en-Provence, 6-8 octobre 2008), Paris, Société préhistorique française (coll. Mémoire, 52), $395 \mathrm{p}$.

Goutas N., Tejero J.-M. (2016) - Osseous Technology as a Reflection of Chronological, Economic and Sociological Aspects of Palaeolithic Hunter-gatherers: Examples from key Aurignacian and Gravettian Sites in South-West Europe, Quaternary International,

Goval É., Hérisson D. (2012) - Découverte inédite de trois occupations du Pléniglaciaire moyen du Weichselien à Havrincourt «Les Bosquets » (Pas-de-Calais, France), Bulletin de la Société préhistorique française, 109, 2, p. 342345 .

Haesaerts P., De Heinzelin J. (1979) - Le site paléolithique de Maisières-Canal, Bruges, De Tempel (coll. Dissertationes Archaeologicae Gandenses, 19), 119 p.

Haesaerts P., Damblon F. (2004) - Les dates radiocarbones de Maisières-Canal, in R. Miller, P. Haesaerts et M. Otte (dir.), L'atelier de taille aurignacien de Maisières-Canal (Belgique), Liège, université de Liège (coll. ERAUL, 110), p. 27-28.

Haesaerts P., Damblon F., Gerasimenko N., Spagna P., PIRSON S. (2016) - The Late Pleistocene Loess-palaeosol Sequence of Middle Belgium, Quaternary International, 411, p. 25-43.

Hubert F. (1968) - Maisières (Hain.) - Wartons : gisement périgordien supérieur en plaine, Archéologie, 1, p. 7-9.

INIZAN M.-L., Tixier J. (1978), Outrepassage intentionnel sur pièces bifaciales néolithiques du Qatar (Golfe arabo-persique), Quaternaria, 20, p. 29-40.

Inizan M.-L., Reduron M., Roche H., Tixier J. (1995) Technologie de la pierre taillée, Meudon, Cercle de recherches et d'études préhistoriques, $199 \mathrm{p}$. 
JACовi R. M. (1980) - The Upper Palaeolithic of Britain with Special Reference to Wales, in J. A. Taylor, Culture and Environment in Prehistoric Wales. Selected essays, Oxford, Archaeopress (BAR British Series, 76), p. 15-100.

JACOBI R. M. (2007) - A Collection of Early Upper Palaeolithic Artefacts from Beedings, near Pulborough, West Sussex, and the Context of Similar Finds from the British Isles, Proceedings of the Prehistoric Society, 73, p. 229-326.

Jacobi R. M., Higham T. F. G., Haesaerts P., Jadin I., BASELl L. S. (2010) - Radiocarbon Chronology for the Early Gravettian of Northern Europe: New AMS Determinations for Maisières-Canal, Belgium, Antiquity, 84, p. 26-40.

KLARIC L. (2003) - L'unité technique des industries à burins du Raysse dans leur contexte diachronique. Réflexions sur la diversité culturelle au Gravettien à partir des données de La Picardie, d'Arcy-sur-Cure, de Brassempouy et du Cirque de la Patrie, Thèse de doctorat, université Paris 1 - PanthéonSorbonne, Paris, $426 \mathrm{p}$.

KozŁowsKi J. K. (2015) - The Origin of the Gravettian, Quaternary International, 359-360, p. 3-18.

KozŁowski J. K., KozŁowski S. K. (1981) - Paléohistoire de la grande plaine européenne, Archeologia Interregionalis, 1, p. 143-162.

Lacarrière J., Bodu P., Julien M.-A, Dumarçay G., Goutas N., Lejay M., Peschaux C., Naton H.-G., ThéryParisot I., Vasiliu L. (2015) - Les Bossats (Ormesson, Paris Basin, France): a New Early Gravettian Bison Processing Camp, Quaternary International, 359-360, p. 520-534.

LANSAC P. (2002) - Fonction des pointes de la Font-Robert : étude archéologique et expérimentale appliquée aux collections de la Font-Robert, Pré-Aubert et la Grotte des Morts (Corrèze), mémoire de DEA, université de Rennes, Rennes, $24 \mathrm{p}$.

Le Brun-Ricalens F. dir. (2005) - Productions lamellaires attribuées à l'Aurignacien : chaînes opératoires et perspectives technoculturelles, actes du $14^{e}$ congrès de l'UISPP, Section 6 - Paléolithique supérieur, colloque C6.7 (Liège, 2-8 septembre 2001), Luxembourg, Musée national d'histoire et d'art (coll. ArchéoLogiques, 1), 568 p.

Le Mené F. (1999) - Proposition pour une nouvelle approche de la pointe de la Font-Robert - les données de la Ferrassie et de Maisières-Canal, mémoire de maîtrise, université Paris 1 - Panthéon-Sorbonne, Paris, 168 p.

Le Mignot Y. (1998) - La question de la production d'armatures sur le site gravettien de Plasenn'al-Lomm (Côtes d'Armor), mémoire de DEA, université Paris 1 - Panthéon-Sorbonne, Paris, $60 \mathrm{p}$.

Le Mignot Y. (2000) - La question de la production d'armatures sur le site gravettien de Plasenn-al-Lomm (Île de Bréhat, Côtes d'Armor), Revue archéologique de l'Ouest, 17, p. 7-24

Milks A. (2010) - Spear Throwing in the European Early Upper Palaeolithic, mémoire de master, University College London, Londres, 73 p.

Milks A., Dinnis R., Pope M. (2016) - Morpho-metric Variability of Early Gravettian Tanged "Font-Robert" Points, and Functional Implications, in R. Iovita et K. Sano (dir.),
Multidisciplinary Approaches to the Study of Stone Age Weaponry, Springer, p. 135-146.

Miller R. (2001) - Lithic Resource Management During the Belgian Early Upper Paleolithic. Effects of Variable Raw Material Context on Lithic Economy, Liège, université de Liège (coll. ERAUL, 91), 220 p.

Miller R., Guillaume A., Flas D. (2004) - L'occupation gravettienne de l'atelier de taille de la berge nord-est, in $\mathrm{R}$. Miller, P. Haesaerts et M. Otte (dir.), L'atelier de taille aurignacien de Maisières-Canal (Belgique), Liège, université de Liège (coll. ERAUL, 110), p. 121-128.

Miller R., Haesaerts P., Otte M. dir. (2004) - L'atelier de taille aurignacien de Maisières-Canal, Liège, université de Liège (coll. ERAUL, 110), $136 \mathrm{p}$.

Moreau L. (2010) - Geißenklösterle. The Swabian Gravettian in its European Context, Quartär, 57, p. 79-93.

Moreau L. (2011) - La fin de l'Aurignacien et le début du Gravettien en Europe centrale : continuité ou rupture ? Étude comparative des ensembles lithiques de Breitenbach (Sachsen-Anhalt, D) et Geißenklösterle (AH I) (Bade-Wurtemberg, D), Notae Praehistoricae, 31, p. 21-29.

Moreau L. (2012a) - Breitenbach-Schneidemühle, Germany: a Major Aurignacian Open Air Settlement in Central Europe, Eurasian Prehistory, 9, 1-2, p. 51-75.

Moreau L. (2012b) - Le Gravettien ancien d'Europe centrale revisité : mise au point et perspectives, L'Anthropologie, 116, 5, p. 609-638.

Moreau L., Hauzeur A., Jadin I. (2013) - La gestion des ressources lithiques dans l'ensemble gravettien de Maisières-Canal (Bassin de Mons, Hainaut, B). Nouvelles perspectives, Notae Praehistoricae, 33, p. 105-126.

Moreau L., Brandl M., Filzmoser P., Hauzenberger C., Goemaere É., Jadin I., Collet H., Hauzeur A., Schmitz R. W. (2016) - Geochemical Sourcing of Flint Artifacts from Western Belgium and the German Rhineland: Testing Hypotheses on Gravettian Period Mobility and Raw Material Economy, Geoarchaeology: An International Journal, 31, p. 229-243.

Oтте M. (1976) - Observations sur l'industrie lithique de Maisières et sur ses relations avec les autres ensembles périgordiens de Belgique, Bulletin de la Société préhistorique française, 73, 1, p. 335-351.

Отте M. (1979a) - Documentation archéologique, in P. Haesaerts et J. De Heinzelin, Le site paléolithique de Maisières-Canal, Bruges, De Tempel (coll. Dissertationes Archaeologicae Gandenses, 19), p. 69-89.

Отте M. (1979b) - Le Paléolithique supérieur ancien en Belgique, Bruxelles, musées royaux d'Art et d'Histoire (coll. Monographies d'Archéologie nationale, 5), 684 p.

OтTе M. (1990) - Les industries à pointes foliacées du NordOuest européen, in J. K. Kozłowski (éd.), Feuilles de pierre. Les industries à pointes foliacées du Paléolithique supérieur européen, actes du colloque de Cracovie (1989), Liège, Université de Liège (coll. ERAUL, 42), p. 247-270.

Otte M., CASPar J.-P. (1987) - Les pointes de la Font Robert : outils emmanchés ?, in D. Stordeur (éd.), La main et l'outil. Manches et emmanchements préhistoriques, Lyon, Maison de l'Orient et de la Méditerranée Jean Pouilloux, p. 65-74. 
Paris C., Antoine P., Auguste P., Claud É, Coutard S., Coudret P., Deneuve É, Fagnart J.-P., Font C., Goutas N., Lacarrière J., Moine O., Peschaux C., Goval É, HÉrisson D. (sous presse) - Les gisements gravettiens d'Amiens-Renancourt (Somme) : premières données palethnologiques, in C. Montoya, J.-P. Fagnart et J.-L. Locht (dir.), Actes du $28^{e}$ congrès préhistorique de France, Paris, Société préhistorique française.

Paris C., Fagnart J.-P., Coudret P. (2013) - Du Gravettien final dans le Nord de la France? Nouvelles données à Amiens-Renancourt (Somme, France), Bulletin de la Société préhistorique française, 110, 1, p. 123-126.

Pelegrin J. (2000) - Les techniques de débitage laminaire au Tardiglaciaire : critères de diagnose et quelques réflexions, in B. Valentin, P. Bodu et M. Christensen (éd.), L'Europe centrale et septentrionale au Tardiglaciaire, actes de la table ronde (Nemours, 13-16 mai 1997), Nemours, APRAIF (coll. Mémoires du musée de Préhistoire d'Île-de-France, 7), p. 73-86

Pesesse D. (2008a) - Les premières sociétés gravettiennes. Analyse comparée des systèmes lithiques de la fin de l'Aurignacien aux débuts du Gravettien, thèse de doctorat, université de Provence, Aix-en-Provence, 455 p.

Pesesse D. (2008b) - Place du Bayacien dans la structuration du Gravettien, Gallia Préhistoire, 50, p. 23-44.

Pesesse D. (2009-2010) - La pointe de Font-Yves et les productions lithiques des derniers Aurignaciens, Paléo, 21, p. 203-222.

Pesesse D. (2010) - Quelques repères pour mieux comprendre l'émergence du Gravettien en France, Bulletin de la Société préhistorique française, 107, 3, p. 465-487.

Pesesse D., Flas D. (2012) - The Maisierian, at the Edge of the Gravettian, Proceedings of the Prehistoric Society, 78, p. 95-109.

Petrognani S. (2013) - De Chauvet à Lascaux. L'art des cavernes reflet de sociétés préhistoriques en mutation, Paris-Arles, Errance, 251 p.

Rigaud J.-PH. (dir.) (2007-2008) - Le Gravettien : entités régionales d'une paléoculture européenne, actes de la table ronde des Eyzies (juillet 2004), Les Eyzies-de-Tayac, SAMRA (coll. Paléo, 19-20), p. 9-255, et p. 257-471.

Rots V. (2002a) - Are Tangs Morphological Adaptations in View of Hafting? Macro- and Microscopic Wear Analysis on a Selection of Tanged Burins from Maisières-Canal, Notae Praehistoricae, 22, p. 61-69.

Rots V. (2002b) - Hafting Traces on Flint Tools: Possibilities and Limitations of Macro- and Microscopic Approaches, thèse de doctorat, Katholieke Universiteit Leuven, Leuven, 649 p.

Roussel M., Bourguignon L., Soressi M. (2009) - Identification par l'expérimentation de la percussion au percuteur de calcaire au Paléolithique moyen : le cas du façonnage des racloirs bifaciaux Quina de Chez Pinaud (Jonzac, CharenteMaritime), Bulletin de la Société préhistorique française, 106, 2, p. 219-238.

Roussel M., Soressi M., Hublin J.-J. (2016) - The Châtelperronian Conundrum: Blade and Bladelet Lithic Techno- logies from Quinçay, France, Journal of Human Evolution, 95, p. 13-32.

SChMider B. (1971) - Les industries du Paléolithique supérieur en Île-de-France, Paris, CNRS Éditions (coll. Supplément à Gallia Préhistoire, 6), $243 \mathrm{p}$

Surmely F., Ballut C. avec la collaboration de Texier J.-P., Hays M., Pasty J.-F., Alix P., Murat R., Boudon P. (2011) - Le site gravettien ancien du Sire (Mirefleurs, Puyde-Dôme, France) : données lithiques, chronologiques et sédimentaires, in N. Goutas, L. Klaric, D. Pesesse et P. Guillermin (dir.), À la recherche des identités gravettiennes: actualités, questionnements et perspectives, Actes de la table ronde sur le Gravettien en France et dans les pays limitrophes (Aix-en-Provence, 6-8 octobre 2008), Paris, Société préhistorique française (coll. Mémoire, 52), p. 311328.

Touzé O., Coppe J., Schmit S. (2016) - Nouvel indice d'une occupation de l'Est de la France au Paléolithique supérieur ancien : découverte d'une pointe pédonculée à Rimling « Kohlhecke », Moselle, Notae Praehistoricae, 36, p. 149165

Touzé O., Flas D., Pesesse D. (2016) - Technical Diversity within the Tanged-tool Gravettian: New Results from Belgium, Quaternary International, 406, p. 65-83.

VAlentin B., Weber M.-J., Bodu P. (2014) - Initialisation and Progression of the Core Reduction Process at DonnemarieDontilly (Seine-et-Marne, France), Site of the Belloisian Tradition. New Interpretative Key for Comparisons with Contemporaneous Industries and Federmesser-Gruppen Assemblages, Bulletin de la Société préhistorique française, 111, 4, p. 659-678.

Ziesaire P. (1986) - Les pointes pédonculées du Paléolithique supérieur ancien du Grand-Duché de Luxembourg, Helinium, 26, p. 182-192.

\author{
Olivier Touzé \\ Aspirant F.R.S.-FNRS \\ Université Paris 1 - Panthéon-Sorbonne \\ UMR 7041 ArScAn \\ équipe Ethnologie préhistorique \\ Université de Liège, Préhistoire \\ 7 Place du 20-Août (bât. A1) \\ 4000 Liège \\ Belgique \\ otouze@hotmail.com
}


